\title{
3 Rainer Maria Rilke: Der Engel als Motor und (Re-)Medium moderner Paradiesferne
}

Dass in der Moderne nichts zeitgemäßer ist als das scheinbar Unzeitgemäße und dass Engelsfiguren unmittelbar an den Aushandlungsprozessen dieser Epochenspezifik beteiligt sind, das zeigt das Werk von Rainer Maria Rilke auf exemplarische Weise. Zwischen diesem und einem angelisch überhöhten Autorschaftsbild, das auf der für Rilke typischen Verflechtung von Selbsterhöhung und -erniedrigung basiert, ${ }^{1}$ bildet die Engelsfigur ein zentrales Scharnier. „,[M]eine Arbeit ist herrlich, aber ich werde sie nie den Händen der Engel entreißen und immer nur handeln wenn Engel da sind“`2, verkündet Rilke am 11. März 1913 seinem Unterstützer Karl von der Heydt. Derartige Stilisierungen waren so erfolgreich, dass Rilkes Werk bis heute vom Nimbus eines auratischen Dichtertums lebt. Je nach Blickwinkel geht damit das Verdikt von Wirklichkeitsflucht und Rückwärtsgewandtheit oder aber die Weihe des reinen Dichters einher. ${ }^{3}$ Im letzten Fall erscheint die beschworene Einheit des Gesamtkunstwerks Rilke nicht als Peinlichkeit, sondern als Trutzburg gegenüber der zunehmenden Ökonomisierung und Professionalisierung des Schreibens. Diesem steht das Dichten als eine sakrale, sich kommerzieller Verwertbarkeit entziehende Praxis von Berufenen entgegen. ${ }^{4}$ An dem „Mythos Rilke“5 wirkten editorische Formungsprozesse ebenso mit wie die Rezeption als Erbau-

1 Vgl. Martina King, Pilger und Prophet. Heilige Autorschaft bei Rainer Maria Rilke, Göttingen 2009, S. 185.

2 Rainer Maria Rilke, Brief an Karl von der Heydt, 11. März 1913. In: Rilke, Die Briefe an Karl und Elisabeth von der Heydt 1905-1922, hg. von Ingeborg Schnack u. Renate Scharffenberg, Frankfurt am Main 1986, S. 186-188, hier S. 187.

3 Zur Rückwärtsgewandtheit vgl. Egon Schwarz, Das verschluckte Schluchzen. Poesie und Politik bei Rainer Maria Rilke. In: „Ich bin kein Freund allgemeiner Urteile über ganze Völker“. Essays über österreichische, deutsche und jüdische Literatur, hg. von Dietmar Goltschnigg u. Hartmut Steinecke, Berlin 2000, S. 176-194. Zum reinen Dichtertum vgl. die Rede von Stefan Zweig, Abschied von Rilke. Rede im Rahmen einer Gedächtnisfeier am 20. Februar 1927, gehalten im Staatstheater München. In: Rainer Maria Rilke und Stefan Zweig in Briefen und Dokumenten, hg. von Donald A. Prater, Frankfurt am Main 1987, S. 113-129. Vgl. dazu Klaus E. Bohnenkamp, Der reine Dichter. Rainer Maria Rilke im Urteil Robert Musils und Stefan Zweigs. In: „Auf geborgtem Boden“. Rilke und die französische Sprache. In: Blätter der RilkeGesellschaft, 26, hg. v. Rudi Schweikert, Frankfurt am Main; Leipzig 2005, S. 99-144 sowie Gabriela Wacker, Poetik des Prophetischen. Zum visionären Kunstverständnis in der klassischen Moderne, Berlin; Boston 2013, S. 180-181.

4 Vgl. King, Pilger und Prophet, S. 31-37.

5 King, Pilger und Prophet, S. 162.

Ә Open Access. (C) 2022 Lena Zschunke, publiziert von De Gruyter. (c) BY-SA Dieses Werk ist lizenziert unter einer Creative Commons Namensnennung - Weitergabe unter gleichen Bedingungen 4.0 International Lizenz. https://doi.org/10.1515/9783110552621-003 
ungsschriftsteller, ${ }^{6}$ die zusammen mit einer entsprechenden Forschung dafür sorgten, dass Rilke ,als eine im esoterischen Arom [sic] extramundaner Schönheit verdunstete Substanz erscheinen konnte“7 . Rilke, dem die Bezeichnung als Schriftsteller „abscheulich“8 ${ }^{\text {“ }}$ war, ist nicht ganz unschuldig an der Verbreitung seiner auratischen Autorschaft, vielmehr hat er sie als „epistolare[r] Netzwerker“9 aktiv in Umlauf gebracht. ${ }^{10}$ In einer Zeit, in der die Atomisierung des Individuums und die Zertrümmerung großer, insbesondere religiöser Zusammenhänge wahlweise gefeiert oder beklagt werden, kultiviert er eine nicht avantgardistisch, sondern anachronistisch anmutende Einheit von Werk und Autorleben. Das spiegelt sich in der von Rilke bevorzugten Gattung des Gedichts, das Anspruch auf Formvollendung erhebt und besonderes Auratisierungspotential verspricht.

In diesen Dichter-Mythos scheinen die ebenfalls dunstigen Engel sich bestens einzufügen, die wie der reine Dichter in der Moderne auf den ersten Blick denkbar unzeitgemäße Phänomene sind. So ist es wiederum Ausdruck eines bestimmten, wesentlich säkular geprägten Epochenverständnisses, dass der Engel in Rilkes Werk von der Forschung kaum je als eigenständige Figur wahrgenommen wurde. Als Platzhalter für verschiedene Abstrakta wie vollkommene Idealität soll er vielmehr je nach Erfordernis des Interpretationszusammenhangs unterschiedliche Lesarten beglaubigen. ${ }^{11}$ Trotz ihrer Bekanntheit sind die Engel in Rilkes Werk daher als eigenständige Figuren seltsam unbestimmt. Anders als es die Kon-

6 So verweist Joachim W. Storck darauf, dass das Bild Rilkes als ein „über der gesellschaftlichen Wirklichkeit schwebende[r] Sänger“ neben „zeitgeschichtlichen Umstände[n]“, die die Briefeditionen der 1930er Jahre prägten, auch auf die Verlagspolitik des Insel-Verlags unter Anton und Katharina Kippenberg zurückzuführen sei (Joachim W. Storck, Politisches Bewußtsein bei Rilke. In: Rilke, Briefe zur Politik, hg. von Joachim W. Storck, Frankfurt am Main; Leipzig 1992, S. 697-725, hier S. 703).

7 Hans Richard Brittnacher, Stephan Porombka u. Fabian Störmer, Einleitung. In: Poetik der Krise. Rilkes Rettung der Dinge in den ,Weltinnenraum', hg. von Hans Richard Brittnacher, Stephan Porombka u. Fabian Störmer, Würzburg 2000, S. 7-20, hier S. 7.

8 Stattdessen spricht Rilke von dem „künstlerisch Schreibenden (ich vermeide das abscheuliche: ,Schriftsteller')“ (Rainer Maria Rilke, Brief an Margot Gräfin Sizzo-Noris-Crouy, 17. März 1922. In: Rilke, Briefe zur Politik, hg. von Joachim W. Storck, Frankfurt am Main; Leipzig 1992, S. 373-378, hier S. 376).

9 King, Pilger und Prophet, S. 156.

10 Vgl. King, Pilger und Prophet, S. 176. Nach Martina King ist die Autorschaft Rilkes das Produkt verschiedener Sozialpraktiken: „Selbststilisierung zum poeta vates, Inszenierung von ,Leben als Kunstwerk' und Versammeln einer Jüngergemeinde“ (King, Pilger und Prophet, S. 63).

11 So bleibt der Engel in den Duineser Elegien für Stephan Jaeger „inhaltlich eine Leerstelle“ (Stephan Jaeger, Theorie lyrischen Ausdrucks. Das unmarkierte Zwischen in Gedichten von Brentano, Eichendorff, Trakl und Rilke, München 2001, S. 272), während Ulrich Schödlbauer in seinem Essay Rilkes Engel befindet: „[D]er Engel ist niemand“ (Ulrich Schödlbauer, Rilkes 
zentration der Forschung auf die Duineser Elegien (1912-1922) vermuten lässt, treten sie darin aber in einer veritablen Fülle auf. Von den frühen Gedichten aus dem ersten Band Leben und Lieder (1984) bis zu den späten französischen aus den Jahren 1924 bis 1926 durchzieht der Engel mit großer semantischer Vielfalt Rilkes Werk als eine seiner zentralen Konstanten und ist in dieser Persistenz mehr als ein austauschbares Motiv.

Die seltsame Leere der bisherigen Engelslektüren ist, so eine erste These, vor dem Hintergrund der in der Forschung lange dominanten Annahme einer

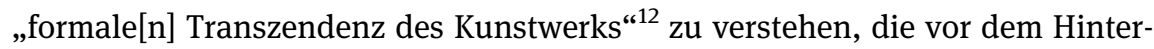
grund des Axioms der Sprachautonomie systematisch Strukturen auf Kosten von Inhalten privilegierte. ${ }^{13}$ So kann Perdita Rösch noch 2009 befinden, dass es, so „befremdlich“ dies klingen möge, „keine umfassende Untersuchung zur Figur des Engels in Rilkes Werk“ gebe, die die „grundlegende funktionelle Bedeutung dieser Figur erkennt“"14. Die poetischen Implikationen des Engels, auf die Perdita Rösch in ihrer Untersuchung abstellt, wurden durchaus beleuchtet, wenngleich mit deutlichem Schwerpunkt auf den Duineser Elegien. Religiöse

Engel, Heidelberg 2002, S. 51). Andere inhaltliche Bestimmungen wiederum sind abstrakt und eher apodiktisch, sodass auch sie nicht besonders aufschlussreich sind. In Anbetracht der vielfältigen, widerspruchsvollen Semantik, die sich im Lauf der Geschichte um die Figur des Engels angereichert hat, scheint es eine unverständliche Verkürzung, ,den“ rilkeschen Engel, insbesondere in den Duineser Elegien, als mythische Figur vollkommener Idealität, die zugleich ihr Gegenteil inkorporiert, zu begreifen (vgl. Karin Schulze, „Ein luftiger Austausch“. Das implizite Wissen vom Subjekt in den „Duineser Elegien“ Rainer Maria Rilkes, Frankfurt am Main u. a. 1988, S. 76-87); die Engel auf die Funktion der Klage zu reduzieren (vgl. Käte Hamburger, Rilke. Eine Einführung, Stuttgart 1976, S. 109); in ihnen „lediglich eine spirituelle Entwicklungsstufe, die über dem Menschsein steht“ (Magnússon, Dichtung als Erfahrungsmetaphysik, S. 206), oder einen Wegweiser „in eine innere Heimat“ (Bernd Oei, Rilke und die Magie des Ortes, Berlin 2010, S. 76) zu sehen respektive ihre Eigentümlichkeiten in einem Paradigma mit anderen Mythopoiemen der Elegien zu nivellieren (vgl. Winfried Eckel, Wendung. Zum Prozeß der poetischen Reflexion im Werk Rilkes, Würzburg 1994, S. 154). Zuletzt hat Wolfgang Braungart diese willkürliche Umbesetzung religiöser Bezeichnungen kritisiert: „Man kann die Vokabeln ,Gott‘, ,Engel', ,Maria‘ usw. also nicht beliebig umsemantisieren [...]. Sie können nicht einfach ,für irgendetwas anderes ,stehen““ (Wolfgang Braungart, Literatur und Religion in der Moderne, Paderborn 2016, S. 266).

12 Martina King, Säkularisierung und Re-Sakralisierung. Rainer Maria Rilke als poeta vates der Moderne. In: Ästhetik - Religion - Säkularisierung II. Die Klassische Moderne, hg. von Silvio Vietta u. Stephan Porombka, München 2009, S. 89-105, hier S. 91.

13 Für eine Kritik dieser Position vgl. Magnússon, Dichtung als Erfahrungsmetaphysik, S. $146-151$.

14 Perdita Rösch, Die Hermeneutik des Boten. Der Engel als Denkfigur bei Paul Klee und Rainer Maria Rilke, München 2009, S. 151. 
Semantiken hingegen mussten zum hermeneutischen Sperrgebiet für eine Lektüre werden, der vor allem anderen an der Modernität und künstlerischen Qualität von Rilkes Werk gelegen war. ${ }^{15}$ Scheinbar bestätigt wird die moderne Scheu vor dem religiösen Gehalt des Engels durch Rilke selbst mit seinem Ausspruch, der Engel der Duineser Elegien sei kein christlicher. ${ }^{16}$ Nun ist aber in der Untersuchung der angelologischen Kontroversen deutlich geworden, dass es so etwas wie einen in sich stimmigen christlichen Engel gar nicht gibt. Die Engel und jene Figuren aus der Bibel, die erst später als solche rubriziert wurden, sind überaus hybride Konstruktionen, immer mehr und zugleich weniger als sie selbst: überdeterminiert, indem in sie ältere Sagenmotive und zeitgleich kursierende pagan-polytheistische Göttervorstellungen eingingen, indeterminiert aufgrund der vielen Leerstellen in der Bibel, die wiederum zu kreativem Weiterbasteln in apokryphen Texten und einer Fülle ikonischer Bearbeitungen einluden. Anders als die verlegenen Identifizierungen der Forschung, aber auch die teils ätherisch entrückten Wesen in den Gedichten Rilkes selbst es zunächst vermuten lassen, treten Engel in diesem Werk nicht nur als Medien von prononcierten Anfangs-, End- und Schwellenzuständen, ${ }^{17}$ sondern auch immer wieder als handfeste Störfaktoren in Erscheinung. Als solche öffnen sie den Blick von einer vermeintlich hermetischen Dichtung auf einen Epochendiskurs der Exilierung und des Sinnverlusts. Durchbricht man das Schema von vormoderner Religion und atheistischer Moderne, gerät die Zeitgemäßheit dieser

15 Wolfgang Braungart vergleicht die Angst vor dem Religiös-Erbaulichen in Rilkes Werk mit dem vor dem Weihwasser zurückscheuenden Teufel (vgl. Braungart, Literatur und Religion in der Moderne, S. 268).

16 Vgl. Rainer Maria Rilke: „Der ,Engel“ der Elegien hat nichts mit dem Engel des christlichen Himmels zu tun“ (Rainer Maria Rilke, Brief an Witold Hulewicz, 13. November 1925. In: Rilke, Briefe aus Muzot 1921-1926, hg. von Ruth Sieber-Rilke u. Carl Sieber, Leipzig 1935, S. 330-338, hier S. 337).

17 Analog zur Bibel sind Engel auch bei Rilke mit Anfang und Ende verbunden. In den Augen eines Engels liegt „Glanz von dem ersten Tag“ (Rainer Maria Rilke, Seine Hände blieben wie blinde. In: Rilke, Gedichte 1895-1910. Kommentierte Ausgabe in vier Bänden, Bd. 1, hg. von Manfred Engel u. Ulrich Fülleborn, Frankfurt am Main; Leipzig 1996, S. 74-75, hier S. 75) und er wirkt am Jüngsten Gericht mit (vgl. Rainer Maria Rilke, Das Jüngste Gericht. In: Rilke, Gedichte 1895-1910. Kommentierte Ausgabe in vier Bänden, Bd. 1, hg. von Manfred Engel u. Ulrich Fülleborn, Frankfurt am Main; Leipzig 1996, S. 528). Auch als Figur des besonderen Verhältnisses von Leben und Tod ist der Engel an Anfangs- und Endpunkten postiert. In den „Engelliedern“ aus dem Zyklus Mir zur Feier tritt er als Figur an der Schwelle der Adoleszenz auf (vgl Kapitel 3.2.3 dieser Studie). Anthropologische und religiöse Dimension verbinden sich mitunter: So fungiert der Engel als Bote, der Maria nicht nur die Geburt Jesu, sondern auch ihren eigenen Tod verkündet und im Anschluss ihren Einzug in den Himmel begleitet (so in den Gedichten „Vom Tode Mariae I“ und „Vom Tode Mariae II“ von 1913). 
Figur als modernes Krisenphänomen in den Blick, die eine Vielzahl exilischer Strukturen in Rilkes Werk sichtbar macht.

So bietet sich Rilkes Werk als Einsatzpunkt dieser Untersuchung an, weil hier um 1900 der Engel als Ausdruck und potentielles Medium der Überwindung einer Krise auftritt, die sich im Laufe des 20. Jahrhunderts immer weiter zuspitzen wird. Die erste Zäsur in dieser Entwicklung stellen die Kriegsjahre 1914 bis 1918 dar. Als individuelle wie kollektive Gewalterfahrung markieren sie einen traumatischen Bruch und machen zugleich Wucht und Ausmaß technologischer Modernisierungsprozesse erfahrbar. Oder besser gesagt, und dies ist ein zentrales Thema in Rilkes Werk, sie stellen die Bedingungen der Möglichkeit menschlicher Erfahrung und (künstlerischer) Darstellung fundamental in Frage. ${ }^{18}$ Denn das massenhafte, technisch fabrizierte Sterben auf den Schlachtfeldern und der Einsatz neuer Medien sprengten das Maß menschlicher Erfahrung und „machten den Ersten Weltkrieg zum ersten historischen Großereignis, das die Grundsatzfrage der Darstellbarkeit aufwarf“19. Damit ist die zentrale Eigenheit von Engeln als Medien der Darstellung des Undarstellbaren berührt. Insbesondere in Texten nach der Zäsur des Ersten Weltkriegs sind Engel daher immer auch als Medien darstellerischer Krisen oder Selbstvergewisserungsbemühungen, als Ausdruck des Bruchs oder als dessen potentielle Überwindung zu lesen. So zeugt die Vordergründigkeit des Mediums Engel in Rilkes Werk nicht von eskapistischem Kitsch, sondern von einem hochgradig aktuellen Diskurs.

Die modernespezifischen Brüche und Unterbrechungen manifestieren sich dabei auf mehreren Ebenen: Erstens ästhetisch, anthropologisch und epistemisch, da Erfahrbarkeit, Erkennbarkeit und Darstellbarkeit der Welt und des Menschen nicht mehr selbstverständlich, sondern Gegenstand eines künstlerischen Ringens sind. Zweitens historisch-geschichtsphilosophisch, weil die Möglichkeit sinnvoller Beziehungsstiftung zwischen Vergangenheit, Gegenwart und Zukunft durch den Krieg fundamental erschüttert wird. Drittens metaphysisch, insofern diese Krise auch die Fragwürdigkeit einer sinnvollen Einrichtung der Welt und der Beheimatung des Menschen in ihr weiter verschärft. Und viertens biographisch, da sich mit dem Krieg Rilkes Wanderleben zum endgültigen Exil ausweitet, als ihm der Rückweg in seine Pariser Wohnung versperrt ist.

\footnotetext{
18 Vgl. Eva Horn, Erlebnis und Trauma. Die narrative Konstruktion des Ereignisses in Psychiatrie und Kriegsroman. In: Modernität und Trauma. Beiträge zum Zeitenbruch des Ersten Weltkrieges, hg. von Inka Mülder-Bach, Wien 2000, S. 131-162, hier S. 131.

19 Bernd Hüppauf, Medien des Krieges. In: Erster Weltkrieg. Kulturwissenschaftliches Handbuch, hg. von Lars Koch, Stefan Kaufmann u. Niels Werber, Stuttgart; Weimar 2014, S. 311340, hier S. 327.
} 
Auf diesen verschiedenen Ebenen des Exils ist der Engel nicht Ausdruck einer intakten Religiosität, vielmehr bringt er die dysfunktional gewordene Vermittlung zwischen ästhetisch erfahrbarer Umwelt und einer unsichtbaren, von Gott besetzten Sphäre zum Ausdruck. Diese Kluft wird auch anhand gattungspoetischer Weichenstellungen deutlich: Der Erste Weltkrieg und damit zusammenhängend öffentlich-politische Fragen thematisiert Rilkes fast ausschließlich in privaten Briefen und in Bezug auf seine eigene Situation, während sich das Repertoire seiner öffentlichkeitszugewandten Lyrik aus scheinbar zeitenthobenen Bildern speist. Eingeholt werden können die vielfältigen Facetten des historischen Exils daher größtenteils nur über das Medium des privaten Briefs. Aufgrund dieser gattungspoetischen Besonderheit sind bei Rilke Reflexion des Zeitgeschehens und autobiographische Dokumentation untrennbar verflochten. Beide verbindet, dass der Krieg in Rilkes Perspektive sowohl menschheitsgeschichtlich als auch biographisch als ein vor- wie rückwärtig unbegrenztes Exil erscheint. Da der Zugang zu Vergangenheit und Zukunft versperrt ist, kann die Exilgegenwart für Rilke weder sinnvoll über eine zukunftsgerichtete Erwartung motiviert noch rückwärtig durch das nostalgische Versichern der Vergangenheit plausibilisiert werden. Wie wichtig die geistige (Un-)Verfügbarkeit von Zeit für Rilkes Reflexion des künstlerischen Schaffens ist, wird daran ersichtlich, dass er in dieser Situation Schweigen und Schreien als einzig adäquate Ausdrucksformen bestimmt. ${ }^{20}$ In dieser Imbalance der Welt erscheint Gott nicht zugunsten einer Inthronisierung des Menschen aus der Welt vertrieben, sondern die Menschen werden als im selben Maße Leidtragende dieser Entwicklung dargestellt.

In den folgenden Kapiteln soll untersucht werden, wie Engelsfiguren in dieser Situation eine moderne Zeittopologie von gegenwärtiger Deterritorialisierung und zukünftiger Fülle aufspannen; wie sie eine verlorene Wahrnehmungs- und Erfahrungsqualität reflektieren und zugleich als poetische Figuren zur Überwindung dieses Verlusts mobilisiert werden, die in der Kunst mit ihrem Versöhnungs- und Erlösungsversprechen erfolgen soll. Dafür wird zunächst „Das Märchen von den Händen Gottes“ (1900) als exemplarische Moderne-Erzählung gelesen. In ihr stellt der Engel einen Störfaktor dar, der die Entfremdung zwischen Gott und Mensch ebenso wie die zwischen Gott und seinen eigenen Händen auslöst. Mit seiner Unterbrechung gibt der Engel zugleich aber auch den Anstoß für das Erzählen und damit für eine anthropologische Praxis, die an der Überwindung eben jener Entfremdung mitwirken soll. In Anlehnung an die geschichtsphilosophische Konzeption in Kleists Schrift „Über das Marionettentheater“ schreibt Rilke an Eva Cassirer im August 1908: „[M]an kann sich von einem

20 Vgl. Kapitel 3.1.3 dieser Studie. 
Gott nur entfernen, um im Kreise mühsam wieder auf ihn zuzugehen. “21 Das Erzählen als Kunstform ist so Ausdruck der Entfremdung ebenso wie ihr Remedium - die Künstler sollen über ihr Schaffen Gott zeigen, wie der Mensch wirklich ist und damit eine Versöhnung herbeiführen, so die Pointe des „Märchens“. Ausgehend von dem Engel als geschichtsphilosophischer Scharnierstelle zwischen Exil und dessen Überwindung werden im Anschluss Darstellungsformen der Entfremdung und des geistigen wie realgeschichtlichen Exils in Rilkes Werk untersucht.

Die Diagnose eines sich krisenhaft ausweitenden Exils wird anhand der Briefe vertieft, die Rilke während des Ersten Weltkriegs schrieb. Wie sich dieser zeitgeschichtliche Befund des Exils in der scheinbar zeitenthobenen Lyrik niederschlägt, wird an dem Engel als Medium eines modernen Exils in den Duineser Elegien deutlich. Gleichzeitig tritt der Engel dort nicht nur als Störfaktor, sondern auch als Remedium der fragmentierten menschlichen Wahrnehmung auf. In den darauffolgenden Kapiteln wird nachvollzogen, wie Rilke den Künstler als angelisch inspiriertes Zukunftsmedium positioniert, das an dieser geschichtsphilosophischen Arbeit entscheidend beteiligt ist. Auch hier werden für die Untersuchung Briefe herangezogen, da die Figur des Engels als Teil von Rilkes Autorschaftspolitik immer wieder auch in seinen epistolaren Selbstaussagen tragend ist. Der Fokus liegt aber auf ausgewählten Engelsgedichten aus den Bänden Gedichte an die Nacht, Neue Gedichte, Stunden-Buch, Larenopfer, Buch der Bilder und Mir zur Feier. Dabei geht es nicht darum, Entwicklungen in Rilkes Werk auszumachen, sondern die Bedeutung des Engels in seiner ästhetischen Wirkung als Zukunftsmedium zyklusübergreifend herauszuarbeiten. Indem er als Relais zwischen Sichtbarem und Unsichtbarem wirkt und als Verbindungsglied künstlerischer Filiationen Poesie, Malerei, Bildhauerei und Musik verbindet, verspricht er eine ästhesiologische Weitung des menschlichen Erfahrungsbereichs. Über das lyrische Experimentieren mit einer Reskalierung von Wahrnehmungswerten und multimedialen Übersetzungsprozessen stellt der Engel eine Befreiung aus dem Zustand moderner Beziehungslosigkeit in Aussicht.

Diese Überwindung des Bruchs setzt allerdings wiederum einen Trennungsvorgang an anderer Stelle voraus, der zeigt, dass sich die moderne Signatur nicht ausradieren lässt. So ist die Erweiterung der Wahrnehmung an die Vertiefung der sozialen Isolation des Künstlers geknüpft. Diese inszeniert Rilke als Voraussetzung für Engelsbegegnungen und die damit verbundene hyperästhetische Überwindung der conditio humana. Die Engelsfigur behält ihre Ambivalenz bei: Neben der Sublimierung des menschlichen Leids steht sie ebenso für eine Bewegung des Brechens

21 Rainer Maria Rilke, Brief an Eva Cassirer, 20. August 1908. In: Rilke, Briefe zur Politik, hg. von Joachim W. Storck, Frankfurt am Main; Leipzig 1992, S. 73-74, hier S. 73. Vgl. Heinrich von Kleist, Über das Marionettentheater. In: Kleist, Werke und Briefe in vier Bänden, Bd. 3, Berlin; Weimar 1978, S. 473-481, hier S. 476. 
und Überwindens des Menschen selbst ein; etwa in Gestalt des Angreifers, der in der Genesis Jakob am Jabbok stellt und über die Metaphorisierung des Körpers als Musikinstrument und Gegenstand bildhauerischer Bearbeitung den Übergang des

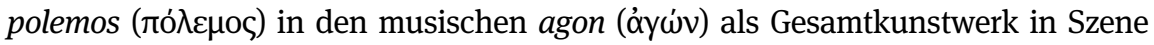
setzt. Auf poetologischer Ebene werden damit paradoxe Abhängigkeitsverhältnisse des künstlerischen Schaffensprozesses berührt, die ins Zentrum von Rilkes medialer Poetik zwischen schöpferischer Autonomie und Fremddiktion führen. ${ }^{22}$

\subsection{Gestörte Schöpfung: Die Engelslüge als Ursprung von Geschichte(n)}

Die Anthropogonie „Das Märchen von den Händen Gottes“ bildet den Auftakt zu Rilkes zwischen dem 10. und dem 21. November 1899 verfassten und 1900 publizierten Geschichtensammlung Vom lieben Gott und Anderes, die 1904 überarbeitet unter dem Titel Geschichten vom lieben Gott erschien. Die Grundlage des „Märchens“ ist die biblische Erzählung des Sündenfalls (1 Mos 3,23-24). Es knüpft damit an die Zeit um 1800 an, als über den Sündenfall anthropologische, epistemologische, ästhetische und geschichtsphilosophische Fragen verhandelt wurden. ${ }^{23}$ Gleichzeitig werden diese Diskurse inhaltlich durch das Ineinsfallen von Menschenschöpfung und Gottessünde und formal durch den parodistischen Duktus als eine Erzählung der Moderne aktualisiert. Diese durchzieht eine doppelte Achse des Exils: als postlapsaler Zustand wie als spezifische Pointe der Zeit.

Das „Märchen“ erzählt in betont kindgerechtem Ton und allerlei komischen Bildern wie den knienden Händen Gottes von einem paralysierten Schöpfer, der die Kontrolle über das Geschehen auf der Erde ebenso wie über seinen anthropomorphen Körper verliert. Urheber dieser Störungen ist ein Engel, der mit einer Lüge für die Unvollkommenheit des Menschen, die andauernde Selbstentfremdung des Schöpfergottes von dem Werkzeug seiner Hände und die bis in die Gegenwart fortwirkende Entfremdung zwischen Gott und Mensch verantwortlich ist. Eingefasst sind diese Ereignisse in eine in der Gegenwart situierte Rahmenhandlung, in der sich der Ich-Erzähler mit seiner Nachbarin unterhält. Diese beklagt sich über ihre wissbegierigen Töchter, die immerzu nach dem

$22 \mathrm{Zu}$ Autonomie und Fremddiktion bei Rilke vgl. Wacker, Poetik des Prophetischen, S. 192.

23 Vgl. Martin Metzger, Die Paradieserzählung (Genesis 2,4b-3,24). Die Geschichte ihrer Auslegung von J. Clericus bis W.M.L. de Wette, Bonn 1959 sowie Johannes Friedrich Lehmann, Vom Fall des Menschen. Sexualität und Ästhetik bei J.M.R. Lenz und J.G. Herder. In: Die Grenzen des Menschen. Anthropologie und Ästhetik um 1800, hg. von Maximilian Bergengruen, Roland Bogards u. Johannes Friedrich Lehmann, Würzburg 2001, S. 17-35. 
„,lieben Gott““24 fragen. Als der Erzähler erwähnt, dass ihm über die Hände Gottes zufällig einiges bekannt sei, fordert die Nachbarin ihn auf, er möge gleich ihren Töchtern davon erzählen. Der Erzähler wehrt ab mit der Begründung, dass das Sprechen mit Kindern ihn in Verlegenheit bringe, zumal sie „,meine Verwirrung dahin deuten [könnten], daß ich mich lügen fühle ...““ (M 348). Da dem Erzähler aber an der Wahrhaftigkeit der Geschichte im höchsten Maße gelegen ist, will er selbst zunächst „,nur die einfachen Tatsachen in der kürzesten Form berichten““ (M 348). Die Nachbarin möge sie ihren Kindern weitererzählen und dabei „,verknüpfen und ausschmücken““ (M 348). Das „Märchen“ wendet sich also nicht direkt an Kinder, wie auch im Untertitel der ersten Gesamtausgabe („An Große für Kleine erzählt“) explizit gemacht, vielmehr fungieren diese in ihrer Abwesenheit als Anlass für eine Erzählung von Gott in einem modernen Setting. Dieses juvenile Märchen soll im Folgenden nicht mit seinem Verfasser als ,jugendlich[e] Vor-Prosa (die noch keine war) “25 diskreditiert, sondern als Gegenstand literaturwissenschaftlicher Betrachtung ernst, ja programmatisch genommen werden für Überlegungen zum geschichtsphilosophischen Fundament von Rilkes Poetik.

Das Erzählen von Gott ist ein heikles Unterfangen: „Darüber weiß man doch nicht Bescheid““ (M 347), so die Nachbarin. Entsprechend groß ist ihre Verlegenheit, als eine vorübergehende Frau die Frage nach ihrem Gesprächsgegenstand stellt und mit der Annahme, die Unterhaltung drehe sich um „,Herrn Schmidt““ (M 349), den ersten komischen Kontrapunkt zur intradiegetischen Schöpfungsgeschichte setzt. Vor dieser Störung, in deren Folge der Erzähler sich prompt in seiner Erzählung verheddert, hatte er bereits ganz biblisch mit „,Im Anfang ...“ (M 348) begonnen, sich allerdings sogleich unterbrochen: „Ich kann bei Ihnen, Frau Nachbarin, ja manches als bekannt voraussetzen, was ich den Kindern erst erzählen müßte. Zum Beispiel die Schöpfung ...' Es entstand eine ziemliche Pause. Dann: ,Ja - - und am siebenten Tage ...', die Stimme der guten Frau war hoch und spitzig." (M 348) Ob Pause und Leerstelle von Wissen, Unwissen oder bloß wiederum peinlicher Berührtheit der Nachbarin zeugen, bleibt offen, der Erzähler fällt jedenfalls mit einem „,Halt!““ (M 348) ein, es solle um die früheren Tage gehen, also gewissermaßen um einen anfänglicheren Anfang.

24 Rainer Maria Rilke, Das Märchen von den Händen Gottes. In: Rilke, Prosa und Dramen. Kommentierte Ausgabe in vier Bänden, Bd. 3, hg. von August Stahl, Frankfurt am Main; Leipzig 1996, S. 347-354, hier S. 347. Im Folgenden M.

25 Rainer Maria Rilke, Brief an Anton Kippenberg, 26. Mai 1925. In: Rilke, Briefe an seinen Verleger 1906 bis 1926, Wiesbaden 1949, S. 419. 
Damit ist die Kernstruktur dieser Geschichte berührt. Deren grundlegendes narratives Muster von Einsatz, Unterbrechung und erneutem Aufgreifen des Erzählfadens stellt die jedem Anfang eigene Diskontinuität aus; die multiplen Anfangseinsätze des „Märchens“ erbringen den performativen Beweis seiner Kontingenz. Zugleich präludieren Neuansatz und Störung den nun endlich folgenden Schöpfungsbericht, der als Kontrafaktur die unterbrochenen Abläufe der Schöpfung referiert. Diese sind mitnichten „sehr gut“ (1 Mos 1,31), wie Gott in der Bibel noch abschließend befinden kann. Der Gott in Rilkes „Märchen“ verliert bei der Schöpfung des Menschen das Geschehen auf der Erde aus den Augen. Ein Engel zieht vorbei und behauptet fälschlicherweise, Gott sähe alles, woraufhin dieser erschrickt - „[e]r hatte den Engel in Sünde gebracht, denn eben hatte dieser eine Lüge gesungen“ (M 350). Die Lüge besteht darin, dass sich ein Vogel von seinem angestammten Ort entfernt hat, was seinem Schöpfer verborgen blieb. Gott ärgert sich sehr über diese Eigenmächtigkeit: „,Die Vögel haben sitzen zu bleiben, wo ich sie hingesetzt habe. Aber er erinnerte sich, daß er ihnen auf Fürbitte der Engel Flügel verliehen hatte, damit es auch auf Erden so etwas wie Engel gebe, und dieser Umstand machte ihn nur noch verdrießlicher.“ (M 350)

Die Ordnungsstörung ist also ein Gemeinschaftswerk von Engeln und Vögeln. ${ }^{26}$ Die Nähe zwischen beiden ergibt sich aus ihrer Mittlerstellung zwischen Himmel und Erde, wobei Vögel auf die dichterische Inspiration und Engel auf Gott weisen. Ihr Zusammenwirken ruft hier den Schwellenbereich zwischen Re-

26 In seinem Aufsatz „Himmlisches Geflügel“ untersucht Thomas Macho die motivgeschichtlichen Entsprechungen zwischen Engeln und Vögeln und stellt fest: „Engel sind Boten und Medien; doch gerade als Boten und Medien stehen sie abermals in der Schuld der Vögel. Denn die Praxis der Brieftaubenzucht ist mußmaßlich älter als die seltsamen Flügelwesen aus dem alten Orient, die zumeist als Vorfahren der Engel gewürdigt werden“ (Thomas Macho, Himmlisches Geflügel. Beobachtungen zu einer Motivgeschichte der Engel. In: Engel, :Engel. Legenden der Gegenwart, hg. von Cathrin Pichler, Wien 1997, S. 83-100, hier S. 95). Neben der Botentätigkeit liegt eine weitere Parallele in der Doppelgänger-Eigenschaft der Engel bzw. der Angleichung an sie über das bios angelikos: „Manche Seelenvögel bezeichneten nicht die Position des Toten, sondern verschiedene Arten möglicher Selbstbeziehung (im Sinne reflexiver Doublierung). Die Metamorphose zum Vogel, die Ausbildung eines zweiten, flugfähigen Ichs, konnte im Traum oder im Rausch glücken: So mochten Schamanen, Priester oder weise Frauen ihre Seelenreisen und Himmelfahrten antreten; sie konnte ebensogut auf dem Boden kontemplativer Übungen und asketischer Disziplin gedeihen“ (Macho, Himmlisches Geflügel, S. 95). Eine weitere bekannte Engführung bei Rilke sind die Engel in der „Zweiten Elegie“, die das lyrische Ich als „fast tödliche Vögel der Seele“ ansingt (Rainer Maria Rilke, Duineser Elegien. In: Rilke, Gedichte 1910-1926. Kommentierte Ausgabe in vier Bänden, Bd. 2, hg. von Manfred Engel u. Ulrich Fülleborn, Frankfurt am Main; Leipzig 1996, S. 199-234, hier S. 205. Im Folgenden DE). 
ligion und Kunst auf. Wie die Engel verfügen die Vögel außerdem mit ihren Flügeln über das Potential, sich Gott zu entziehen, und spiegeln darin auf der Erde die Störung, die die Lüge des Engels im Himmel angestoßen hat. Während der Vogel sich nur unbeobachtet entfernt, wirkt der Engel insofern diabolisch, als Satan nicht Gott schaut, „sondern sieht, welche blinden Flecken Gottes Sicht aufweist“27.

Nach dieser Unterbrechung wendet Gott sich erneut der - angelisch vermittelten - Schöpfung des Menschen zu: „Er hatte die Augen der Engel wie Spiegel vor sich, maß darin seine eigenen Züge und bildete langsam und vorsichtig an einer Kugel auf seinem Schoße das erste Gesicht.“ (M 350) Während die Stirn ihm gut gelingt, stellt schon die Symmetrie der Nasenlöcher diesen allzu menschlichen Gott vor Probleme. Zudem wird er erneut unterbrochen und zwar durch denselben Engel, der ihn nun stumm verspottet: „[M]an hörte diesmal keine Hymne, denn in seiner Lüge war dem Knaben die Stimme erloschen, aber an seinem Mund erkannte Gott, daß er immer noch sang: ,Der Du alles siehst.““ (M 350) Eine weitere Störung bringt die Klage des heiligen Nikolaus', der sich bei Gott über den Hochmut der Löwen beschwert und außerdem darauf hinweist, dass ein Terrier vom Rand der Erde zu stürzen droht. Nach einer wütenden Entgegnung Gottes schlägt Nikolaus die „Türe“ (M 350) des Himmels so fest zu, dass dem Terrier ein Stern auf den Kopf fällt. Nach diesen kuriosen Vorfällen beschließt der Gott des „Märchens“, sich nun ganz auf die irdischen Vorgänge zu konzentrieren. Die Erschaffung des Menschen überlässt er seinen Händen, die ihm das Produkt ihrer Arbeit erst kurz vor dem Eintritt ins Leben zeigen sollen. Auch dies misslingt: Ungeduldig wartend sieht Gott plötzlich „,etwas durch den Raum fallen““ (M 351). Der Fall des Menschen ist hier keine göttliche Strafe für eine Übertretung, sondern zeugt wiederum von einem Kontrollverlust Gottes, da der Mensch, so jedenfalls die Vorhaltung der Hände, in seinem unbändigen Lebensdrang entwischt ist. Gott verstößt daraufhin seine Hände, mit folgenschweren Konsequenzen. Sie sollten machen, was sie wollen, und

27 Hafner, Angelologie, S. 147. Nach Hafner ist Satan dadurch charakterisiert, dass er „die Perspektive eines externen Beobachters Gottes ein[nimmt], statt in reiner Schau zu verweilen“ (Hafner, Angelologie, S. 146). Da so das göttliche Handeln als eine Möglichkeit neben anderen erscheint, wird „[d]ie göttliche Notwendigkeit [...] als Willkür entlarvt, indem Gott daraufhin getestet wird, ob sein Vorschlag der beste aller möglichen ist. Im Grunde steht der Teufel für die Religionswissenschaft. Er denkt über Gott nach, ohne sein Nachdenken als Funktion von Gottesdienst zu verstehen, sondern setzt Gott in eine ihm übergeordnete Funktion ein“ (Hafner, Angelologie, S. 146-147). 
[d]as versuchten die Hände auch seither, aber sie können nur beginnen, was sie auch tun. Ohne Gott giebt es keine Vollendung. Und da sind sie es endlich müde geworden. Jetzt knien sie den ganzen Tag und tun Buße, so erzählt man wenigstens. Uns aber erscheint es, als ob Gott ruhte, weil er auf seine Hände böse ist. Es ist immer noch siebenter Tag.

Auf Nachfrage der Nachbarin erklärt der Erzähler, es bestehe Hoffnung auf Versöhnung, und zwar dann, wenn „Gott wissen wird, wie der Mensch, den die Hände gegen seinen Willen losgelassen haben, aussieht“ (M 352). Das Wissen von der wahren Beschaffenheit des Menschen ist also die Voraussetzung für die Versöhnung Gottes mit seinen Händen und damit auch mit seiner Schöpferkraft. Die anhaltende Unwissenheit Gottes verschulden die Hände nicht nur durch ihre Unachtsamkeit, sondern auch, indem sie ihm die Sicht auf die Erde versperren. Denn aus diesem Grund sieht Gott die Menschen erst, als sie schon millionenfach vorhanden und überdies bekleidet sind:

„Und da die Mode damals gerade sehr häßlich war und auch die Gesichter arg entstellte,
so bekam Gott einen ganz falschen und (ich will es nicht verhehlen) sehr schlechten Be-
griff von den Menschen.“ „Hm“, machte die Nachbarin und wollte etwas bemerken. Ich
beachtete es nicht, sondern schloß mit starker Betonung: „Und darum ist es dringend
notwendig, daß Gott erfährt, wie der Mensch wirklich ist. Freuen wir uns, daß es solche
giebt, die es ihm sagen ...“ Die Frau Nachbarin freute sich noch nicht: „Und wer sollte
das sein, bitte?“ „Einfach die Kinder und dann und wann auch diejenigen Leute, welche
malen, Gedichte schreiben, bauen ...“ „Was denn bauen, Kirchen?“ „Ja, und auch sonst,
überhaupt ...“
(M 352)

In dem zunächst reichlich absonderlich anmutenden Gedanken, dass schlechte Mode eine undurchdringliche Barriere für das göttliche Auge darstellen soll, artikuliert sich der Gedanke eines Akzidentiellen des Menschen, das seine nackte Eigentlichkeit verdeckt. Mit der Verbindung zur Kleidung, also zum Textil und damit zum Text, stellt die Mode ein weiteres autopoetisches Signal dar. Überdies verweist sie als Form prononcierter Gegenwärtigkeit auf die Moderne, ${ }^{28}$ in der die Substanz des Menschseins verhüllt und so Gott bis zum heutigen Tag verborgen ist. Der Topos der Unerkennbarkeit Gottes ist hier verkehrt in die Unerkennbarkeit des Menschen. Komplementär zur negativen Theologie entwirft die Erzählung in einer Inversion des Blicks eine negative Anthropologie: Die Leerstelle ist der Mensch, dessen Schwächen wie Unachtsamkeit und Ungeduld zur conditio divina geworden sind. Neben diesem Perspektivwechsel, der mit

$28 \mathrm{Zu}$ etymologischen, historischen und semantischen Zusammenhängen von Mode und Moderne vgl. Julia Bertschik, Mode und Moderne. Kleidung als Spiegel des Zeitgeistes in der deutschsprachigen Literatur (1770-1945), Köln 2005, S. 7-17. 
der Darstellung von Gottes Ungeschicklichkeit, aber auch mit der komödientheoretisch zentralen Kategorie der Versöhnung wesentlich zur Komik des „Märchens“ beiträgt, liegt die Besonderheit dieser Entfremdung darin, dass sie der Schöpfungsgeschichte nicht nachgeordnet, sondern als Trennung Gottes von seinen Händen und den Menschen in ihrem Herzen selbst wirkmächtig ist. Anders als in der Genesis und anderen menschlichen Urzeiterzählungen steht hier am Anfang kein intaktes Paradies. Vielmehr ist der Zustand der Paradiesferne von jeher konstitutiv für das Menschsein, und auch der Mensch ist als ein Non-finito der Schöpfung nie eine Einheit gewesen. Da es ohne Gott keine Vollendung gibt, sind die unvollendeten Menschen ebenso sehr wie Gott auf die in Aussicht gestellte Versöhnung angewiesen, die Künstler und Kinder bewerkstelligen sollen.

Die Bedeutung, die der Engel für die gesamte Erzählung einnimmt, betont der Erzähler am Ende der Geschichte: „,Sehen Sie, wäre ein Engel vorübergeflogen, singend: ‘Der Du alles weißtı, so wäre alles gut geworden ... , Und diese Geschichte wäre überflüssig?‘ ,Gewiß', bestätigte ich.“ (M 350) Die in Gott wirksame Differenz zwischen Wissen und Sehen, die der Engel sichtbar und virulent macht, verweist auf die Differenz zwischen analytischem Wissen, das keiner Anschauung bedarf, und einem auf das Sehen gegründeten synthetischen Wissen, das an den Verlauf von Zeit gebunden und damit ein Wissen von kontingenten Ereignissen ist. Das Defizit Gottes, der zwar alles weiß, im Zuge der Ausdifferenzierung der Schöpfung aber weder einen Überblick über die Erde hat, noch über eine konkrete Anschauung des Menschen verfügt, eröffnet den Raum für die Nobilitierung der Kunst. Als ästhetisches Wissen ist sie Ausdruck des menschlichen Wesens und leistet zugleich eine Erkenntnisvermittlung für Gott. In Entgegensetzung zur christlichen Tradition der Erbsünde verschiebt sich das Gewicht der auf dem Menschen lastenden Verantwortung vom ethischen in den künstlerischen Bereich: Die Überwindung der göttlichen Erstarrung glückt nicht durch ein gottgefälliges Leben, sondern durch die Kunst. Damit ist ein struktureller Perspektivwechsel verbunden. Nicht die Menschen bedürfen für ihre Kunstwerke der göttlichen Inspiration, sondern umgekehrt ist Gott für seine Einheit und Selbstidentität auf das menschliche Kunstschaffen angewiesen. Kunst ist Verständigung mit Gott, indem der Mensch sich selbst wahrhaftig vor Gott aussagen und so die Folgen der Engelslüge überwinden soll. Zusätzlich zu der ihr zugetrauten Wahrheitsfähigkeit wird die Bedeutung von Kunst und Kindlichkeit dadurch gesteigert, dass Gott selbst sein schöpferisches Potential eingebüßt hat. Da er in der Trennung von seinem Schöpfungswerkzeug im Ruhezustand des siebten Tages verharrt, wird der kindlich-künstlerische Mensch als homo creator zum exemplarischen Schöpfer, von dessen Fertigkeit auch die Restitu-

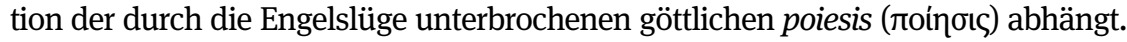


Die Pole Wahrheit und Lüge sowie Ordnung und Ordnungsstörung als Pfeiler der Schöpfungsgeschichte werden auf extradiegetischer Ebene in der Frage nach dem Wahrheitsstatus in einer fiktionalen Gattung sowie in Form der vielfachen Unterbrechungen des Erzählens gespiegelt. Darüber hinaus stellt die ganze Erzählung, die in kindlichem Ton einen schrulligen Gott mit aufbrausendem Temperament und ungehorsamen Körperteilen präsentiert, eine parodistische Abweichung von der christlichen Schöpfungsgeschichte dar, die den Takt für die Geschichten vom lieben Gott insgesamt vorgibt. Diese betreiben „eine geradezu polemisch-subversive Infragestellung der biblischen Gottesvorstellung“29. Über die Unterscheidung von göttlicher Allwissenheit und göttlichem Nichtsehen wird überdies retrospektiv das ganze erzählenswerte Geschehen - das Chaos auf der Erde, die Verselbstständigung der Hände und die bis in die Gegenwart andauernde Entzweiung zwischen Gott und Menschen - als ,ungute، und das bedeutet erzählenswerte Folge der Engelslüge ausgewiesen. Die mit dem Engel verbundenen Momente von Störung und Lüge fungieren daher nicht nur als Triebfedern der intradiegetischen Erzählung, sondern werden auch auf extradiegetischer Ebene zum Ursprung des Erzählens erhoben. Ohne die Unterbrechung durch den lügenden Engel gäbe es keine Geschichte, was sich auch im Sinne der historischen Zeit an sich als Produkt einer angelischen Abweichung von Gott verstehen lässt. Dass die Übertretung des Engels grundlos ist, darauf deutet die ausweichende Reaktion des Erzählers, als die Nachbarin nach der Rolle des Engels fragt:

Dann kehrte sie nochmals zurück: „Aber weshalb ist gerade dieser Engel ...“ „Frau Nachbarin“, sagte ich, indem ich sie unterbrach, „ich merke jetzt, daß Ihre beiden lieben Mädchen gar nicht deshalb so viel fragen, weil sie Kinder sind -“ „Sondern?“ fragte meine Nachbarin neugierig. „Nun, die Ärzte sagen, es giebt gewisse Vererbungen ...“

(M 353)

Die Rolle, die der Engel in diesem Gefüge spielt, ist somit eine ambivalente. Ist er mit seiner Lüge einerseits Urheber der Unterbrechungen, so ermöglicht der lügende Engel andererseits, dass vom Anfang des Menschen in der Moderne überhaupt noch erzählt werden kann. Als prototypische Figur der Übertretung avanciert der Engel damit nicht nur inhaltlich, sondern auch formal zur Reflexionsfigur des Erzählens in der Moderne als einer Zeit von empfundener Gottesferne und Krisenerfahrung. Dieses Erzählen vom Anfang des Menschen ist wie die in ihm verhandelte Schöpfung in seiner Fragmentierung spezifisch modern: Konstitutiv für das „Märchen“ sind Figuren wie Parodie, Störung, Spiegelung

29 August Stahl, Kommentar [Geschichten vom lieben Gott]. In: Rilke, Kommentierte Ausgabe in vier Bänden, Bd. 3, hg. von August Stahl, Frankfurt am Main; Leipzig 1996, S. 848-858, hier S. 851 . 
und Neuansetzen, die die erzählerische (Un-)Ordnung organisieren und den Gedanken des Anfangs im emphatischen Sinne, wie ihn das performative Gotteswort der Bibel in Szene setzt, korrumpieren. Da das „Märchen“ selbst eine Abweichung von der biblischen Schöpfungsgeschichte darstellt, wirken Störung und Lüge autopoetisch als Pfeiler eines angelischen Erzählens. Exemplarisch zeigt sich der moderne Index des „Märchen“ in seiner Anfangsformel, die nicht „Es war einmal“ lautet, sondern als lapidares „Neulich“ (M 347) die Aktualität dieser Erzählung herausstreicht. Gleichzeitig reflektiert das Erzählen selbst

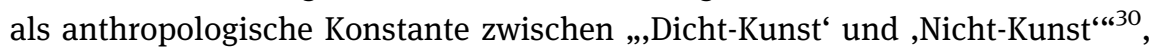
deren Anfänge sich im Mythischen verlieren, die Frage nach dem Anfang der Kunst. Das „Märchen“ greift diese auf; denn wenn „die Erzählung [...] mit der Geschichte der Menschheit" ${ }^{\text {*31 }}$ beginnt, wie Roland Barthes schreibt, dann handelt das Erzählen vom Anfang des Menschen auch vom Anfang des Erzählens.

Das Erzählen als Ausdrucksform, die die Ausbildung von Identität allererst ermöglicht ${ }^{32}$ ist daher im „Märchen“ nicht nur Spiegel eines gestörten Schöpfungsvorgangs, sondern als „,anthropologische Universalie“33 ebenso eingebunden in das antizipierte Versöhnungswerk, das in der Sichtbarmachung der menschlichen Identität besteht. Denn die Störung des Engels, der als Medium des Entfremdungsgeschehens fungiert, stößt eine geschichtsphilosophische Dynamik an und schafft damit erst die Voraussetzung für das Erzählen: ohne Lüge keine Erzählung. Diese stellt wiederum selbst einen Eingriff in die Konstruktion dar, von der sie erzählt, insofern sie als Form menschlichen Kunstschaffens der immanenten Logik des „Märchens“ nach als Remedium des Entfremdungszustands wirkt. Diese rekursive Verfasstheit stellt die Erzählung aus, indem das an Kinder gerichtete „Märchen“ mit Kindlichkeit und Kunst jene privilegierten Modi der wahrhaftigen anthropologischen Selbstaussage vor Gott vereint. Autopoetisch erweist sich das „Märchen“ damit als Bearbeitung des in ihm aufgeworfenen Problems: Es ist selbst Teil dessen, wovon es spricht. Nicht nur durch den einfachen Ton und die parodistisch-verniedlichende Form, sondern auch durch die zweifach

30 Rüdiger Zymner u. Manfred Engel, Nichtkunst und Dichtkunst. In: Die Anthropologie der Literatur. Poetogene Strukturen und ästhetisch-soziale Handlungsfelder, hg. von Rüdiger Zymner u. Manfred Engel, Paderborn 2004, S. 7-10, hier S. 8.

31 Roland Barthes, Einführung in die strukturale Analyse von Erzählungen. In: Barthes, Das semiologische Abenteuer, Frankfurt am Main 1988, S. 102-143, hier S. 102.

32 Vgl. Michael Scheffel, Erzählen als anthropologische Universalie: Funktionen des Erzählens im Alltag und in der Literatur. In: Die Anthropologie der Literatur. Poetogene Strukturen und ästhetisch-soziale Handlungsfelder, hg. von Rüdiger Zymner u. Manfred Engel, Paderborn 2004, S. 121-138, hier S. 126-129.

33 Scheffel, Erzählen als anthropologische Universalie, S. 121. 
fingierte Mündlichkeit des Erzählens und das Anknüpfen an die romantische Tradition des Kindermärchens ebenso wie an den zeitgenössischen Primitivismus-Diskurs schließt es an die in ihm entworfenen Paradigmen an. ${ }^{34}$ Mit der über die Kindheit entwickelten Utopie partizipiert das „Märchen“ überdies an der „neue[n] Kultur der Kindheit“35 in der reformpädagogischen Bewegung um 1900.

Der Schwerpunkt liegt allerdings auf dem gebrochenen Zustand der Gegenwart: Form und Inhalt sind in einer Rekursionsschleife verbunden, indem das „Märchen“ in seiner gebrochenen Form zeigt, wie der Mensch in der Moderne ,wirklich“ ist - nämlich von Gott getrennt. Auch das Verwobensein von Kunst und Religion in einer dezidiert poetischen Kommunikation mit Gott orientiert sich an dem Engel als Schnittstelle zwischen religiöser Vermittlung und ästhetischer Eigenpräsenz. Da es sich in der Logik des „Märchens“ nicht auf eine vorgängige Paradieseinheit stützen kann, bedeutet das künstlerische Vermittlungswerk einer zu stiftenden Einheit etwas genuin Neues - die strikt antisentimentalische Pointe dieses progressiv ausgerichteten Auftaktmärchens liegt darin, dass es nichts Verlorenes zu betrauern gibt. Der vermeintlich „unverfälscht[e] Ursprung“ ist ebenso wie die ,von allen ideologischen, gesellschaftlichen und institutionellen Vorgaben freie Sicht auf die Welt" ${ }^{* 36}$, die August Stahl in den Geschichten vom lieben Gott am Werk sieht, nur als Zielpunkt, nicht aber als je Gewesenes vorgestellt. Diese Sicht ist vielmehr - das illustriert das „Märchen“ überaus plastisch - selbst Gott versperrt.

\subsubsection{Der Zukunft verpflichtet. Heimatlose Künstler als Träger zeitlicher Transzendenz}

Die Lüge des Engels bewirkt Entfremdung und Spaltung und verweist zugleich auf eine ersehnte zukünftige Erlösung. Diese angelisch grundierte Geschichtsphilosophie wird für Rilke von den Künstlern getragen. Die „Pflicht des Künstlers“37 in seiner Wirkweise als geschichtsphilosophisches Zukunftsmedium führt er in dem im Juli und August 1898 verfassten Aufsatz „Über Kunst“ aus. Die Kunst als Träge-

34 Zum Primitivismus-Diskurs in der Moderne vgl. Nicola Gess, Primitives Denken. Wilde, Kinder und Wahnsinnige in der literarischen Moderne (Müller, Musil, Benn, Benjamin), München; Paderborn 2013.

35 Mareike Schildmann, Poetik der Kindheit. Literatur und Wissen bei Robert Walser, Göttingen 2019, S. 63.

36 Stahl, Kommentar, S. 851.

37 Rainer Maria Rilke, Über Kunst. In: Rilke, Schriften. Kommentierte Ausgabe in vier Bänden, Bd. 4, hg. von Horst Nalewski, Frankfurt am Main; Leipzig 1996, S. 114-120, hier S. 115. Im Folgenden ÜK. 
rin des Neuen hatte Rilke wenige Monate zuvor in dem am 5. März 1898 in Prag gehaltenen Vortrag „Moderne Lyrik“ inauguriert - er sei „voll [...] eines großen Neuen, von dem ich Hohes Herrliches zu verkünden habe“38. Dieses Neue umfasst sowohl eine „neue Kunst“39 als auch eine „in hundert Sinnen neu[e] Zeit“ ${ }^{\star 40}$.

Dass der Künstler an dieser neuen Zeit mitwirken kann, hat mit seinem besonderen Verhältnis zu Vergangenheit, Gegenwart und Zukunft zu tun. Während die anderen Menschen „kommen und gehen“, ist er derjenige, der „kein[e] Vergangenheit hinter sich“ hat, der „dauert“ (ÜK 115) und über ein besonderes Gottesverhältnis in die Zukunft ausgerichtet ist: „Die anderen haben Gott hinter sich wie eine Erinnerung. Dem Schaffenden ist Gott die letzte, tiefste Erfüllung.“ (ÜK 115) Kunst ist hier losgelöst von der Gegenwart, sie erscheint „gleichsam als die Weltanschauung des letzten Zieles“ (ÜK 114), als Bereich einer zeitlichen Transzendenz. In seiner Bestimmung von Kunstwerken als „zukünftige Dinge“41 in der kleinen Schrift „Kunstwerke“ (1902) trifft Rilke sich mit Bataille in dessen emphatischem Ausspruch, es sei „sogar nicht übertrieben zu sagen, daß Poesie niemals Sehnsucht nach der Vergangenheit sei““22. Die Grundspannung von Rilkes Ausführungen liegt darin, dass das Kunstwerk als ein göttlich anmutendes Überweltliches und in logischer Unabhängigkeit „,nicht aus der Zeit resultiert“ (ÜK 114), temporal aber aus der Reibung mit ihr entstehen soll. Denn „erst aus diesem Zwiespalt zwischen der gegenwärtigen Strömung und der zeitfremden Lebensmeinung des Künstlers entsteht eine Reihe kleiner Befreiungen, wird des Künstlers sichtbare Tat: das Kunstwerk“ (ÜK 115). Als in sich freier Ausdruck einer Befreiung kann das Kunstwerk unabhängig vom Künstler bestehen. Seine Schönheit besteht gerade in seiner „Selbstständigkeit“ (ÜK 115). Dennoch ist das Kunstwerk für Rilke trotz aller Gegenwartsferne „immer eine Antwort auf ein Heute“ (ÜK 115). Analog zu der prägenden Ästhetik der Moderne, die Baudelaire in „Der Maler des modernen Lebens“ (1863) entwirft, ist „das Schöne jederzeit unweigerlich ein Doppeltes“43 - Kunst und Kunstwerk oszillieren zwischen zeitlos-metaphysischer Entrücktheit und fait social.

38 Rainer Maria Rilke, Moderne Lyrik. In: Rilke, Schriften. Kommentierte Ausgabe in vier Bänden, Bd. 4, hg. von Horst Nalewski, Frankfurt am Main; Leipzig 1996, S. 114-120, hier S. 61. Das Wort „neu“ taucht darin in Variationen fast $50 \mathrm{Mal}$ auf.

39 Rainer Maria Rilke, Moderne Lyrik, S. 85.

40 Rainer Maria Rilke, Moderne Lyrik, S. 67.

41 Rainer Maria Rilke, Kunstwerke. In: Rilke, Schriften. Kommentierte Ausgabe in vier Bänden, Bd. 4, hg. von Horst Nalewski, Frankfurt am Main; Leipzig 1996, S. 303-304, hier S. 303.

42 Georges Bataille, Die Literatur und das Böse, München 1987, S. 39.

43 Charles Baudelaire, Der Maler des modernen Lebens. In: Baudelaire, Sämtliche Werke/ Briefe in acht Bänden, hg. von Friedhelm Kemp u. Claude Pichois, München; Wien 1989, S. 213-258, hier S. 215. 
Sowohl hinsichtlich des Künstlers als auch in Bezug auf das Kunstwerk rangiert in dieser ästhetischen Theorie die Ontologie vor dem Effekt: Während die Schönheit eine Größe für sich ist, wie ein „,wilder Garten, der vor sich hinblüht irgendwo und von dem Keiner weiß“ (ÜK 116), ist Kunst personal gedacht eine „Lebensanschauung“ (ÜK 116), verstanden als eine bestimmte Art zu sein. Diese Seinsform hat nach Rilke eine Nähe zu dem „Reich der großen Gerechtigkeit und der tiefen Liebe“ (ÜK 116), in dem alle Dinge gleichwertig sind, es kein Besitzstreben und keine Verlustangst, sondern nur Hingabe an den Moment gibt, und in dem die Liebe alles unverlierbar im Bild bewahrt - kurz, eine Nähe zur Kindheit. In seinem Aufsatz reflektiert Rilke damit die Affinität von Künstlertum und Kindheit, die im „Märchen“ postuliert wird. Künstler-Sein bedeutet, an kindlicher Wahrnehmung festzuhalten. Diese ist bedroht durch eine begriffliche und urteilsförmige Schematisierung des individuellen Erlebens. An dem Scheidepunkt seiner Entwicklung wird das Kind entweder zum zugerichteten Bürger - „es tritt in den Orden seiner Zeit ein“ - oder zum transhistorischen Künstler als „Mensch im Geiste aller Zeiten“ (ÜK 117).

Diese für die Zeit typische Entgegensetzung von Bürger und Künstler, die die romantische Außenseiter-Zuschreibung des Künstlers aktualisiert, hängt wesentlich am Umgang mit dem Überschuss, dem Unzeitigen und Ungelebten der Kindheit. Indem er sich gegen die Zurichtung zum Staatsbürger durch eine Erziehung sperrt, die „die ersten unwillkürlichen und ganz individuellen Eindrücke durch überkommene und historisch entwickelte Begriffe ersetzt“ (ÜK 117), agiert der Künstler einerseits in hohem Maße subjektiv, das heißt im Widerstand gegen die eigene Zeit. Andererseits hat sein Schaffen einen historisch-objektiven Index, indem er als Resonanzkörper seiner Zeit wirkt, und einen transhistorisch-objektiven Auftrag, indem er an der Gestaltung einer Vollendung (Gottes) beteiligt ist.

Bei seiner Arbeit an dieser Vollendung ist der Künstler keineswegs allein, sondern Glied in einer archetypischen Reihe. Es sind „Fürsten und Philosophen, Kanzler und Könige, Mütter und Märtyrer, denen ihre Zeit Wahn und Widerstand war“ (ÜK 118), die nicht aufgehen in ihr, sondern den Keim der Zukunft tragen. Irgendwann wird diese Zukunft eingeholt von einer Gegenwart, in der sie wiederaufleben und in die sie eingehen: „So sind die Vergangenheiten wie Gerüste, die zusammenbrechen vor dem fertigen Bau; aber wir wissen, daß jede Vollendung wieder Gerüst wird und daß, von hundert Stürzen verhüllt, das letzte Gebäude ersteht, das Turm und Tempel sein wird und Haus und Heimat.“ (ÜK 119) Die Tätigkeit des Künstlers richtet sich folglich nicht an der Vollendung eines einzelnen Werks beziehungsweise des gesamten Lebenswerks aus, sondern ist eingebunden in das Bauen an einer religiös durchwirkten, das einzelne Leben transzendierenden Zukunft. 
Ihre Vollender sind die „Allerzukünftigsten“ (ÜK 119). Sie sind unzeitgemäß im besten Sinne, und darin sowohl ihren Zeitgenossen als auch den gegenwärtigen Menschen fremd. Unter ihnen können selbst die Schaffenden ,jene Großen, deren Heimat erst sein wird, nicht zu Gäste laden; denn sie sind selber nicht zu Hause und sind Wartende und einsame künftige und ungeduldige Einsame“ (ÜK 119). Dass der „Allerzukünftigste“ an der „Unentschlossenheit“ seiner Zeit „zu Grunde“ (ÜK 118) geht, ist nur auf den ersten Blick ein „Scheitern“44. Tatsächlich ist diese Uneingebundenheit in die eigene Zeit die Voraussetzung, um an der künftigen Vollendung mitzuwirken. Vor dem Hintergrund dieser unbedingten Zukunftsfixierung erklärt sich auch Rilkes Ablehnung einer Ästhetik, die die Wirkung auf vergangene oder gegenwärtige, noch dazu in ihre Zeit verstrickte Betrachterinnen und Betrachter untersucht und der die für Rilkes Ästhetik zentrale Achse der Zukünftigkeit fehlt. Die Ausrichtung auf die Zukunft stimmt ihn auch skeptisch in Bezug auf die Rezeption des geplanten Buches, das aus „Über Kunst“ entstehen sollte; er wisse, „daß es viel zu sehr von Zukünften spricht, um die zu berühren, welche mit der Gegenwart so ganz zufrieden sind“45.

Das negative Fundament dieser Zukunftsausrichtung ist die geistige Heimatlosigkeit des Dichters in der Moderne, der heimatlos in der gegenwärtigen Heimatlosigkeit ist. Die Einsamkeit und das Lauschen sind für Rilke „die Haupteigenschaften, welche den neuen Dichtern gemeinsam sind““46. Da der Künstler keine Vergangenheit hat und die Gegenwart ihm keine Heimat bietet, bleibt nur der Weg in die Zukunft. Aktive Heimatlosigkeit und das Warten werden hier zur Bedingung für das Ankommen in einer transzendenten Heimat in der Zukunft gemacht, an der die Künstler als „Zufrühgekommene“ und „Nochnichtlebend[e]“ (ÜK 120) bauen. Das Moderne dieser Wendung gegen die eigene Zeit liegt hier nicht in einer an der Projektion vergangener Ganzheit aufgespannten Antimodernität, sondern in einer Abkehr von der Gegenwart, die durch die Zukunft motiviert ist.

\subsubsection{Nichts für die „Ausgestreuten“. Das Verhältnis von Engel, Kunst und Einsamkeit}

Die zeitliche Fremdheit des Künstlers als „Einsamer mitten im Heute“ (ÜK 115) geht in Rilkes Entwurf der neuen Kunst notwendig mit einer räumlichen Isolation

44 Wacker, Poetik des Prophetischen, S. 206.

45 Rainer Maria Rilke, Brief an Karel Maria Pol de Mont, 10. Januar 1902. In: Rilke, Briefe zur Politik, hg. von Joachim W. Storck, Frankfurt am Main; Leipzig 1992, S. 42-46, hier S. 46.

46 Rilke, Moderne Lyrik, S. 69. 
einher. Erst durch seine ex-zentrische Position gegenüber der Menge kann der Künstler frei gegenüber den Verlockungen seiner Zeit bleiben und als einer der „Allerzukünftigsten“ (ÜK 119) zum Medium der Zukunft avancieren. Dem äußerlich isolierten Künstler entspricht Rilkes behauptete Einsamkeit des Gedichts und seine Rücksichtslosigkeit gegenüber seinen Leserinnen und Lesern. ${ }^{47}$

Der einem ökonomisch-technischen Zugriff sowie der Menge unverfügbare Engel stellt eine Möglichkeit bereit, dieses doppelte, räumliche wie zeitliche Entzogensein nicht bloß als Negativum zu postulieren, sondern als positive Qualität zu inszenieren. So heißt es in Die Aufzeichnungen des Malte Laurids Brigge (1910) zu der besonderen Verbindung von Einsamkeit und Engeln über einen alten Mann, der Vögel füttert: „Wenn die Zuschauer nicht wären und man ließe ihn [den alten Mann, L.Z.] lange genug dastehn, ich bin sicher, daß auf einmal ein Engel käme und überwände sich und äße den alten, süßlichen Bissen aus der verkümmerten Hand. Dem sind nun, wie immer, die Leute im Wege. Sie sorgen dafür, daß nur Vögel kommen [...].“48

Nicht nur entsteht Kunst in der Einsamkeit, sie macht auch selbst wiederum einsam. In diesem Gedanken liegt ein zentraler Bestandteil von Rilkes Stilisierung des eigenen Schaffens, die auf dem Engel als dezidiert unmenschlicher Figur basiert. Die anthropophobe Dimension des Kunstschaffens als Grundlage für die Annäherung an den Engel fasst Rilke in einem Brief an Magda von Hattingberg im Februar 1914 in ein sonderbares Gleichnis. Engel und Stein stecken darin als Formen des Anorganischen einen Bereich des Unmenschlichen ab, in den der Einsame sich in letzter Konsequenz hineinbewegt und in den ihm niemand folgen kann. Er sei, so schreibt Rilke, ,in einen Berg“ gegangen, wundersamer Weise durch Stein hindurch, habe „Stein eingeathmet und Stein

47 Vgl. eine entsprechende Äußerung Rilkes: „Jene Bücher (das Stunden-Buch zumal) nahmen ebensowenig auf einen Leser Rücksicht und Bezug, wie was ich seither habe ausgehen lassen [...]“ (Rainer Maria Rilke, Brief an Jakob von Uexküll, 19. August 1909. In: Rilke, Briefe aus den Jahren 1907 bis 1914, hg. von Ruth Sieber-Rilke u. Carl Sieber, Leipzig 1933, S. 72-75, hier S. 73). Mit Martina King, die sich den sozialstrategischen Aspekten von Rilkes Autorschaft widmet, lässt sich darin ein Charakteristikum der modernen Avantgarde erblicken, deren Akteure „der umgekehrten Güterlogik autonomer Kunst [folgen], welche den Warencharakter von Literatur ausblendet und Publikumserfolg als negatives Qualitätskriterium wertet“ (King, Pilger und Prophet, S. 43). Mag die Rezeption durch die „Masse“ Rilke unliebsam und seiner Stilisierung zum Fremden in seiner Zeit abträglich gewesen sein, so bezieht er das „Primärpublikum“ seiner „Briefgemeinde“ durchaus in seine Werkgenese ein, sodass sich diese „als KoAutoren fühlen dürfen“ (King, Pilger und Prophet, S. 57).

48 Rainer Maria Rilke, Die Aufzeichnungen des Malte Laurids Brigge. In: Rilke, Prosa und Dramen. Kommentierte Ausgabe in vier Bänden, Bd. 3, hg. von August Stahl, Frankfurt am Main; Leipzig 1996, S. 453-635, hier S. 510. 
ausgeathmet“49 , bis wohlmeinende Menschen ihn auf sein Geschrei hin her-

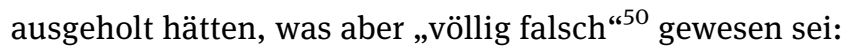

Ich habe keine Übung mit Menschen, ich stellte mich schlecht mit ihnen an, ich bat sie am Ende, zu gehen, und kaum waren sie fort, so kroch ich wieder in meinen Berg hinein, denn draußen verlor ich mich so sinnlos in die Leute hinüber, gab mich weg und bekam, aus Ungeschicklichkeit, nichts dafür wieder, während das Gestein mich wenigstens zusammenhielt und mir so rein und stätig [sic] zu thun gab, es war nicht überall gleich hart -; da übersprang mein Gefühl die Menschen, und ich wollte bleiben oder höchstens von einem Engel gerettet sein, mit dem getraute ich mir schon den richtigen Umgang zu haben. Auch giebt es sicher einen Grad von Noth, auf den die Engel hören, äußerste Nothstrahlen, die die Menschen gar nicht wahrnehmen, die durch ihre dichte Welt durchdringen und erst drüben in eines Engels Schein ein leises leidvolles Violett anschlagen, wie der Amethyst in den Drusen des Bergkrystalls. ${ }^{51}$

Dem in der Welt und unter ihren Menschen Heimatlosen ist auch die menschliche Kommunikation nicht mehr möglich. So wie zu Rilkes Rodin als dem großen Einsamen und Propheten keine Menschen redeten, sondern „Steine sprachen“52, ist hier der Austausch nur über zwei transhumane Extreme möglich: über die geballte Dichte des Steins und den unstofflichen Schein der Engel. Seine Nähe zu ihnen und die darüber begründete angelologische Kompetenz macht Rilke gegenüber Karl von der Heydt mit Augenzwinkern ebenfalls über das Bild des Überspringens der Menschen geltend, der hier aber immerhin noch mit „Herzlichkeit“ gedacht wird:

[E]s vertrüge sich nicht mit der Leidenschaftlichkeit der Engel, Zuschauer zu sein, [...] ich halte sie für die Eingreifer [/Angreifer, s. Fußnote, L.Z.] par excellence, - und da müssen Sie mir schon nachgeben, ich habs verbürgt: denn da ich mich, von Dingen und Thieren gründlich herkommend, danach sehnte, im Menschlichen ausgebildet zu sein, da wurde mir, siehe, das Übernächste, das Engelische beigebracht, und darum hab ich die Leute übersprungen und schau zu ihnen zurück mit Herzlichkeit. ${ }^{53}$

49 Rainer Maria Rilke, Brief an Magda von Hattingberg, 4. Februar 1914. In: Rilke, Briefwechsel mit Magda von Hattingberg „Benvenuta“, hg. von Ingeborg Schnack u. Renate Scharffenberg, Frankfurt am Main 2000, S. 34-36, hier S. 35.

50 Rilke, Brief an Magda von Hattingberg, 4. Februar 1914, S. 36.

51 Rilke, Brief an Magda von Hattingberg, 4. Februar 1914, S. 36.

52 Rainer Maria Rilke, Auguste Rodin. In: Rilke, Schriften. Kommentierte Ausgabe in vier Bänden, Bd. 4, hg. von Horst Nalewski, Frankfurt am Main; Leipzig 1996, S. 401-480, hier S. 418.

53 Rainer Maria Rilke, Brief an Karl von der Heydt, 15. März 1913. In: Rilke, Die Briefe an Karl und Elisabeth von der Heydt 1905-1922, hg. von Ingeborg Schnack u. Renate Scharffenberg, Frankfurt am Main 1986, S. 188-189. Während es in der Ausgabe von 1986 „Eingreifer“ heißt, steht in der Ausgabe von 1933 „Angreifer“ (Rainer Maria Rilke, Brief an Karl von der Heydt, 15. März 1913. In: Rilke, Briefe aus den Jahren 1907 bis 1914, hg. von Ruth Sieber-Rilke u. Carl Sieber, Leipzig 1933, S. 275-277, hier S. 275). 
Am äußersten Ende der anthropologischen Skala situiert, veranschaulicht der Engel Ressourcen, die sich dem menschlichen Zugriff entziehen. Dem Verhältnis von Menschlichem und Angelischem liegt bei Rilke dabei kein klar strukturierter Raum zugrunde, vielmehr bricht das Angelische nur momenthaft in das Leben ein. So beschreibt Rilke in einem Brief an Marie von Thurn und Taxis am 26. November 1915 einen ,angelischen Raum“, der weniger inhaltlich gefüllt als vielmehr durch Unverfügbarkeit und Aussparung bestimmt ist:

[I]ch las und war voller Sammlung und voll reiner Haltung im Geiste, draußen der Park: alles war Einklang zu mir, eine jener Stunden, gar nicht gebildet, sondern nur gleichsam ausgespart, als ob die Dinge zusammenträten und Raum gäben, einen Raum, unberührt wie ein Roseninnres, einen angelischen Raum, in dem man sich still hält; damals vergaß ich diesen Augenblick, er war in keiner Weise bestimmend für den ganzen Tag, jetzt steht er in einer eigenen Stärke und Überstandenheit in mir, als wäre er von einem höheren Grade Seins gewesen. Ich weiß zwei, drei solche Augenblicke aus den letzten Jahren (einmal wars, über die Maßen schön, in Cordoba, davon erzählte ich Ihnen), mir ist, als genügten sie, mein Inneres mit einem lauteren gleichmütigen Glanz zu erfüllen, sie sind so recht Lampen in ihm, ruhige Lampen -, und je mehr ich sie in der Erinnerung und im aufmerksamen Nachgefühl erwäge, desto mehr scheinen mir diese im hiesigen Sinn inhaltlosen Erlebnisse in eine höhere Ereignis-Einheit zu gehören. Aber was bin ich für ein Anfänger in ihnen; denn was müsste aus einer einzigen solchen Erfahrung für endgültige Lebensverwandlung hervorgehen können [meine Hervorhebung, L.Z.]. ${ }^{54}$

Der Momenthaftigkeit des angelischen Raums, dem die Macht zugesprochen wird, eine „endgültige Lebensverwandlung“ zu bewirken, korrespondiert eine von Rilke entworfene Inspirationspoetik, nach der künstlerisches Schaffen nicht herbeizuzwingen ist. ${ }^{55}$ Über die Figur des Engels wird so eine Praxis beschworen, die an den Rändern der menschlichen Wahrnehmung kratzt, gleichzeitig aber getragen ist von der einbekannten Unmöglichkeit, vollends in jenen un- und übermenschlichen Raum übergehen zu können. Dieser ist nicht gebildet, sondern „nur gleichsam ausgespart“. Er verweigert sich damit künstlerischer Formung. Der Engel als Figur der Unverfügbarkeit steht hier für eine sich menschlichem

54 Rainer Maria Rilke, Brief an Marie von Thurn und Taxis, 26. November 1915. In: Rilke und von Thurn und Taxis, Briefwechsel, Bd. 1, hg. von Ernst Zinn, Zürich 1951, S. 452-455, hier S. 452-453. 55 Vgl. Rilkes Erläuterung in einem Brief an Ellen Key: „Ich muß auf das Klingen warten in der Stille, und ich weiß, wenn ich das Klingen dränge, dann kommt es erst recht nicht. [...] Manchmal ist es da, dann bin ich der Herr meiner Tiefen, die sich auftun, strahlend und schön und schimmernd im Dunkel; aber ich habe nicht den Zauberspruch getan, Gott tut ihn, wenn es Zeit ist, und mir gebührt nur, geduldig zu sein und zu warten und meine Tiefen gläubig zu ertragen, die, wenn sie verschlossen sind, wie ein schwerer Stein sind viele Tage des Jahres“ (Rainer Maria Rilke, Brief an Ellen Key, 13. Februar 1903. In: Rilke, Briefe zur Politik, hg. von Joachim W. Storck, Frankfurt am Main; Leipzig 1992, S. 52-54, hier S. 54). 
Zugriff entziehende Wahrnehmungs- und Lebensqualität, die dem in seiner Zeit exilierten Künstler momenthaft zugänglich ist.

Auch das Gedicht „Wer könnte einsam leben und nicht dies“, das Rilke im Dezember 1906 auf Capri schrieb und seiner dortigen Gastgeberin widmete, streicht die Exzeptionalität und Exklusivität des Einsamen über den Engel als Distinktionsfigur heraus. Dabei spiegelt sich das Unkontrollierbare und Ungewisse dieser Begegnung in den sich verunklarenden Bezügen:

\author{
Wer könnte einsam leben und nicht dies \\ bewundern lernen: daß zu ihm zuweilen \\ die Engel treten, um mit ihm zu teilen \\ was sich den Anderen nicht geben ließ, \\ den Ausgestreuten und den Aufgelösten \\ die Trübe trinkend treiben im Geschrei; \\ er aber legt sich leise für den Größten \\ beiseite / nicht als ob er brauchbar sei: \\ greifbarer nur dem wählenden Verschmäher \\ unreifen Anrufs -. Aber dann und wann \\ kommt hülfreich eine Hand und schiebt ihn näher \\ an jene ungeheure Hand heran, \\ die durch die Erde ging und durch das Meer, \\ die noch zu hart ist unsern Kinder-Händen \\ und unserm schwachen Herzen noch zu schwer \\ als daß wir ihre Zärtlichkeit empfänden. ${ }^{56}$
}

Die lautliche Scheidelinie, die zwischen A und E verläuft, trennt die „Anderen“ als die „Ausgestreuten“ und „Aufgelösten“ von dem Einsamen, zu dem die Engel treten. Deren Nähe ist eine physische, keine qualitative. Nicht „brauchbarer“, nur „greifbarer“ ist dem Engel der Einsame, der sich „leise“ beiseitelegt hat, als diejenigen, die sich im Lärm der Welt verlieren. Die letzten beiden Strophen sind geprägt von der referentiellen Kluft, die sich zwischen „einer Hand“ und ,jener Hand“ auftut und die das Oszillieren des Engels zwischen Eigen- und Fremdbezug als Adressat eigener Aufmerksamkeit einerseits und Mittler zu Gott andererseits ausstellt. Während „der wählende Verschmäher unreifen Anrufs“ noch den Engel zu bezeichnen scheint, folgt auf die Zäsur des Gedankenstrichs eine adversative Verknüpfung von unklarer Beschaffenheit. War der Engel zunächst Subjekt der Be-

56 Rainer Maria Rilke, Wer könnte einsam leben und nicht dies. In: Rilke, Gedichte 18951910. Kommentierte Ausgabe in vier Bänden, Bd. 1, hg. von Manfred Engel u. Ulrich Fülleborn, Frankfurt am Main; Leipzig 1996, S. 375-376. 
gegnung, eröffnet sich in der Hand, die an eine andere Hand heranschiebt, eine zweite Bedeutungsebene des Engels als Mittler, der dem Einsamen die Annäherung an Gott ermöglicht. Die Perspektive eines zukünftigen Reich Gottes wird artikuliert in den Wendungen „noch zu hart“ und „noch zu schwer“ - die körperlichräumliche Nähe-Distanz-Relation verschränkt sich zeitlich mit der noch nicht erlangten Einheit mit Gott. Eine solche wird durch die Gemeinschaft der Engel mit dem Einsamen evoziert, ihre exakte Beschaffenheit verweigert sich aber als zukünftige konsequenterweise einer genauen Ausgestaltung.

Der Gedanke, dass die Absonderung des Einsamen von anderen Menschen ihn unmenschlicher und damit engelsnäher macht, ruft mit dem bios angelikos einen klassischen angelologischen Topos auf. ${ }^{57}$ Über die Vorstellung einer Permeabilität zwischen menschlichem und angelischem Bereich, der wesentlich temporal gedacht ist, markiert der Engel an dieser Stelle nicht nur die Exklusivität des Einsamen, sondern auch jene raumzeitliche Vermittlung des engelsgleichen Lebens. In diesem ist die zukünftige Auferstehung nach dem Tod schon in der Gegenwart auf Erden vorweggenommen. In Rilkes Werk übersetzt sich diese Bewegung in die Antizipation und Vermittlung des Neuen durch den Künstler, der aus seiner sozialen Trennung heraus eine Erweiterung des menschlichen Erfahrungsspektrums schafft. So ist die gegenläufige Bewegung zur Isolation des Einzelnen, die ebenfalls in dieser Form einer angelischen Poetik enthalten ist, die Vermittlung, die die Einsamkeit in einem zweiten Schritt kommuniziert, also wieder in eine (Rezeptions-)Gemeinschaft einbindet. Das Gedicht „Wer könnte einsam leben und nicht dies“ nimmt selbst eine engelhafte Rolle ein, indem es analog zum Engel als Mittler zwischen irdischem und transzendentem Bereich die für die ,Massenmenschen' unerreichbare Erfahrung räumlich-zeitlicher Überweltlichkeit evoziert und sie ihnen zugleich über den Topos der Einsamkeit des Künstlers entzieht. Eigens betont wird diese Wendung nach außen auch durch die Widmung des Gedichts. Der angelisch inszenierte Balanceakt zwischen Isolation und Kommunikation liegt schließlich dem Oszillieren von Rilkes poetischen Selbststilisierungen zwischen Isolation und Innenorientierung des Anachoreten und expressiver Kraft und öffentlicher Verkündigungstätigkeit des Propheten zugrunde. ${ }^{58}$

57 Dazu vgl. Kapitel 2.3 dieser Studie.

58 Diese „Paradoxie des ,integrierten Solitärs““ (King, Pilger und Prophet, S. 145) wird nach Martina King über die plural differenzierte „Rilke-Gemeinde“ als Mischung aus Gruppe und Netzwerk realisiert. Auf diese konzentriert sich eine auch in der Literaturwissenschaft lange nachwirkende Rezeptionslenkung in Form der Deutungsangebote, die Rilke epistolarisch gegenüber dem eigenen Werk macht und die über die Adressatenweihe auch die jeweiligen 


\title{
3.1.3 „Eden brennt“. Gott und Mensch im Kriegsexil
}

\author{
Nächtens will ich mit dem Engel reden, \\ ob er meine Augen anerkennt. \\ Wenn er plötzlich fragte: Schaust du Eden? \\ Und ich müßte sagen: Eden brennt \\ Meinen Mund will ich zu ihm erheben, \\ hart wie einer, welcher nicht begehrt. \\ Und der Engel spräche: Ahnst du Leben? \\ Und ich müßte sagen: Leben zehrt \\ Wenn er jene Freude in mir fände, \\ die in seinem Geiste ewig wird, - \\ und er hübe sie in seine Hände, \\ und ich müßte sagen: Freude irrt ${ }^{59}$
}

Der intime Umgang mit Engeln, der die Exklusivität des Einsamen markiert, wird während des Ersten Weltkriegs zum Ausdrucksmedium der menschlichen Krise. In diesem im September 1914 konjunktivisch imaginierten Dialog installiert das lyrische Ich den Engel zunächst als Autorität, der er die Anerkennung seiner sinnlichen Wahrnehmung anheimstellen will. Im Verlauf des Gedichts wird allerdings deutlich, dass der Engel weniger als Prüfinstanz denn als rhetorischer Stichwortgeber benötigt wird. Er spielt die großen Signifikate „Eden“, „Leben“ und „Freude“ ein, die das lyrische Ich dann demontiert - nicht aus diabolischer Verneinungslust, sondern weil es dies unter dem Zwang der realen Verhältnisse „müßte“. In der Wahrnehmung des lyrischen Ichs gibt es kein intaktes Paradies („Eden brennt“) und damit auch keinen Raum, der vor der um sich greifenden Zerstörung sicher wäre. Während in den ersten beiden Strophen der Engel jeweils eine Frage stellt, prüft er in der letzten Strophe mit seinen Händen die Freude, sollte er sie finden; aber selbst dann unterliegt ihr laut lyrischem Ich ein Irrtum. „Eden brennt“, „Leben zehrt“, „Freude irrt“ - ohne abschließende Punkte weisen diese Erwiderungen auf die Unabgeschlossenheit des Leids, das durch keinen Einspruch des Engels begrenzt wird; die historische Deformation behält in diesem Gedicht das letzte Wort. Diesen Eindruck erweckt auch das trochäische Versmaß, das ohne jede Überraschung ist. Einzig die Unvollständigkeit der

Empfängerinnen und Empfänger einbeziehen. Exemplarisch zeigt Martina King dies an den sogenannten Jubelbriefen (vgl. King, Pilger und Prophet, S. 330-345).

59 Rainer Maria Rilke, Nächtens will ich mit dem Engel reden. In: Rilke, Gedichte 1910-1926. Kommentierte Ausgabe in vier Bänden, Bd. 2, hg. von Manfred Engel u. Ulrich Fülleborn, Frankfurt am Main; Leipzig 1996, S. 120. 
letzten Strophe, die auf einer Wenn-dann-Struktur ohne ausgeführtem ,dann` basiert, deutet unterschwellig auf eine mögliche andere Fortsetzung, die unausgesprochen bleibt. Das entspricht dem Wechsel von Sprechen in Be-greifen, den der Engel vollzieht. So ist auch hier der Engel die Figur, die es ermöglicht, eine Erfahrung am Rand menschlicher Ausdrucksfähigkeit im Gedicht zu kommunizieren. Der konjunktivische Modus im Verbund mit dem Engel als Figur, die die Frage nach der Darstellbarkeit des Undarstellbaren aufwirft, weist zugleich auf die Grenzen der Lyrik als Ausdrucksmedium hin.

Die Balance zwischen Gemeinschaft und Absonderung, Darstellbarem und Undarstellbarem gerät für Rilke durch den Ersten Weltkrieg ins Wanken und lässt sich nicht mehr im Medium der Kunst auffangen. In dieser Hinsicht steht Rilke trotz der teils irritierend privaten Perspektive auf den Krieg symptomatisch für seine Zeit. Der Krieg, von dem sich viele die Möglichkeit intensiven Erlebens erhofften, erwies sich als „der totale Ausfall des Erlebnisses“60 und beeinträchtigte entsprechend auch entscheidend die (Un-)Möglichkeit seiner künstlerischen und - zumindest bei Rilke - auch seiner öffentlichen Verarbeitung. So lässt sich Rilkes Epochenbefund zur Verbindung von Kriegsgeschehen, moderner Entfremdung und medialer Vermittlung nur über die sich in Briefen entfaltende private Krise einholen, die der Erste Weltkrieg für ihn bedeutete. Mit diesem ist für Rilke um seine „interne Heimsuchung nun auch noch die Welt so heimgesucht zusammengeschlagen“61.

In einem direkten Zusammenhang mit der individualbiographischen Heimatlosigkeit als Voraussetzung für eine aus vielfältigsten kulturellen Bezugsquellen lebende Produktion (Rilke schrieb in drei Sprachen und übersetzte aus acht) ${ }^{62}$ steht die dezidierte Ablehnung der Nationalismen, die sich im Ersten Weltkrieg Bahn brechen. ${ }^{63}$ Rilkes kosmopolitische Haltung findet allerdings keinen Niederschlag in einer öffentlichkeitswirksamen Schreibpraxis. Sein Schweigen kontrastiert mit der lautstarken Produktivität, die der Krieg bei vielen Künstlerinnen und

60 Horn, Erlebnis und Trauma, S. 139.

61 Rainer Maria Rilke, Brief an Ilse Erdmann, 11. September 1915. In: Rilke, Briefe zur Politik, hg. von Joachim W. Storck, Frankfurt am Main; Leipzig 1992, S. 138-139, hier S. 138.

62 Vgl. Manfred Engel u. Dieter Lamping, Einleitung. In: Rilke und die Weltliteratur, hg. von Manfred Engel u. Dieter Lamping, Düsseldorf; Zürich 1999, S. 7-16, hier S. 7.

63 Vgl. Storck, Politisches Bewußtsein bei Rilke, S. 722-723. Vgl. auch folgende Äußerung Rilkes: „Auch mir liegt, seit ich denken kann, das Nationale unendlich fern -, dennoch verwirrt es mich oft, daß ich angewiesen bin, mich in meinen eigensten Ausdrücken der Sprache eines Volkes zu bedienen, mit dessen Erscheinung und öffentlichem Willen ich immer, wenigstens im Zeitgenössischen, durchaus uneins war [...]“ (Rainer Maria Rilke, Brief an Reinhold von Walter, 4. Juni 1921. In: Rilke, Briefe zur Politik, hg. von Joachim W. Storck, Frankfurt am Main; Leipzig 1992, S. 296-298, hier S. 298). 
Künstlern freisetzte und die gerade zu Beginn vielfach im Dienst einer „geistigen Mobilmachung“64 stand. Während auch Rilke im Krieg zunächst noch „den Kriegs-Gott“65 zu erblicken glaubte, dem er Anfang August 1914 „Fünf Gesänge“ in hölderlinscher Manier widmete, vermochte er in den ausgreifenden Verheerungen bald nichts Göttliches mehr zu erkennen. Diese Leerstelle wird wie in dem berühmten Novalis-Ausspruch durch das Gespenstische besetzt. ${ }^{66}$ Schließlich ist der Krieg in Rilkes Wahrnehmung zu einer auf fatale Weise profan-menschlichen Begebenheit herabgesunken, an der es keine höhere Metaphysik zu besingen gibt. ${ }^{67}$ Aber nicht nur „Kriegslieder“68 sind von nun an Mangelware. Rilke schafft es nicht, sich gegenüber dem äußeren Zeitgeschehen ,abzudichten $^{69}$ und damit die für sein künstlerisches Schaffen als notwendig postulierte Isolation gegenüber der Gegenwart herzustellen. Eingang in sein verschanztes Dichtertum findet diese vor allem über die Zeitung: „[...] [I]ch lese täglich fünf

64 Kurt Flasch, Die geistige Mobilmachung. Die deutschen Intellektuellen und der Erste Weltkrieg, Berlin 2004.

65 Rainer Maria Rilke, Fünf Gesänge. In: Rilke, Gedichte 1910-1926. Kommentierte Ausgabe in vier Bänden, Bd. 2, hg. von Manfred Engel u. Ulrich Fülleborn, Frankfurt am Main; Leipzig 1996, S. 106-111, hier S. 106.

66 Vgl. Rilkes rückblickende Beschreibung: „Nur die ersten drei, vier Tage im August 1914 meinte ich einen monströsen Gott aufstehen zu sehen; gleich darauf wars nur das Monstrum, aber es hatte Köpfe, es hatte Tatzen, es hatte einen alles verschlingenden Leib -, drei Monate später sah ich das Gespenst - und jetzt, seit wie lange schon, ist's nur die böse Ausdünstung aus dem Menschensumpf“ (Rainer Maria Rilke, Brief an Marianne Mitford, 15. Oktober 1915. In: Rilke, Briefe zur Politik, hg. von Joachim W. Storck, Frankfurt am Main; Leipzig 1992, S. 144145, hier S. 144).

67 Schon im Oktober 1914 erklärt Rilke seinem ehemaligen Verleger Axel Juncker: „,Kriegslieder" "sind keine bei mir zu holen, beim besten Willen" (Rainer Maria Rilke, Brief an Axel Juncker, 19. Oktober 1914. In: Rilke, Briefe zur Politik, hg. von Joachim W. Storck, Frankfurt am Main; Leipzig 1992, S. 97-98, hier S. 97). Robert Theel allerdings nimmt den „besten Willen“ wörtlich und entnimmt dieser und weiterer Äußerungen Rilkes, dass Rilke trotz einer schnellen Abkühlung der Kriegsbegeisterung eine „generelle Bereitschaft zu erkennen“ gebe, „poetische Legitimationsarbeit leisten zu wollen“ und entsprechend „verärgert seine widerständige Mentalität“ registriere (Robert Theel, „Analphabet des Unheils“. Rilke, der Krieg, die „poetische Mobilmachung“ und der Cornet. In: Blätter der Rilke-Gesellschaft, 20, 1993, S. 87114, hier S. 96). Rilke führt seine Ablehnung jedoch aus: Auch die Gesänge seien „nicht als Kriegs = Lieder zu betrachten “ und Rilke möchte „sie nicht an anderer Stelle wiederverwendet wissen“ (Rilke, Brief an Axel Juncker, 19. Oktober 1914, S. 97-98).

68 Rilke, Brief an Axel Juncker, 19. Oktober 1914, S. 97.

69 Vgl. die Äußerung in einem Brief an Leopold von Schlözer: „Aber wer vermöchte sich dicht zu machen, das Zeitliche dringt doch durch manche Ritze herein“ (Rainer Maria Rilke, Brief an Leopold von Schlözer, 12. Februar 1914. In: Rilke, Briefe zur Politik, hg. von Joachim W. Storck, Frankfurt am Main; Leipzig 1992, S. 86-87, hier S. 86). 
Zeitungen und gräme mich zu Tode. [...] Aber das Schlimmste ist, daß ich doch nichts anderes hören und lesen mag, als was nun geschieht, und damit für mich selbst, meine Dinge, meine Maße, meine gute einstige Welt unfähig bleibe.“70 Trotz gegenteiliger Behauptungen verstummt Rilkes „Schreibstimme““71 in der Kakophonie der Kriegswelt aber nicht, sie findet vielmehr Unterschlupf im Medium des Briefs als Hybrid aus Kommunikationsmittel und literarischer Expression. In den Brief gehen als Sammelbecken des Nichtpoetischen all jene Gedanken Rilkes ein, die sich in einem weiteren Sinne als politisch bezeichnen lassen. ${ }^{72}$

Das Exil des Ersten Weltkriegs sprengt für Rilke das Exil als stilisierte Bedingung künstlerischer Produktivität. Zuvor hatte Rilke, wie gezeigt, das in der Gegenwart nicht Beheimatete zur Quelle des künstlerischen Schaffens und damit auch zur Ermöglichungsbedingung des Einigungsgeschehens der Kunst in der Zukunft erklärt. Während in den Reflexionen über moderne Kunst der gegenwärtige Zustand von Unverbundenheit, Einsamkeit und Warten als Voraussetzung für das künstlerische Zukunftswirken nur im Vorübergehen gestreift wird, tritt er mit dem Beginn des Ersten Weltkriegs gewaltsam in den Vordergrund. Mit diesem werden für Rilke räumliche wie zeitliche Freiheit als Bedingung von Produktivität zerstört. Nach einem Besuch in Leipzig, zu dem er am 19. Juli 1914 aufgebrochen war, ist ihm der Zugang zu seiner Pariser Wohnung samt seinen Habseligkeiten abgeschnitten. Seitdem befindet er sich ,in einer Art abwartendem Exil“"73. Physische wie geistige Verwerfungen des Kriegs machen ihm eine Sesshaftigkeit dabei wortwörtlich unmöglich: „Ich wohne in einer mir völlig inkommensurablen Welt und warte das Ergebnis ihrer Einflüsse ab, stehend, wie einer der eben nur noch wartet“"74, schreibt er am 2. Oktober

70 Rainer Maria Rilke, Brief an Thankmar von Münchhausen, 3. Februar 1918. In: Rilke, Briefwechsel mit Thankmar von Münchhausen 1913 bis 1925, hg. von Joachim W. Storck, Frankfurt am Main; Leipzig 2004, S. 78.

71 Rainer Maria Rilke, Brief an Magda von Hattingberg, 2. September 1914. In: Rilke, Briefwechsel mit Magda von Hattingberg „Benvenuta“, hg. von Ingeborg Schnack u. Renate Scharffenberg, Frankfurt am Main 2000, S. 187-188, hier S. 187.

72 Der Topos des „unpolitischen Rilke“ ist so weit verbreitet, dass Brigitte Bradley ihn bereits 1972 als „Gemeinplatz“ bezeichnet (Brigitte L. Bradley, Marginalien zur Biographie Rilkes. Briefliche Äußerungen zu Kriegs- und Nachkriegserscheinungen. In: Colloquia Germanica, 7, 1973, S. 9-27, hier S. 9). Dagegen zeigt Joachim Storck, inwiefern sich bei Rilke durchaus von politischem Bewußtsein sprechen lässt (vgl. Storck, Politisches Bewußtsein bei Rilke).

73 Rilke, Brief an Axel Juncker, 19. Oktober 1914, S. 98.

74 Rainer Maria Rilke, Brief an Magda von Hattingberg, 2. Oktober 1919. In: Rilke, Briefwechsel mit Magda von Hattingberg „Benvenuta“, hg. von Ingeborg Schnack u. Renate Scharffenberg, Frankfurt am Main 2000, S. 188-190, hier S. 189. 
1914 an die Pianistin Magda von Hattingberg. Das Warten ist bei Rilke nun nicht mehr bloß Kulturmuster und geschichtsphilosophische (Kunst-)Theoriefigur, ${ }^{75}$ sondern es tritt in Form einer existentiellen Erfahrung auf den Plan: „[S]o wird die Zeit wieder unmittelbar zur Warte-Zeit; nichts ist mir quälender.“76 Damit ist ein zentraler Topos der Moderne berührt, nämlich die Krise des „leeren Wartens“77. In diesem ist mit dem Verlust einer Zielorientierung die sinnstiftende Dimension einer Zukunfts-Erwartung gekappt. ${ }^{78}$ Das exilische Warten kann weder sozialutopisch noch messianisch über den Bezug auf eine ersehnte Zukunft mit Sinn und Struktur versehen werden, stattdessen verdichtet es sich zum krisenhaften Dauerzustand von „Un-Heil und [...] Un-Sinn“79, den Rilke als den einer todesartigen Erstarrung beschreibt. ${ }^{80}$ Die Gegenwart wird dabei zur prekären Schwelle zwischen den Abgründen einer verlorenen Vergangenheit und einer unausdenklichen Zukunft.

Das Spezifische des Ersten Weltkriegs besteht für Rilke darin, dass er als menschlich geprägtes Geschehen eine Welt hervorbringt, die „aus allen Himmeln ausgerenkt ${ }^{\text {“81 }}$ ist. Den Befund einer selbstverschuldeten transzendentalen Verlassenheit des Menschen, den Rilke anlässlich des Balkankriegs 1912/13 äußert, ${ }^{82}$ unterfüttert er im Ersten Weltkrieg sozioökonomisch:

75 Vgl. Daniel Kazmaier, Julia Kerscher u. Xenia Wotschal, Warten als Kulturmuster - eine Einführung. In: Warten als Kulturmuster, hg. von Daniel Kazmaier, Julia Kerscher u. Xenia Wotschal, Würzburg 2016, S. 7-20.

76 Rainer Maria Rilke, Brief an Ellen Delp, 10. Oktober 1915. In: Rilke, Briefe zur Politik, hg. von Joachim W. Storck, Frankfurt am Main; Leipzig 1992, S. 142-143, hier S. 142 (der konkrete Anlass ist die Musterung von Rilkes Jahrgang im Oktober 1915).

77 Pikulik, Warten, Erwarten, S. 11.

78 Nach Lothar Pikulik kennzeichnet das aktive Erwarten eine Zielorientierung, während die Moderne geprägt sei durch „die Situation des bangen, ungewissen, leeren Wartens“ (Pikulik, Warten, Erwarten, S. 11).

79 Rilke, Brief an Ellen Delp, 10. Oktober 1915, S. 142.

80 Vgl. Rilkes Äußerung in einem Brief an Sidonie Nádherný von Borutin: „[I]ch habe mich, um nur unentstellt zu überstehen, tot-gestellt, ich habe den Athem angehalten vier einhalb Jahre“ (Rainer Maria Rilke, Brief an Sidonie Nádherný von Borutin, 7. Februar 1919. In: Rilke, Briefe an Sidonie Nádherný von Borutin, hg. von Bernhard Blume, Frankfurt am Main 1973, S. 286-288, hier S. 288).

81 Rainer Maria Rilke, Brief an Marianne Mitford, 5. März 1915. In: Rilke, Briefe zur Politik, hg. von Joachim W. Storck, Frankfurt am Main; Leipzig 1992, S. 105-108, hier S. 105.

82 Vgl. Rilkes Bemerkung in einem Brief an Sidonie Nádherný von Borutin: „Seit die Menschen meinen, allein auszukommen, ziehn sich die großen Kräfte wirklich zurück und die Ereignisse stoßen sich untereinander herum wie die Schuljungen“ (Rainer Maria Rilke, Brief an Sidonie Nádherný von Borutin, 26. November 1912. In: Rilke, Briefe an Sidonie Nádherný von Borutin, hg. von Bernhard Blume, Frankfurt am Main 1973, S. 165-167, hier S. 167). 
[D]as Verstörende [...] ist nicht die Thatsache dieses Krieges, sondern daß er in einer vergeschäfteten, einer nichts als menschlichen Welt ausgenutzt und ausgebeutet wird, daß der Gott, wenn schon einer ihn hereingeschleudert hat, ihn nicht zurücknehmen kann, weil die Menschen habgierig, mit allem Gewicht ihres schweren Gewissens daran hängen. Menschenmache, wie schon alles die letzten Jahrzehnte Menschenmache war, schlechte Arbeit, Profitarbeit, bis auf ein paar schmerzliche Stimmen und Bilder, bis auf ein paar Warnende, bis auf ein paar Eifernde, die zu ihrem eigenen Herzen hielten, das gegen den Strom stand..$^{83}$

Irritierenderweise scheint an dieser Stelle nicht der Krieg selbst das Problem zu sein, sondern seine spezifisch moderne Form. Die Vertreibung Gottes und die Entwertung der individuellen, gefühlsbasierten Erfahrung erscheinen hier als Ergebnis einer Quantifizierung und Kommerzialisierung des Kriegs. Dieser bedeutet darin nichts qualitativ Neues, er radikalisiert vielmehr eine gesamtgesellschaftliche Entwicklung. Der Erste Weltkrieg ist für Rilke vor allem eine Fortsetzung moderner Tendenzen, namentlich „ein[es] ins Todestechnische verschlagene[n] Geschäftstrieb[s] “84. Nicht nur das Göttliche zieht sich aus dieser menschlich verwalteten Welt zurück, auch der Mensch selbst hat in ihr keinen Platz mehr: Für Rilke führt die Loslösung aus menschlichen wie übermenschlichen Zusammenhängen im Krieg zum „Abbrechen der Menschheit an sich selbst“ ${ }^{* 5}$ und zum „Selbstmord“"86 der Welt. Bemerkenswert ist in diesem Zusammenhang, dass das Exil Gottes und das der Menschen als Folge einer Schere, die sich zwischen göttlicher und menschlicher Welt auftut, Teil ein und derselben Entwicklung ist. Die Vertreibung Gottes führt nicht zu einer Ausweitung und Befreiung der Welt aus den Fängen einer auf das Jenseits vertröstenden Kirche, sondern die Welt ist in ihrer Erfahrbarkeit im selben Maße von Zerstörung bedroht.

Einen wesentlichen Antrieb dieser menschlichen Selbstzerstörung macht Rilke in der spezifischen Medialisierung des Kriegs aus. Indem die propagandistische Berichterstattung einen Keil in die adaequatio rei et intellectus treibt, beschleunigt und radikalisiert sie die allgemeine Entwicklung hin zu Beziehungs- und Referenzlosigkeit. Über die Zeitungen sieht Rilke die Menschen in eine Hyperrealität verwickelt - sie ließen sich „mit dem zweideutigen Scheinge-

83 Rainer Maria Rilke, Brief an Helene von Nostitz, 12. Juli 1915. In: Rilke, Briefe zur Politik, hg. von Joachim W. Storck, Frankfurt am Main; Leipzig 1992, S. 125-126.

84 Rilke, Brief an Marianne Mitford, 5. März 1915, S. 106.

85 Rainer Maria Rilke, Brief an Eva-Marie Freifrau von Heyl zu Herrnsheim, 1. März 1919. In: Rilke, Briefe zur Politik, hg. von Joachim W. Storck, Frankfurt am Main; Leipzig 1992, S. 258259, hier S. 259.

86 Rainer Maria Rilke, Brief an Thankmar von Münchhausen, 5. August 1918. In: Rilke, Briefwechsel mit Thankmar von Münchhausen 1913 bis 1925, hg. von Joachim W. Storck, Frankfurt am Main; Leipzig 2004, S. 85-86, hier S. 86. 
schehen überfüllen“, bis sie „Schmerz und Sorge schließlich nur noch in ihrer Übersetzung denken können“ ${ }^{87}$. Durch die Vordergründigkeit der medialen Vermittlung, die die Wirklichkeit verdrängt, würden „die Menschen geübt, eine Welt von Nachrichten beständig anstelle der Wirklichkeiten hinzunehmen“88. In dieser Derealisierung büße das Leid als nicht mehr unvermittelt erfahrbares auch seine Fähigkeit ein, menschliche und göttliche Sphäre einander anzunähern. ${ }^{89}$ Während die Kunst über ihre vermittelnde Kraft im „Märchen“ noch dazu berufen war, die Kluft zwischen Menschen und Gott zu schließen, vertieft die Medialisierung des Kriegs die herrschende Entfremdung nicht nur zwischen Menschen und Gott, sondern auch zwischen den Menschen untereinander bis zur völligen Unerkennbarkeit.

Differenzierende Wertungen gehen unter in der Berichterstattung als einem „Gedräng, in dem Überholendes und Vermutetes neben Tatsächlichem, Merkantilstes neben Unberechenbarstem steht“ 90 . Das mediale Simulakrum des Kriegs wirkt darüber hinaus, so Rilkes erstaunlich aktueller Befund, als Brandbeschleuniger auf diesen zurück:

[D]ie Täuschung selbst kann auch wieder zur Verwirklichung des Vorgetäuschten führen, diesen ganzen Krieg über haben voreilige Zeitungslügen lebende junge Thatsachen zur Welt gebracht, man hat den Eindruck, seit es eine bis zum Äußersten getriebene Presse giebt, kann ein Krieg, der einmal da ist, überhaupt nicht mehr aufhören, denn die infamen Blätter kommen seinem eigenen Verlauf ohne Ende zuvor. ${ }^{91}$

Mit der zeitlichen Ordnung hat sich auch die Wirkrelation von vorgängigem Kriegsgeschehen und nachträglicher Berichterstattung verkehrt. Die vorauseilende Zeitungsmeldung, die sich von dem tatsächlichen Geschehen abgelöst hat und autonom kursiert, ist ganz wörtlich kriegstreibend: In einer scheinbar unendlichen (Ir-)Realisierung treibt sie das Geschehen vor sich her und zwingt dem Krieg seinen Fortgang auf. Die Diagnose der (Erfahrungs-)Armut verbindet sich bei Rilke mit der Forderung nach einer „neuen Armut“. So verknüpft Rilke schon

87 Rainer Maria Rilke, Brief an Bernhard von der Marwitz, 9. März 1918. In: Rilke, Briefe zur Politik, hg. von Joachim W. Storck, Frankfurt am Main; Leipzig 1992, S. 212-214, hier S. 213.

88 Rilke, Brief an Bernhard von der Marwitz, 9. März 1918, S. 213.

89 Vgl. Rilkes Äußerung: „So fürchterlich der Krieg an sich ist, dies scheint mir noch entsetzlicher, daß sein Druck nirgends dazu beigetragen hat, den Menschen kenntlicher zu machen, ihn Gott gegenüber zu drängen, den Einzelnen oder die Masse, wie das in früheren Zeiten die Kraft großer Nöte war“ (Rilke, Brief an Bernhard von der Marwitz, 9. März 1918, S. 213).

90 Rilke, Brief an Bernhard von der Marwitz, 9. März 1918, S. 213.

91 Rainer Maria Rilke, Brief an Erica Yvette Hauptmann-von Scheel, 5. März 1915. In: Rilke, Briefe zur Politik, hg. von Joachim W. Storck, Frankfurt am Main; Leipzig 1992, S. 133-135, hier S. 134. 
im Mai 1914 in einem Brief an Marie von Thurn und Taxis mit der Definition des Geldes in der Moderne als einem „fast vom Besitzenden unabhängige[n] Element“ das Postulat, „zu diesem neuen ,Reichtum“ die neue Armuth zu finden“. Da sich „,alles [...] ja weit ins Unsichtbare hinein zurückgezogen“ hat, muss „die richtige Armuth [...] wieder von neuem innen in der Seele geboren werden“92.

Das Verhältnis von Sichtbarkeit und Unsichtbarkeit stellt auch die zentrale Größe von Rilkes Kriegsreflexionen dar. Seine „Fünf Gesänge“ aus den ersten Augusttagen 1914 streichen noch emphatisch den Übergang vom indirekten Hörensagen zum eigenständigen Sehen in der Wahrnehmung des sich erhebenden „Kriegs-Gottes“ heraus: „Zum ersten Mal seh ich dich aufstehn / hörengesagter fernster unglaublicher Kriegs-Gott. “93 Bald darauf aber büßt der Krieg für Rilke seine sinnliche Potenz ein. Nicht nur wird er zum unbestimmten Schemen, er zerstört auch das ehedem Sichtbare: „Alles Sichtbare ist eben wieder einmal in die kochenden Abgründe geworfen, es einzuschmelzen“94, teilt Rilke im November 1914 Karl und Elisabeth von der Heydt mit. Im August 1915 beschreibt er die „Farbe“ der Zeit als eine, die sich „,an einer noch unentdeckten Stelle des Spektrums ab[spielt], in einem Ultra-roth, das über unsere Sinne geht“95. Als Folge dieser unmenschlichen Zeit verschieben auch „unsere Erlebnisse sich immer weiter ins Unsichtbare, ins Bazillare und Mikroskopische“"96. Dass technische Vorrichtungen den Radius der menschlichen Wahrnehmung notwendig erweitern, ist für Rilke ein Trugschluss, zumindest dann, wenn sie nicht anthropologisch rückgebunden sind. So fragt er in dem Aufsatz „Ur-Geräusch“ (1919), „[o]b nicht die Erwerbung des Mikroskops, des Fernrohrs und so vieler, die Sinne nach oben oder unten verschiebender Vorrichtungen in eine andere Schichtung zu liegen kommen, da doch der meiste, so gewonnene Zuwachs sinnlich nicht durchdrungen, also nicht eigentlich ,erlebt‘ werden kann“97. Der

92 Rainer Maria Rilke, Brief an Marie von Thurn und Taxis, 18. Mai 1914. In: Rilke und von Thurn und Taxis, Briefwechsel, Bd. 1, hg. von Ernst Zinn, Zürich 1951, S. 376-379, hier S. 377-378.

93 Rilke, Fünf Gesänge, S. 106.

94 Rainer Maria Rilke, Brief an Karl und Elisabeth von der Heydt, 6. November 1914. In: Rilke, Briefe zur Politik, hg. von Joachim W. Storck, Frankfurt am Main; Leipzig 1992, S. 101-102.

95 Rainer Maria Rilke, Brief an Marie von Thurn und Taxis, 2. August 1915. In: Rilke, Briefe zur Politik, hg. von Joachim W. Storck, Frankfurt am Main; Leipzig 1992, S. 128-130, hier S. 128-129.

96 Rainer Maria Rilke, Brief an Elisabeth Taubmann, 18. Mai 1917. In: Rilke, Briefe zur Politik, hg. von Joachim W. Storck, Frankfurt am Main; Leipzig 1992, S. 165-167, hier S. 166-167.

97 Rainer Maria Rilke, Ur-Geräusch. In: Rilke, Schriften. Kommentierte Ausgabe in vier Bänden, Bd. 4, hg. von Horst Nalewski, Frankfurt am Main; Leipzig 1996, S. 699-704, hier S. 704. Umgekehrt sei die Erweiterung durch die Kunst zwar eine erlebte, aber keine, die Allgemeinheit beanspruchen dürfe (vgl. Rilke, Ur-Geräusch, S. 704). 
Bereich, der dem Menschen und seiner Sensorik zwischen mikroskopischer und makroskopischer Unsichtbarkeit noch bleibt, wird immer kleiner. ${ }^{98}$

Die den Krieg prägende Sprache ist entsprechend eine chimärische ohne Verankerung in der Welt. ${ }^{99}$ Für das Grauen, das die menschlichen Sinne übersteigt und in seiner völligen Unanschaulichkeit als Pervertierung göttlicher Transzendenz erscheint, kann es keine Sprache geben. Neben Rilkes Stilisierung der verstummenden, öffentlichkeitsscheuen „Schreibstimme“100 des Dichters legen seine Briefe auch eine aus der Beschaffenheit des modernen Kriegs abgeleitete Begründung für das Schweigen offen, nämlich die von der Unsagbarkeit, der Namenlosigkeit, die der unsichtbare Krieg über die Welt gebracht hat. Der angemessene Umgang mit Sprache kann dann nicht darin bestehen, dem Krieg, der durch den Tropf der Zeitungen am Leben gehalten wird, durch Sprachproduktion weitere Nahrung zu geben. Stattdessen ruft Rilke in dem kurzen Prosa-Stück „Wir haben eine Erscheinung“ vom Oktober 1914, das in „ZeitEcho. Ein Kriegstagebuch der Künstler 1914/15“ erscheint, dazu auf, ihn kognitiv „auszuhungern“"101. In einer unwahren Welt paktiert die konventionelle Bedeutungssprache mit der gegenwärtigen Vernichtung, übrig bleibt an ihren Rändern neben dem Schweigen nur der Schrei als nichtreferentieller, protosprachlicher Urlaut jenseits von Wahrheit und Lüge als legitime (Un-)Form. ${ }^{102}$

98 Der konstatierte Zug ins Anästhetische ist Teil einer allgemeinen Entwicklung in der Moderne, die durch den Krieg beschleunigt und vertieft wird; dies deutet sich hier auch über die Terminologie der Mikrobiologie an, die Teil eines Anschaulichkeitsverlusts in der modernen Wissensgeschichte ist (vgl. Hartmut Böhme, Das Unsichtbare - Mediengeschichtliche Annäherungen an ein Problem neuzeitlicher Wissenschaft. In: Performativität und Medialität, hg. von Sybille Krämer, München 2004, S. 215-245).

99 Vgl. Rilke, Brief an Ellen Delp, 10. Oktober 1915, S. 142.

100 Rilke, Brief an Magda von Hattingberg, 2. September 1914, S. 187.

101 Vgl. Rilkes Aufforderung: „Ihr sollt ihm nicht das Zubehör und die Zunamen früherer Kriege anhängen, denn ob es gleich ein Krieg ist, so kennt ihr ihn doch nicht. [...] Wir haben eine Erscheinung, - und es hat sie mancher angerufen; sie aber weicht nicht und schreitet durch unsere Wände und steht nicht Rede. Weil ihr tut, als kenntet ihr sie. Erhebt eure Augen und kennt sie nicht; schafft ein Hohles um sie mit der Frage eurer Blicke; hungert sie aus mit Nichtkennen! Und plötzlich, in der Angst nicht zu sein, wird euch das Ungeheuere seinen Namen schrein und wegsinken“ (Rainer Maria Rilke, Wir haben eine Erscheinung. In: Briefe zur Politik, hg. von Joachim W. Storck, Frankfurt am Main; Leipzig 1992, S. 98-100, hier S. 100).

102 Vgl. Rilke, Brief an Ellen Delp, 10. Oktober 1915, S. 142-143. Zu der religiösen, über den Psalter vermittelten Dimension des Schreis vgl. Ulrich Fülleborn, Rilkes Gebrauch der Bibel. In: Rilke und die Weltliteratur, hg. von Manfred Engel u. Dieter Lamping, Düsseldorf; Zürich 1999, S. 19-38, hier S. 22-23. 
An Rilkes Heimatlosigkeit als Gefühl wie als Lebensrealität ändert sich auch nach Kriegsende nichts. Der Frieden von 1918 ist kein heiler, sondern in seinem Einsetzen in einer fragmentierten Gegenwart selbst schon ,in tausend Stücke“103 zersprungen. In die Zeit des militaristisch aufgeheizten Klimas der Ermordung des von Rilke geschätzten Walther Rathenau im Juni 1922 und der Ruhrbesetzung, an der ihm kommende Kriege sichtbar werden, fällt auch Rilkes scharfe Abrechnung mit dem Deutschen Reich. ${ }^{104}$ Bereits 1919 hatte er Deutschland verlassen und war in die Schweiz gegangen, wo er 1920 nach einer drohenden Ausweisung als „Ausländer“105 aus München und allerhand bürokratischen Komplikationen die tschechoslowakische Staatsbürgerschaft erhielt. Abgesehen von kurzen, hoffnungsvolleren Anflügen vermag Rilke von der Zukunft als der tragenden Größe seiner ästhetischgeschichtsphilosophischen Reflexionen weder in der Kriegs- noch in der Nachkriegswelt etwas zu entdecken. Die weltgeschichtlichen Ereignisse sind ihm „,von einer obstinaten Rückständigkeit“106 und trennen „wie ein riesiges gefährliches Gebirg“ die Menschheit von ihrer Zukunft, die „wie unerreichbar“107 dahinterliege.

Unabhängig davon, wie gelungen man Rilkes Reaktion auf seine Zeit finden mag - und es gibt vieles, was zu ihrer Kritik einlädt, am provokantesten vielleicht seine ambivalente, bis ins Sakrale reichende Feier der Armut im Verbund mit Verzicht auf konkrete Sozialkritik -, ${ }^{108}$ ist festzuhalten, was im gängi-

103 Rainer Maria Rilke, Brief an Dorothea Freifrau von Ledebur, 19. Dezember 1918. In: Rilke, Briefe zur Politik, hg. von Joachim W. Storck, Frankfurt am Main; Leipzig 1992, S. 236-238, hier S. 237.

104 Ist für Rilke im Januar 1920 der Ausnahmezustand der Welt noch keiner Nation im Besonderen anzulasten, sondern auf das „ratlos[e] Verlorensein Aller“ zurückzuführen (Rainer Maria Rilke, Brief an Leopold von Schlözer, 21. Januar 1920. In: Rilke, Briefe zur Politik, hg. von Joachim W. Storck, Frankfurt am Main; Leipzig 1992, S. 296-298, hier S. 297), rechnet er im Januar 1923 mit dem Deutschen Reich ab: „Wem die Schuld?! - Liebe, wieder, wieder, kann ich nur Deutschland anklagen [...]“ (Rainer Maria Rilke, Brief an Nanny Wunderly-Volkart, 30. Januar 1923. In: Rilke, Briefe zur Politik, hg. von Joachim W. Storck, Frankfurt am Main; Leipzig 1992, S. 409-413, hier S. 411). Damit gehört Rilke für Joachim W. Storck „zu jener langen Reihe bedeutender Geister, die ihr jeweiliges ,Leiden an Deutschland“ zu gewichtigen Kritikern und vielverkannten Warnern werden ließ“ (Storck, Politisches Bewußtsein bei Rilke, S. 724).

105 Vgl. Rainer Maria Rilke, Brief an Hanns Buchli, 25. April 1920. In: Rilke, Briefe zur Politik, hg. von Joachim W. Storck, Frankfurt am Main; Leipzig 1992, S. 306-309, hier S. 306-307.

106 Rainer Maria Rilke, Brief an Thankmar von Münchhausen, 5. März 1918. In: Rilke, Briefwechsel mit Thankmar von Münchhausen 1913 bis 1925, hg. von Joachim W. Storck, Frankfurt am Main; Leipzig 2004, S. 81-82, hier S. 81.

107 Rilke, Brief an Magda von Hattingberg, 2. September 1914, S. 188.

108 Zur Sakralität der Feier vgl. King, Pilger und Prophet, S. 196-197; zur fehlenden Sozialkritik vgl. Rainer Maria Rilke, Brief an Hermann Pongs, 21. Oktober 1924. In: Rilke, Briefe zur Politik, hg. von Joachim W. Storck, Frankfurt am Main; Leipzig 1992, S. 432-440. 
gen Bild des weltflüchtigen Dichters allzu leicht aus dem Blick gerät: dass Rilke entgegen dem Etikett des Konservativismus sehr konsequent und ohne Not an dem Anspruch einer unbedingten Zukunftsausrichtung festgehalten hat, die das Fundament seiner sozialen, pädagogischen und ästhetischen Reflexionen bildet. Dazu gehört auch die Einsicht, dass die kriegsversehrte Welt sich nicht ohne Weiteres wieder in die Himmel „einrenken“109 lässt: „[I]ch sagte immer, um das Unheil, das Menschen sich angethan haben, wirklich zu versöhnen, müßten schon die Engel eingreifen, ich warte hier auf die Engel ... Aber wer hat die in seiner Macht!“110, so Rilke zwei Jahre nach Kriegsende.

\subsubsection{Angelozentrik als modernes Krisenphänomen: Engel in den Duineser Elegien (1912-1922)}

Die Präsenz der Engel bleibt ambivalent, auch wenn Rilke sie als Quelle der Versöhnung beschwört. Denn der moderne Index des angelischen Mittlertums besteht medientheoretisch in einem Ungleichgewicht von Transparenz und Störung in Vermittlungsvorgängen. In seiner medialen Funktion trifft auf den Engel zu, was Sybille Krämer allgemein über Vermittler schreibt: Dass sie solche sind „im Sinne der ,Mitte“ und des ,Mittleren` zwischen zwei Polen oder Positionen, zwischen denen sie ein Sinnlichkeitskontinuum stiften “111. Wenn nun aber, wie Rilke bezüglich des Ersten Weltkriegs reflektiert, Gott und Mensch sich im Exil befinden, also jene Bezugspunkte instabil werden, zwischen denen der Engel ein Sinnlichkeitskontinuum stiften soll, zerbricht die von Gott zu Mensch aufgespannte Kommunikationsachse. Der Engel, der Beziehung stiften soll, zeigt in seiner modernen Präsenz Beziehungslosigkeit an. Dass Engel die Bruchstelle dieser Beziehungskonstellation bilden, ist in Anbetracht ihrer immer schon prekären Tätigkeit nicht verwunderlich: „Sie stehlen die Werte, die sie übertragen, übersetzen die Botschaften zu ihren eigenen Gunsten, besetzen die Kanäle wie Parasiten ... Sie treten unablässig in Erscheinung, statt zu verschwinden“112, wie Michel Serres das grundsätzliche Dilemma der Engel beschreibt. ${ }^{113}$ Im Ram-

109 Vgl. die Diagnose einer ,ausgerenkt[en]“ Welt (Rilke, Brief an Marianne Mitford, 5. März 1915, S. 105).

110 Rainer Maria Rilke, Brief an Sidonie Nádherný von Borutin, 20. November 1920. In: Rilke, Briefe zur Politik, hg. von Joachim W. Storck, Frankfurt am Main; Leipzig 1992, S. 315-319, hier S. 318-319.

111 Krämer, Was haben ,Performativität‘ und ,Medialität‘ miteinander zu tun?, S. 25.

112 Krämer, Was haben ,Performativität‘ und ,Medialität‘ miteinander zu tun?, S. 103-104.

113 Vgl. dazu auch Kapitel 2.4 dieser Studie. 
penlicht der Aufmerksamkeit verlieren sie ihre Transparenz und werden selbst zum Thema. ${ }^{114}$ Indem Engel sich als verdichtete Präsenz vor das göttliche Zentrum schieben, wird das Hintergründige vordergründig und evoziert eine selbstbezügliche Erfahrung, die nicht mehr an eine höhere Instanz rückgebunden ist.

Wenn die gelungene Auftragserfüllung der Engel sich gerade an ihrer größtmöglichen sinnlichen Diskretion erweist, dann sind sie in ihrer hartnäckigen Omnipräsenz im rilkeschen Werk nicht Ausdruck einer anachronistischen Religiosität. Sie erscheinen im Gegenteil als herausragende Trope einer Rhetorik der Krise von Religion und Welt, in der Gott und Mensch sich zunehmend fremd werden. Eine Form, in der die Störung der vordergründigen Engel thematisch wird, ist der Ausfall oder die Verschiebung der zu übertragenden Bedeutung. So hat der Engel in dem Gedicht „Verkündigung“ (1899) seine Botschaft an Maria zunächst vergessen, findet sein Wort dann aber in ihr wieder und übermittelt im Verlauf des Gedichts die Aussage des biblischen Prätextes schließlich doch mit zunehmender Sicherheit. ${ }^{115}$ Während hier das Schema der Botschaftsübermittlung erhalten bleibt, kann es auch eine völlige Umkehrung wie im „Märchen“ erfahren, wenn der Engel keinen Zusammenhang mehr durch Mediatisierung stiftet, sondern einen solchen als Figur der Lüge und Trennung durchbricht. ${ }^{116}$ Während die Aneignung der Botschaft durch das Medium im Rahmen einer konsistenten Ursprungsfiktion und eines geschlossenen Sinn- und Werkzusammenhangs negativ besetzt ist, ändern sich die axiologischen Vorzeichen in einer ästhetischen Konzeption der Moderne, die die Kategorie der Einheit von Anfang, Sinn und Verständigung verabschiedet hat.

Auf dieser Schwelle zwischen Störung und Überwindung sind die Duineser Elegien angesiedelt. Sie beginnen mit einer Problematisierung des Beginnens, die schon im „Märchen“ eine wichtige Rolle spielte. Die 1912 verfasste „Erste Elegie“ setzt mit einer Art in Frage gestellter invocatio ein, einem hypothetischen Schrei, der später als „Lockruf“ bestimmt wird. Hier tritt er nicht als Laut der Notwendigkeit, sondern zurückgehalten und samt antizipierter Konsequenzen nur im Konjunktiv auf:

Wer, wenn ich schriee, hörte mich denn aus der Engel

Ordnungen? und gesetzt selbst, es nähme

$114 \mathrm{Zu}$ Störung und Transparenz als den zwei Polen medialer Kommunikation vgl. Ludwig Jäger, Störung und Transparenz. Skizze zur performativen Logik des Medialen. In: Performativität und Medialität, hg. von Sybille Krämer, München 2004, S. 35-73.

115 Vgl. Rainer Maria Rilke, Verkündigung. In: Rilke, Gedichte 1895-1910. Kommentierte Ausgabe in vier Bänden, Bd. 1, hg. von Manfred Engel u. Ulrich Fülleborn, Frankfurt am Main; Leipzig 1996, S. 291-292.

116 Vgl. Kapitel 3.1.1 dieser Studie. 


\begin{abstract}
einer mich plötzlich ans Herz: ich verginge von seinem stärkeren Dasein. Denn das Schöne ist nichts

als des Schrecklichen Anfang, den wir noch grade ertragen,

und wir bewundern es so, weil es gelassen verschmäht, uns zu zerstören. Ein jeder Engel ist schrecklich.

Und so verhalt ich mich denn und verschlucke den Lockruf dunkelen Schluchzens.

(DE 201)
\end{abstract}

Das „denn“ gibt diesem ausbleibenden Anruf eine resignative Färbung, eine gelingende Kommunikation zwischen Mensch und Engel ist so fragwürdig und die Folgen werden als so vernichtend imaginiert, dass es gar nicht erst dazu kommt. Der Engel scheint hier nur zwischen Ignoranz und Zerstörung denkbar und markiert einen Gedichtanfang, der von der bereits bekannten Problematik des Anfangs, hier des Anfangs von Kommunikation, handelt. Eine Überbrückung der konstitutiven Distanz, die der einzelne aus der Ordnung heraustretende Engel bedeuten würde, überstiege das Maß des Menschenerträglichen. Das Adverb „plötzlich“ ruft das Unkontrollierbar-Momenthafte der Engelserscheinung auf, die nicht im Vorhinein abzuschätzen ist. Die Engel als Grenzwächter evozieren den Gedanken der Ordnung, der mit den „Engel Ordnungen“ gleich zu Beginn formuliert wird. Allerdings deutet der Plural auf eine schwarmartige Formation und das herrenloses Schweifen der Engel, die keine Weisungsgebundenheit zu erkennen geben, auf die Auflösung der angelologischen Ordnung. Wie es bei Michel Serres heißt: „Die Engel sollen eigentlich Ordnung herstellen und für die Einhaltung der Etikette sorgen, aber sie zerfallen selbst in eine gewaltige Unordnung.“117

Über die hypothetisch durchgespielte Angelophanie, die hier mit dem Anstrich einer übermenschlichen Elementarkraft versehen ist, werden die Grenzen des menschlich Erträglichen abgesteckt. Indem das lyrische Ich sie rhetorisch imaginiert, wird eine angelische Überwältigungsästhetik aufgerufen und zugleich eingehegt. Die Gefahr wird präzisiert in der Behauptung, dass das Schöne „nichts als des Schrecklichen Anfang“ und somit dessen Übergang ins Schreckliche bloß gradueller Natur ist. Wesentlich für das Schöne ist nicht die Harmlosigkeit im Gegensatz zur schrecklichen Erhabenheit, sondern dass ,es gelassen verschmäht, / uns zu zerstören“. Dem Schrecken, den das Amorphe, Unbegrenzte, Unmenschliche, kurz das Unsichtbare auslöst, wird das Schöne nicht gegenüber, sondern an die Seite gestellt. Indem er die Schwelle zwischen Gestalthaftem und Gestaltlosem, zwischen unstofflicher Unsichtbarkeit und körperlicher Materialität besetzt, figuriert der Engel in den Elegien die Kippfigur zwischen Schönem und Schrecklichen. Dadurch reflektiert er den Aufbau der Duineser Elegien selbst, die mit

117 Serres, Die Legende der Engel, S. 82. 
ihrem Schwanken zwischen Abgeschlossenheit und deren Bedrohung aus dem Innern einer fragmentierten Sprache das Schwanken zwischen Form und Unform inszenieren.

In Gestalt von Negation und gleichzeitigem Vollzug steht so am Anfang der „Ersten Elegie“ eine zweifache Kommunikation: Mit der Eingangsfrage, die die Möglichkeit des kommunikativen Austauschs zwischen lyrischem Ich und Engel bezweifelt, wird gleichzeitig eine Kommunikation zwischen lyrischem Ich und Rezipientinnen und Rezipienten eröffnet. Diese werden unvermittelt mit einer tendenziell unbeantwortbaren Frage konfrontiert - die Wendung des lyrischen Ichs an sie ist selbst von engelhafter Plötzlichkeit -, sodass auch hier nicht ohne weiteres von gelingender Kommunikation ausgegangen werden kann. ${ }^{118}$ Die Mittlerfunktion des Engels ist somit zweifach aufgerufen: als Vermittlung zwischen ,gedeuteter' Welt, das heißt dem beschränkten Weltausschnitt, der in der Gegenwart wahrgenommen wird, und transhumanem Raum im Fall von lyrischem Ich und Engel sowie auf intra- und extratextueller Ebene zwischen lyrischem Ich und Rezipientinnen und Rezipienten.

Allerdings sind die Grenzen dieser Kommunikationsbereiche nicht beständig, sondern werden bereits im fünften Vers der „Ersten Elegie“ grammatikalisch verschliffen, indem die Erweiterung von lyrischem Ich ins lyrische Wir Rezipientinnen und Rezipienten mit einbezieht. Im Lauf der „Ersten Elegie“ spitzt sich der Einklang des Wir dann dialogisch in der Dringlichkeit von direkter Frage und anschließendem Appell zu: „Weißt du's noch nicht? Wirf aus den Armen die Leere zu den Räumen hinzu, die wir atmen“ (DE 201). Dieser Anruf kann Rezipientin oder Rezipienten, aber auch das Herz des lyrischen Ichs meinen, das später explizit adressiert wird („Höre, mein Herz“ (DE 202)). Die Elegien durchzieht so ein seltsamer Kontrast zwischen diffusen Aufforderungen einerseits und apodiktischen Aussagen andererseits (,[j]eder Engel ist schrecklich“ (DE 205), „[n]irgends, Geliebte, wird Welt sein, als innen“ (DE 221), „[m]it allen Augen sieht die Kreatur / das Offene“ (DE 224)). Gleichzeitig wird der apodiktische Anstrich durch die unausgesetzten, oft über Negationen verlaufenden Fragen (,[h]ab ich nicht recht?“ (DE 212)), die konjunktivischen Wendungen und relativierenden Adverbien (,vielleicht“ (DE 201, 231), „beinah“ (DE 218), „manchmal ein wenig“ (DE 203), „fast nicht“ (DE 218)) unterlaufen. ${ }^{119}$

118 Vgl. das „Inventar der Verstehensschwierigkeiten“, das Manfred Engel ausführt (Manfred Engel, Rainer Maria Rilkes ,Duineser Elegien` und die moderne deutsche Lyrik, Stuttgart 1986, S. 38).

$119 \mathrm{Zu}$ einer ausführlichen Analyse der rhetorischen Struktur der Elegien vgl. Engel, Rainer Maria Rilkes ,Duineser Elegien', S. 151-175. 
Konstitutiv für die Kommunikationssituation ist somit die Spannung zwischen Gestus und Inhalt. Der Eindringlichkeit des vokativischen Sprechens, verstärkt noch durch graphische Kursivierung und musikalische Rhythmisierung, steht ein hermetischer Inhalt gegenüber. Dieser lässt aufgrund seiner Mehrdeutigkeit und den verschiedentlich aufgerufenen Verstehenshorizonten, aber auch wegen der permanenten Übergängigkeit jede positive Bedeutungsfixierung kontingent erscheinen. Perspektive und Relation werden im Zuge einer lyrischen Sprachbewegung hergestellt und wieder verwischt. Die Personalpronomen changieren, Bezeichnungsverhältnisse ändern sich oder sind von Anfang an unklar. Vor dem Dunkel des Inhalts hebt sich umso prägnanter die Kommunikationssituation als solche ab, die exponiert ist durch die rhetorische Gestaltung, insbesondere durch die Mündlichkeit suggerierenden Fragen und Appelle ebenso wie die Behauptungen im Zusammenhang mit dem angesprochenen Du: „Es rauscht jetzt von jenen jungen Toten zu dir. / Wo immer du eintratest, redete nicht in Kirchen / zu Rom und Neapel ruhig ihr Schicksal dich an? / Oder es trug eine Inschrift sich erhaben dir auf, / wie neulich die Tafel in Santa Maria Formosa.“ (DE 202)

So entsteht eine Polarität zwischen voraussetzungsreichen, abgebrochenen Kommunikationssträngen und der emphatischen Dringlichkeit, mit der diese vorgebracht werden. Neben der Stimme sind das Schreien und das Hören - nicht das Verstehen - in der „Ersten Elegie“ omnipräsent und markieren ein Sprechen an den Grenzen von bedeutungstragender Sprache. Dabei werden verschiedene Kommunikationsformen aufgerufen, die alle unsicher und brüchig sind: Das lyrische Ich sinniert über sein mögliches Schreien und das Hören des Engels, später fordert es in der mit „Stimmen, Stimmen“ (DE 202) eingeleiteten Strophe das eigene Herz auf, zu hören, wie es nur die Heiligen tun, die „der riesige Ruf / aufhob“ (DE 202). Analog zur Engelsstelle wird auch Gott in seiner Unerträglichkeit über eine Negation und im Konjunktiv beschworen: „Nicht, daß du Gottes ertrügest / die Stimme, bei weitem.“ (DE 202) Ob nun tot oder äonenhaft entrückt, ${ }^{120}$ Gott scheint in den Elegien als Kommunikationspartner nicht mehr in Frage zu kommen. Stattdessen folgt die Aufforderung, „das Wehende“ zu hören, „die ununterbrochene Nachricht, die aus Stille sich bildet“ (DE 202). In dieser

120 Manfred Koch sieht bereits in der Menge der Interrogativpronomen, die die Sinnfrage aufwerfen, eine Evidenz für den „Tod Gottes“ als Ausgangspunkt des lyrischen Sprechens (vgl. Manfred Koch, Rilkes Engel oder Der heilige Kampf um die Sprache. In: Ästhetische und religiöse Erfahrungen der Jahrhundertwenden, Bd. 2, hg. von Wolfgang Braungart, Gotthard Fuchs u. Manfred Koch, Paderborn u. a. 1998, S. 123-140, hier S. 138). Magnússon befindet angesichts der Totenwelt der „Zehnten Elegie“: „Der Omegapunkt bewusstseinsevolutionärer Entwicklung und höchstes Glied der großen Seinskette, Gott, ist für den medialen Dichter außer Reichweite“ (Magnússon, Dichtung als Erfahrungsmetaphysik, S. 350). 
„rauscht“ es „von jenen jungen Toten“ vernehmbar, und die Bereiche von Leben und Tod selbst sind durchzogen von der „ewige[n] Strömung“, die „alle Alter“ in beiden „übertönt“ (DE 203). Auch dem Schluss der „Ersten Elegie“ liegt der Gedanke zugrunde, dass eine Abwesenheit Wahrnehmbares hervorbringt: „Ist die Sage umsonst [...], daß erst im erschrockenen Raum, dem ein beinah göttlicher Jüngling / plötzlich für immer enttrat, die Leere in jene / Schwingung geriet, die uns jetzt hinreißt und tröstet und hilft.“ (DE 204)

Alle diese Stellen zeigen teils hypothetische Perzeptions- und Resonanzphänomene, aber keine konkretisierbare Botschaft. Mit diesen beständig aufgerufenen und ebenso oft enttäuschten Erwartungen des Gelingens von Kommunikation wird der Gedanke des Rauschens als Naturphänomen wie als Störung vor und jenseits der Botschaft evoziert, dem strukturell der Engel als ästhetische Erscheinung ohne Botschaft entspricht. Dass das lyrische Ich durch seine exponierten Anreden ebenfalls intentionell einen Kommunikationsraum eröffnet, rückt ihn als künstlerisches Medium in die angelische Position der Vermittlung eines hermetischen oder ganz ausgefallenen Inhalts. Wie die Engel Gottes Mysterium übermitteln, so evoziert das lyrische Ich die den menschlichen Horizont sprengende ästhetische Angelophanie im Grenzbereich von Schönem und Schrecklichem. Sein Modus ist ein rhetorisches Sprechen, das über Hypothesen, Verneinungen und Auslassungen eine Ästhetik der Überwältigung auf kontrollierte Weise aufruft. Diese Wahrnehmungsphänomene werden durch Adverbien wie ,jetzt“ (DE 202) oder „neulich“ (DE 203) explizit in der Gegenwart verortet; auch die aus dem Malte bekannte „intransitive Liebe“121 begegnet hier als Erfordernis einer ra(s)tlosen Zeit.

Die Gegenwart wird in der „Zweiten Elegie“ aufgegriffen und über die „Tag[e] Tobiae“ (DE 205) mit einer biblischen Urzeit kontrastiert. In dieser waren die Engel noch in einen intakten kommunikativen Ordnungsrahmen eingebunden, sie kamen in Gottes Auftrag mit einer Botschaft:

Jeder Engel ist schrecklich. Und dennoch, weh mir, ansing ich euch, fast tödliche Vögel der Seele, wissend um euch. Wohin sind die Tage Tobiae, da der Strahlendsten einer stand an der einfachen Haustür, zur Reise ein wenig verkleidet und schon nicht mehr furchtbar; (Jüngling dem Jüngling, wie er neugierig hinaussah).

Träte der Erzengel jetzt, der gefährliche, hinter den Sternen eines Schrittes nur nieder und herwärts:

hochaufschlagend erschlüg uns das eigene Herz.

(DE 205)

121 Vgl. die Beschreibung von Abelone im Malte, die sich danach sehnte, ,ihrer Liebe alles Transitive zu nehmen“ (Rilke, Die Aufzeichnungen des Malte Laurids Brigge, S. 628). 
Der Engel war nicht grundsätzlich nicht furchtbar, aber er erschien damals in einer für die Reise verkleideten Form, in der er es „nicht mehr“ war; erträglich ist der Engel in menschlicher Gestalt, „Jüngling dem Jüngling“. Raphael, der Name des Erzengels, der im Buch Tobit in Menschengestalt Tobias auf einer Reise begleitet, heißt so viel wie „Gott heilt“. Diese Gewissheit einer heilenden Kraft Gottes ist offensichtlich nicht mehr gegeben. Käme der Erzengel jetzt, „erschlüg uns das eigene Herz“. Mit der Abwesenheit Gottes in den Elegien ist der sinngenerierende Ursprung der kommunikativen Trias von Gott - Engel - Mensch weggebrochen, was eine Dynamisierung des ganzen Gefüges nach sich zieht und die Engel in den Vordergrund treten lässt. Die Vielzahl ihrer Apostrophierungen suggeriert zunächst Anschaulichkeit und weist sie in ihrem Zusammenklang zugleich ab:

Frühe Geglückte, ihr Verwöhnten der Schöpfung,

Höhenzüge, morgenrötliche Grate

aller Erschaffung, - Pollen der blühenden Gottheit,

Gelenke des Lichtes, Gänge, Treppen, Throne,

Räume aus Wesen, Schilde aus Wonne, Tumulte

stürmisch entzückten Gefühls und plötzlich, einzeln,

Spiegel: die die entströmte eigene Schönheit

wiederschöpfen zurück in das eigene Antlitz. (DE 205)

Mit der Charakterisierung als „frühe Geglückte“ und „morgenrötliche Grate aller Erschaffung“ wird das hohe Alter der Engel betont. Als „Pollen der blühenden Gottheit“ sind die Engel wesentliche Träger der Fruchtbarkeit Gottes; der Pollenflug ist ebenfalls sehr alt und Pollen sind wie die Engel vielzählig und unübersichtlich. „Gänge“ und „Treppen“ verweisen als funktionale Vorrichtungen auf die Engel als Verbindungsglieder, ebenso, in den unstofflichen Bereich entrückt, als „Gelenke des Lichts“. „Throne“ gehören zur Nomenklatur der Angelologie, „Räume aus Wesen“ und „Schilde aus Wonne“ sind wiederum unanschauliche Zusammensetzungen. Und schließlich sind die Engel entgegen den funktionalen Bezeichnungen „Tumulte stürmisch entzückten Gefühls“ und „plötzlich, vereinzelt, / Spiegel: die die entströmte eigene Schönheit / wiederschöpfen zurück in das eigene Antlitz“. Die Vermittlung der Engel - die Aufnahme und Weitergabe einer Botschaft oder, wie im „Märchen“ im Spiegel der Engelsaugen, ${ }^{122}$ eines Bilds - ist darin einem autarken Emanationskreislauf gewichen.

Im Gegensatz dazu verlieren die Menschen sich fortwährend in ihren Lebensäußerungen - „wir, wo wir fühlen, verflüchtigen; ach wir / atmen uns aus und dahin“ (DE 205). In ihrer ungewissen Konsistenz sind die Menschen umso mehr

122 Vgl. Kapitel 3.1.1 dieser Studie. 
auf ihre Rezeption durch die Engel angewiesen. Nachdem in der „Ersten Elegie“ eine stimmliche Kontaktaufnahme mit den Engeln unmöglich erschien, wird in der „Zweiten Elegie“ die Frage nach einer geschmacklichen über den Transport verflüchtigter menschlicher Substanz aufgeworfen: „Schmeckt denn der Weltraum, / in den wir uns lösen, nach uns? Fangen die Engel / wirklich nur Ihriges auf, ihnen Entströmtes, / oder ist manchmal, wie aus Versehen, ein wenig / unseres Wesens dabei? Sind wir in ihre / Züge soviel nur gemischt wie das Vage in die Gesichter / schwangerer Frauen?“ (DE 206) Doch die Engel erhalten sich nach Bekunden des lyrischen Ichs in reiner Selbstbezüglichkeit: „Sie merken es nicht in dem Wirbel / ihrer Rückkehr zu sich. (Wie sollten sie’s merken.)“ (DE 206)

Die selbstgenügsame Vollkommenheit der Engel wird mit der fragilen Dualität der Liebenden auf menschlicher Ebene kontrastiert. Diese rufen zwar das Bild der Verschmelzung auf, aber im Gegensatz zur angelischen Androgynie ist hier die gebrochene Zweiheit akzentuiert. Entgegen Karin Schulzes Deutung, die aus der Selbstbespiegelung eine „Sterilität des Engels und [e]ine durchaus fragwürdige Stellung im Gefüge der ,Elegien““123 ableitet, lässt sich mit der göttlichen Konnotation des Androgynen, die gerade für eine schöpferische Fruchtbarkeit steht, eine Verschiebung im metaphysischen Gefüge annehmen. In diesem artikuliert sich die dem Engel inhärente Tendenz zur Selbstermächtigung gegenüber einem abwesenden Gott. Als Quelle ausströmender Schönheit, die vor allem bei Pseudo-Dionysius Areopagita als wesentliche göttliche Qualität verstanden wird, ${ }^{124}$ besetzen die Engel die Position Gottes. Darauf deutet auch hin, dass die Engel Spiegel der eigenen Schönheit sind, und nicht, wie klassischerweise, das göttliche Licht widerspiegeln. Der Engel wird an dieser Stelle zur Quelle einer hypothetischen Erfahrbarkeit des Numinosen, eine Position, die in der Gegenwart weder Gott in seiner Abwesenheit noch die Kirche als Institution mit ihrer jenseitsvertröstenden Ausrichtung einnehmen kann. Aufgrund der Abwesenheit Gottes können Mensch und Engel als seine Geschöpfe sich nicht mehr auf ihn hin entwerfen. Während aber die Engel - zumindest in der Wahrnehmung des lyrischen Ichs - davon in ihrer ästhetischen Selbstbespiegelung unangefochten sind, befinden die Menschen sich in einem Zustand fundamentaler Orientierungslosigkeit. Auf die anthropologische Tragweite dieses Befunds weisen die vielen Wir-Sätze hin.

In ihrer Vielfalt als Störfaktor, Diagnoseinstrument und Remedium macht die Figur des Engels in den Duineser Elegien eine anthropologische Deformation in der Gegenwart sichtbar und veranschaulicht zugleich die Möglichkeit ihrer

123 Schulze, „Ein luftiger Austausch“, S. 84.

124 Vgl. Kapitel 2.4 dieser Studie. 
Überwindung. Neben dem technischen Fortschritt wurde diese anthropologische Verunsicherung zu Beginn des 20. Jahrhunderts auch durch die Fokussierung animalischer Anteile durch die Rezeption des Darwinismus und der Psychoanalyse angestoßen, die der bewussten Selbstverfügung des Menschen den Boden entziehen. Entsprechend treten Bemühungen um eine anthropologische Neujustierung in den Vordergrund, für die Rilke Tier und Engel als komplementäre Abgrenzungsfiguren des prä- beziehungsweise transrationalen Anderen in der Aktualisierung einer langen Tradition bemüht. ${ }^{125}$ Über die Mischung aus Einschluss und Ausschluss, Ähnlichkeit und Differenz können Engel und Tiere den Menschen als Menschen in dessen gegenwärtiger Heimatlosigkeit konturieren. So heißt es in der „Ersten Elegie“: „Ach, wen vermögen wir denn zu brauchen? Engel nicht, Menschen nicht, und die findigen Tiere merken es schon, / daß wir nicht sehr verläßlich zu Haus sind / in der gedeuteten Welt.“ (DE 201) Im Gegensatz zu Engel und Tier, die gesetzt und verlässlich erscheinen, stellt der Mensch eine schwankende Variable dar - „Wir nur / ziehen allem vorbei wie ein luftiger Austausch“ (DE 206). Wie im „Märchen“, in dem das Sein Gottes gesetzt, das des Menschen hingegen im Ungewissen belassen wird, ist hier nicht der ontologische Status des Engels, sondern das Menschsein ungesichert. Mögliche Implikationen einer Selbsterfahrung durch Berührung (,,[s]eht, mir geschiehts, daß meine Hände einander / inne werden“) werden unverzüglich eingeschränkt: „Doch wer wagte darum schon zu sein?" (DE 206)

Die Engel besetzen zwar in ihrer androgynen Beschaffenheit eine göttliche Position, nehmen aber in ihrer schön-schrecklichen Ambivalenz und Pluralität gegenüber dem Menschen keine paternale Fürsorgerolle wahr. Der Engel ist vielmehr auch deshalb schrecklich, weil er nicht mehr ohne weiteres zu den Menschen kommt, sondern stattdessen für eine Unverfügbarkeit steht, die sich nicht in die Immanenz positivistischer Welterfassung bannen lässt. Analog zu dem Befund aus der Dialektik der Aufklärung, es dürfe „überhaupt nichts mehr draußen sein, weil die bloße Vorstellung des Draußen die eigentliche Quelle der Angst ist“"126, heißt es in der „Siebenten Elegie“: „Und immer geringer / schwindet das Außen. [...] Weite Speicher der Kraft schafft sich der Zeitgeist, / gestaltlos / wie der spannende Drang, den er aus allem gewinnt. Tempel kennt er nicht mehr.“ (DE 221/222) Und: „Was draußen ist, wir wissens aus des Tiers / Antlitz allein [...].“ (DE 224) In diesem Befund spiegelt sich die im Kontext des Ersten Weltkriegs getroffene Gegenwartsdiagnose eines Verlusts an Welt und eines damit zusammenhängenden universalen Exils - „Bleiben ist nirgends“

125 Vgl. Kapitel 2.3 dieser Studie.

126 Adorno u. Horkheimer, Dialektik der Aufklärung, S. 32. 
(DE 202). Der Engel hingegen entzieht sich subjektiver Verfügungsgewalt, weil er sich in kein objektiviertes Raster bannen lässt, sondern den abrupten, unkontrollierbaren Einbruch des Numinosen in eine Weltordnung verkörpert, die dem Paradigma der quantitativen Vermessung wie pragmatischer Zwangsbeziehungen untersteht. Der Engel ist hier gerade kein Symbol für einen Innerlichkeitskult, vielmehr verkörpert er ein sich Einverleibungstendenzen sperrendes Draußen, das unvermittelt ins Innere einbricht.

Im Verlauf der Elegien wandeln sich die Engel von Krisenindikatoren zu Figuren der Rettung, ohne dass sich daraus eine lineare Gesamtbewegung der Elegien im Sinne von Problem und Lösung extrapolieren ließe, die der Grundkonzeption des Zyklus, aber auch der immanenten Spannung der Engel nicht entspricht. Diese bergen das Versprechen einer Verbindung von Vergangenheit und Zukunft, das aus der exilischen Gegenwart heraus entworfen wird. Zum Schluss der „Neunten Elegie“ werden mit Kindheit und Zukunft die in „Über Kunst“ entwickelten wesentlichen Stationen des Künstlerlebens aufgerufen, die dessen Reichtum ausmachen: „Siehe, ich lebe. Woraus? Weder Kindheit noch Zukunft / werden weniger ... Überzähliges Dasein / entspringt mir im Herzen.“ (DE 229) Der Engel ist die Figur, die diesen Überfluss an Zukunft retten soll, indem sie den schwindenden Reichtum der Vergangenheit bewahrt und für eine spätere Zukunft verfügbar hält. So heißt es in der „Fünften Elegie“, die sich mit den „Fahrenden“ beschäftigt, nach dem Lächeln des Akrobaten, das „blindlings“ (DE 215), trotz Tränen, kommt: „Engel! o nimms, pflücks, das kleinblütige Heilkraut. / Schaff eine Vase, verwahrs! Stells unter jene, uns noch nicht / offenen Freuden [...].“ (DE 216)

Der Engel steckt den Bereich des Noch-Nicht ab, der potentielle zukünftige Freuden des Menschen bereithält und der in der letzten Strophe als Raum evoziert wird. Hier wird der Engel ganz ohne die Probleme aus der „Ersten Elegie“ adressiert. Der Konjunktiv der Anrufung ist allerdings nicht verschwunden, sondern in die Aussageebene gewandert. In diesem nichtgewussten, konjunktivischen Bereich ist das konventionelle Berufslächeln der Akrobaten dann in ein wahrhaftes Lächeln der Liebenden verwandelt:

\footnotetext{
Engel!: Es wäre ein Platz, den wir nicht wissen, und dorten, auf unsäglichem Teppich, zeigten die Liebenden, die's hier bis zum Können nie bringen, ihre kühnen hohen Figuren des Herzschwungs, ihre Türme aus Lust, ihre längst, wo Boden nie war, nur an einander lehnenden Leitern, bebend, - und könntens, vor den Zuschauern rings, unzähligen lautlosen Toten:
} 
Würfen die dann ihre letzten, immer ersparten, immer verborgenen, die wir nicht kennen, ewig gültigen Münzen des Glücks vor das endlich wahrhaft lächelnde Paar auf gestilltem Teppich?

Über den Engel wird so ein Raum beschworen, der Menschen unbekannt ist, der sich aber über den Engel als unmenschliche Figur hypothetisch beschreiben lässt. In der „Siebenten Elegie“ kommt die mögliche Rettung aus Verlust und Vergänglichkeit über den Engel wiederum direkt aus dem Zustand des Exils:

\author{
Jede dumpfe Umkehr der Welt hat solche Enterbte, \\ denen das Frühere nicht und noch nicht das Nächste gehört. \\ Denn auch das Nächste ist weit für die Menschen. Uns soll \\ dies nicht verwirren; es stärke in uns die Bewahrung \\ der noch erkannten Gestalt. - Dies stand einmal unter Menschen, \\ mitten im Schicksal stands, im vernichtenden, mitten \\ im Nichtwissen-Wohin stand es, wie seiend, und bog \\ Sterne zu sich aus gesicherten Himmeln. Engel, \\ dir noch zeig ich es, $d a$ ! in deinem Anschaun \\ steht es gerettet zuletzt, nun endlich aufrecht. \\ Säulen, Pylone, der Sphinx, das strebende Stemmen, \\ grau aus vergehender Stadt oder aus fremder, des Doms. (DE 222)
}

Hier wird das geschichtsphilosophische Motiv der Exilierung in der Zeit aufgerufen, dem der universale Zustand des „Bewusstseinsexil[s]““127 des Menschen korrespondiert, ein Zustand des Transits, in dem man weder des Früheren noch des Zukünftigen habhaft ist. In diesem Grenzbereich ist der Engel ein Gegenüber, das das noch Gekannte in seinem Blick zu bewahren vermag. Die Kulturgüter vergangener Epochen, das, was unter Menschen „stand“, soll unter dem Blick des Engels stehen, „gerettet zuletzt“. Dass die Überwindung der gespaltenen Welt und der schwindenden Sichtbarkeit in den Elegien nur punktuell aufscheint, liegt daran, dass sie an eine unverfügbare Zukunft gebunden sind. Anders als in der pessimistischen Sicht auf die Kommunikation zu Beginn der Elegien wird die gelingend-bewahrende Kontaktaufnahme zwischen Mensch und Engel hier nicht bezweifelt. Es handelt sich auch nicht mehr um einen stimmlichen Versuch der Kontaktaufnahme, sondern um ein nonverbales Zeigen, was durch das deiktische „da!“ als nachgestellte, kursivierte Klimax ebenso wie durch das unbestimmte und erst später mit Beispielen gefüllte „dies“ betont wird. In diesem exilischen Zustand

127 Magnússon, Dichtung als Erfahrungsmetaphysik, S. 195. 
ist Rettung nicht sprachlich, sondern nur gestisch zu erwirken, der Engel ist aufgefordert, den Zeugnissen des Vergangenen rettend eine Würde verleihen („nun endlich aufrecht").

In der letzten Strophe, die unmittelbar anschließt, wird der Engel schließlich mit höchstem Pathos aufgefordert, die Rühmung des lyrischen Ichs, der die menschlichen Kulturgüter preist, als Sprachrohr zu übernehmen: „War es nicht Wunder? O staune, Engel, denn wir sinds, / wir, o du Großer, erzähls, daß wir solches vermochten, mein Atem / reicht für die Rühmung nicht aus.“ (DE 222) An dieser Stelle täuscht der weihevolle Duktus nicht darüber hinweg, dass eine Verschiebung stattgefunden hat: In erster Linie wird der Mensch und dann der Engel, der den menschlichen Taten eine größere Resonanz verschaffen soll, gefeiert, während von Gott keine Rede ist. Diese Verschiebung weist nicht nur theologisch, sondern auch medienästhetisch auf den Bruch der Moderne. Dass diese Allianz zwischen Mensch und Medium fragil ist, wird mit dem Schluss der „Siebenten Elegie“ deutlich, der die unterbleibende Eingangsapostrophe der „Ersten Elegie“ variiert. Das konjunktivische Werben des lyrischen Ichs enthält hier Annäherung und Abstoßung zugleich:

\author{
Glaub nicht, daß ich werbe. \\ Engel, und würb ich dich auch! Du kommst nicht. Denn mein \\ Anruf ist immer voll Hinweg; wider so starke \\ Strömung kannst du nicht schreiten. Wie ein gestreckter \\ Arm ist mein Rufen. Und seine zum Greifen \\ oben offene Hand bleibt vor dir \\ offen, wie Abwehr und Warnung, \\ Unfaßlicher, weitauf. \\ (DE 223)
}

Gerade der Versuch, den Engel zu (be-)greifen, ist es, der einen gesicherten Kontakt verhindert, weil er in sich schon die Abwehr dieses Kontakts enthält. Das ist insofern konsequent, als der Engel nur auf diese Weise als unmenschliche Figur andere, gegenwärtig unerfahrbare Räume veranschaulichen kann. Die scheiternde Kommunikation und die ausbleibende Nähe sind so einerseits Ausdruck gegenwärtiger Entfremdung, die mit den „Tagen Tobiae“ kontrastiert wird, gleichzeitig aber auch Voraussetzung für die Imagination anderer Räume, in denen das moderne Exil überwunden ist. Aus diesem Grund ist die genaue Rolle des Engels weniger wichtig als die mit ihm verbundene Struktur des Paradoxen und Unverständlichen, die die Differenz gegenüber dem menschlich Erfassbaren aufrechterhält.

In der „Neunten Elegie“ verschiebt sich die Position des Engels als Figur des Rühmens hin zum Adressat des Weltlobs, das zu vollziehen ein Du aufgefordert wird. Gepriesen werden soll nicht die „unsägliche“ Welt des Überirdisch-Unsicht- 
baren - hier ist der Engel selbst bewandert -, sondern das „Einfache“ der menschlichen Historie, das über Generationen geschaffen wurde.

Preise dem Engel die Welt, nicht die unsägliche, ihm kannst du nicht großtun mit herrlich Erfühltem; im Weltall, wo er fühlender fühlt, bist du ein Neuling. Drum zeig ihm das Einfache, das von Geschlecht zu Geschlechtern gestaltet, als ein Unsriges lebt, neben der Hand und im Blick.

(DE 228)

Der Engel ist an dieser Stelle nicht selbst Vollführer der Verwandlung des Leids oder des Sichtbaren in Unsichtbares, sondern er dient als außerweltlicher Kommunikationspartner, dem die Verwandlung vorgeführt wird:

Und diese, von Hingang

lebenden Dinge verstehn, daß du sie rühmst; vergänglich, traun sie ein Rettendes uns, den Vergänglichsten, zu.

Wollen, wir sollen sie ganz im unsichtbarn Herzen verwandeln in - o unendlich - in uns! Wer wir am Ende auch seien. (DE 229)

In Abgrenzung gegenüber dem im „Weltall“ beheimateten und zeitenthobenen Engel wird die Vergänglichkeit der belebten Dinge und der Menschen sichtbar, die im wiederum mit dem Unendlichen assoziierten Herzen verwandelt werden sollen. Dadurch ist die vormals drängende Frage, wer der Mensch ist, nicht mehr relevant. Dieser Zustand ist allerdings nur als Wunsch der Dinge formuliert, nicht als tatsächliches Geschehen, und auch in der „Zehnten Elegie“ erscheint das Preisen bloß als zukünftige Hoffnung des lyrischen Ichs. Die letzte Elegie beginnt mit einem Nebensatz, der einen in die Zukunft projizierten Einklang von lyrischem Ich und Engel entwirft: „Dass ich dereinst, an dem Ausgang der grimmigen Einsicht, / Jubel und Ruhm aufsinge zustimmenden Engeln.“ (DE 230) Der grammatikalisch unvollständige Nebensatz lässt die Möglichkeit offen, ihn als finalen Anschluss des letzten Satzes der „Neunten Elegie“ zu lesen: „Überzähliges Dasein / entspringt mir im Herzen.“ - „Dass ich dereinst, an dem Ausgang der grimmigen Einsicht, / Jubel und Ruhm aufsinge zustimmenden Engeln.“ (DE 229/230) Dieser elysische Zustand wird in der zweiten Strophe erneut mit dem entfremdeten Zustand der Gegenwart kontrastiert, in der der Engel als apokalyptische Figur der Zerstörung imaginiert wird:

Freilich, wehe, wie fremd sind die Gassen der Leid-Stadt, wo in der falschen, aus Übertönung gemachten Stille, stark, aus der Gußform des Leeren der Ausguß prahlt: der vergoldete Lärm, das platzende Denkmal. 
O, wie spurlos zerträte ein Engel ihnen den Trostmarkt, den die Kirche begrenzt, ihre fertig gekaufte:

reinlich und zu und enttäuscht wie ein Postamt am Sonntag. (DE 230)

Zuletzt tritt der Engel nicht mehr als Figur des Preises auf, sondern als Träger der Vernichtung, die sich gegen eine Kirche richtet, die schon deshalb nicht Teil der Kommunikation mit Gott sein kann, weil sie nicht gebaut ist - im „Märchen" ein Modus der Gottesbegegnung -, sondern gekauft. Die Kirche ist damit das Sinnbild einer Stadt, die aus vergoldeter Leere besteht und in der sich die insbesondere im Zusammenhang mit dem Ersten Weltkrieg von Rilke beklagte Kommerzialisierung materialisiert.

Die durch den Zyklus hindurch entfaltete Spannung aus gegenwärtigem Leid und Exilierung einerseits und den Aussichten auf eine Überwindung andererseits steht ihrerseits unter dem Vorzeichen einer unsicheren, unverständlichen oder gestörten Kommunikation, die mit dem Beginn der Elegien programmatisch eingeführt wurde. Mit der gescheiterten Kommunikation zwischen lyrischem Ich und Engel wird die Störung der Übertragung semantischer Gehalte zwischen Menschlichem und Absolutem ebenso wie die gestörte hermeneutische Beziehung zwischen Kunstwerk und Rezipientinnen und Rezipienten ausgestellt. So bemerkt Anthony Stephens, dass „[d]ie Duineser Elegien [...] im herkömmlichen Sinne nicht ,verstanden“ werden“"128 wollen. Sie inszenieren darüber hinaus aktiven Widerstand gegen das Verstandenwerden, indem sie einer Rhetorik der $o b$ scuritas folgen, zugleich aber das Verstehen durch ihren rhetorischen Gestus fortwährend einfordern. Damit sind sie in ihrem Kern analog zu dem Phänomen der Engel in der Moderne aufgebaut, die als Mittler das Gelingen von Kommunikation in Aussicht stellen und sie zugleich in ihrer Überpräsenz, die den Austausch zwischen Gott und Mensch lahmlegt, fortwährend verhindern.

Formal findet die Störung in den Elegien durch das Aufbrechen syntaktischer Verknüpfungen statt. Flankiert wird diese Bewegung von ins Leere laufenden Kausalkonstruktionen, hypothetisch-konjunktivischen Wendungen oder Negationen sowie unbeantwortbaren Fragen und Appellen, in denen sich gesteigerter Nachdruck und Unverständlichkeit verbinden. Auf der Inhaltsebene werden dadurch scheinbare epistemische Gewissheiten verunsichert. Der ausgestellten Kommunikationssituation des Engels mit kryptischer Botschaft entspricht das

128 Anthony Stephens, Duineser Elegien. In: Rilke-Handbuch. Leben - Werk - Wirkung, hg. von Manfred Engel, Stuttgart; Weimar 2013, S. 365-384, hier S. 369. Vgl. dazu auch Engel, Rainer Maria Rilkes ,Duineser Elegien', S. 30-41. 
sprachbildlich hergestellte Kunstwerk, das eine Kommunikation gegenüber seinen Rezipientinnen und Rezipienten aufruft und zugleich verweigert.

Die Gebrochenheit von Strukturen kennzeichnet überdies auch Rilkes stilisierte Autorschaft mit dem als krisenhaft reflektierten Entstehungsprozess der Elegien, der charakterisiert ist durch „die tiefe verhängnisvolle Unterbrechung““129 des Kriegs. Gleichzeitig ist der Krieg die Voraussetzung für Rilkes ausgiebigen Vollendungsjubel, der sich mit dem Abschluss der Elegien zehn Jahre nach Arbeitsbeginn Bahn bricht und der zu einem machtvollen Instrument der Rezeptionslenkung weit über Rilkes Tod hinaus wurde. ${ }^{130}$ Dem „Wiederanschluß an die Arbeitsbruchstellen des Jahres Vierzehn“131 misst Rilke höchste Bedeutung bei:

Daß ein Mensch, der sich durch das heillose Zusetzen jener Jahre [der Kriegsjahre, L.Z.] bis in seinen Grund zerspalten gefühlt hatte, in ein Früher und ein damit unvereinliches absterbendes Jetzt: daß ein solcher Mensch die Gnade erfährt, wahrzunehmen, wie in noch geheimerer Tiefe, unter diesem aufgerissenen Spalt, die Kontinuität seiner Arbeit und seines Gemüts sich wiederherstellte ..., scheint mir mehr als nur ein privates Ereignis zu sein $\left[\ldots . .{ }^{132}\right.$

Erst die Unterbrechung, so Rilke, ermöglicht wahre Vollendung: „(Der Gedanke liegt mir nahe, daß auch diese Tröstung irgendwie ins Gelingen der großen Elegien eingegangen sei, so daß sie sich vollzähliger aussprechen, als sie ohne Gefährdung und Rettung getan haben würden.)“133 Diese Stilisierung hat in dem zentralen Topos des imaginierten und beschworenen Umschwungs von elegischer Klage in überschwängliches Rühmen in den Elegien selbst ihr Pendant. Insofern umfassen der Zyklus und die Stilisierung seiner Entstehung mit Krise und Rettung die zwei prononcierten Momente, die der Engel in Rilkes gesamtem Werk als Figur zwischen Störung und Heilung ausstellt.

129 Rainer Maria Rilke, Brief an Nora Purtscher-Wydenbruck, 20. Dezember 1923. In: Rilke, Briefe zur Politik, hg. von Joachim W. Storck, Frankfurt am Main; Leipzig 1992, S. 420-422, hier S. 421.

130 Vgl. King, Pilger und Prophet, S. 331.

131 Rainer Maria Rilke, Brief an Arthur Fischer-Colbrie, 20. Dezember 1923. In: Rilke, Briefe zur Politik, hg. von Joachim W. Storck, Frankfurt am Main; Leipzig 1992, S. 458-462, hier S. 459.

132 Rilke, Brief an Arthur Fischer-Colbrie, 20. Dezember 1923, S. 460.

133 Rilke, Brief an Arthur Fischer-Colbrie, 20. Dezember 1923, S. 460. 


\subsection{Angelische Formen des Überwindens}

Die Duineser Elegien zeigen den Engel als verselbstständigtes Medium, das Abläufe stört und darin aus schöpfungstheologischer Perspektive den Zustand der Paradiesferne herstellt, deren Überwindung es zugleich durch eine den Menschen überwölbende Ganzheit in Aussicht stellt. Diese Spannung des Engels zwischen Bruch und Heilung manifestiert sich konkret in zwei über ihre Performativität verbundenen sprachbildlichen Formen, wobei der Schwerpunkt einmal auf dem Sagen und einmal auf dem (Sich-)Zeigen liegt. ${ }^{134}$

Erstens umfasst die kommunikationsästhetische Dimension der Engel die Übertragung und Herstellung von Bedeutung. Die Vordergründigkeit der Engel stört diese Kommunikation und macht darin den Bezug zu Moderne-Diagnosen und -Debatten über einen Mangel an transzendenter Verbundenheit wie im „Märchen“ oder den Duineser Elegien deutlich. Eine Verbindung ist wiederum nur über eine Absonderung an anderer Stelle möglich: In Anlehnung an mönchisch-asketische Praktiken inszeniert Rilke die soziale Abgrenzung als Voraussetzung für Engelsbegegnungen. Indem Rilke die Entrückung des Einsamen zugleich auch zur Prämisse einer ,reinen', das heißt gegenwartsenthobenen Kunst stilisiert, überlappen sich die Sphären der Engel und der Kunst. Hier schließt sich die hermeneutische Frage der Duineser Elegien an, wie der Austausch zwischen Menschlichem und Übermenschlichem (die Begegnung des einsamen Dichters mit dem Engel) sich zu der Kommunikation zwischen Werk und Rezipierenden verhält, wenn Rilke den gelingenden Austausch zwischen Menschlichem und Absolutem an die Trennung auf der sozialen Ebene knüpft. Diese wurde bis hierhin unter den Schlagworten Heimatlosigkeit in der gegenwärtigen Heimatlosigkeit und poetische Sprache am Rand der Signifikation untersucht.

Zweitens beruht die wahrnehmungsästhetische Dimension der Engel auf deren selbstbezüglicher Präsenz in Form der Angelophanie, der eine Überwältigungsästhetik zugrunde liegt, wie sie exemplarisch in der „Ersten Elegie“ vorgeführt wird. In dieser Rolle steht der Engel für die denkbar größte Differenz zu der von Rilke inkriminierten Presse-Sensation: Als Bürge einer ästhetischen Erfahrung außersinnlicher Gehalte verkörpert er eine Gegenbewegung zu modernen Tendenzen des Anschauungs- und Erfahrungsverlusts. Der Engel ist darin Ausdruck einer spezifisch modernen Sprachbildlichkeit, die sich gegen den durch Rationalisierungs- und Abstraktionsprozesse bedingten Verlust an sinnlicher Qualität formiert. Die Analogie zwischen Engelsfigur und modernen Formen

134 Vgl. Krämer, Was haben ,Performativität‘ und ,Medialität‘ miteinander zu tun?, S. 19-20. 
sprachlicher Visualität, die Barbara Thums feststellt, liegt in der „unsinnliche[n] Sinnlichkeit“"135, die beide in Aussicht stellen.

In Rilkes Lyrik wirkt der Engel als sprachbildliches Remedium der fragmentierten menschlichen Wahrnehmung. Deren Radius verengt sich im Kleinen durch eine Verbindung von wissenschaftlichen und ökonomischen Abstraktionstendenzen und im Großen durch eine Vertreibung Gottes und die aus den Himmeln ,ausgerenkt[e] ${ }^{\text {136 }}$ Welt. Die Besonderheit, die Rilkes Ansatz auszeichnet, liegt darin, dass er gegen den Verlust an Sinnlichkeit nicht nur visuelle Qualitäten aufbietet, sondern über den Engel das gesamte Sinnesspektrum in Dienst nimmt. Engel bewerkstelligen Transformations- und Übersetzungsprozesse und zwar als Scharniere zwischen Sichtbarkeit und Unsichtbarkeit ebenso wie als intermediale Figuren zwischen Bildhauerei, Malerei, Musik und Poesie. Die Herausforderung einer numinos-ästhetischen Verbindung qua Kunst reflektiert das „Märchen“ über das Erzählen als Kommunikationsform zwischen „,Nicht-Kunst“ und ,Dicht-Kunst““137. Die Kunstform, die das „Märchen“ neben Malen und Bauen konkret adressiert, ist die, derer sich Rilke nicht nur am häufigsten bedient hat, sondern mit der sein Name als Repräsentant schlechthin verbunden ist - „Gedichte schreiben“ (M 352).

Wie das Erzählen mit dem Paradigma von Oralität assoziiert ist auch die Lyrik in ihrer gattungspoetischen Tradition seit 1800 eng verbunden mit der Vorstellung eines sich in mythischen Untiefen verlierenden Uranfangs. ${ }^{138}$ Spezifika des poetischen Sprechens entfalten sich im Wechselspiel von Begrenzung und Entgrenzung in der Verdichtung von Sprache in einem meist räumlich und zeitlich konzentrierten Ausschnitt. ${ }^{139}$ Gleichzeitig ist die Lyrik offen für akustische und bildliche Phänomene und frei, sich Forderungen der Kausalität, Diskursivität und Referentialität gegenüber zu verschließen. Sie eröffnet so ein breites ästhetisches Spektrum, was sie dazu prädestiniert, Grenzen menschlicher Wahrnehmung zu weiten. Zugleich verfügt sie in ihrer Widerständigkeit gegenüber dem Maßstab der Logizität über eine Lizenz zum verrätselten Sprechen, bei Rilke etwa in Form elliptischer oder mehrdeutiger Formulierungen, die die Lyrik potentiell in die Nähe religiösen Offenbarungswissens rücken.

135 Barbara Thums, Engelsfigurationen in der Literatur der Moderne. In: Himmlisch, irdisch, höllisch. Religiöse und anthropologische Annäherungen an eine historische Ästhetik, hg. von Olivia Kobiela u. Lena Zschunke, Würzburg 2019, S. 205-221, hier S. 206.

136 Rilke, Brief an Marianne Mitford, 5. März 1915, S. 105.

137 Zymner u. Engel, Nichtkunst und Dichtkunst, S. 8.

138 Vgl. Andrea Polaschegg, Literatur auf einen Blick. Zur Schriftbildlichkeit der Lyrik. In: Schriftbildlichkeit. Wahrnehmbarkeit, Materialität und Operarativität, hg. von Sybille Krämer, Eva Cancik-Kirschbaum u. Rainer Totzke, Berlin 2012, S. 245-264, hier S. 246.

139 Vgl. Milan Herold, Der lyrische Augenblick als Paradigma des modernen Bewusstseins. Kant, Schlegel, Leopardi, Baudelaire, Rilke, Göttingen 2017. 
Poetisches und Religiöses lassen Platz für unenthüllbare Geheimnisse, partielle Unverständlichkeit gehört zu ihrem Erwartungshorizont.

Liest man die Lyrik Rilkes unter den Vorzeichen des „Märchens“, in dem Kunst und nicht eine religiöse Praxis das Medium der anthropologischen Selbstaussage vor Gott ist, dann ergibt sich für Rilkes lyrisches Schaffen ein religiöses Setting, dessen Clou darin besteht, Kunst als genuine menschliche Ausdrucksform nicht religiös einzuhegen, sondern ganz in der ihr eigenen Expressivität zu entfalten. Denn wenn Künstler die paradigmatischen Menschen sind, die das wahre Menschsein aussagen sollen, lässt sich umgekehrt folgern, dass Kunst etwas dem Menschen als homo aestheticus beziehungsweise homo creator Wesentliches ist. Und dann, so die Konsequenz, kann das Aussagen des Menschseins in der Kommunikation mit Gott nicht in einem propositionalen Gehalt aufgehen, sondern muss die Dimension des Wie als wesentliches Konstituens von Kunst enthalten - Poetizität und Pragmatik fallen in dieser anthropologischen Selbstaussage in eins. Dieser Logik nach ist gerade die Ausdrucksqualität der Lyrik, die sich nicht in dem Transportieren eines spezifischen Inhalts erschöpft, wesentlicher Teil der Apostrophe Gottes. In Bezug auf die „AtheismusReligion-Dichotomie“ ${ }^{140}$ wird deutlich, dass die Entgegensetzung von religiöser Kommunikation und ihrer ästhetizistischen Entleerung in der Moderne nicht trägt, wenn Kunst selbst als anthropologisch-religiöse Form der Kommunikation aufgefasst wird, ohne dass davon das moderne Kriterium ihrer Selbstreferentialität beeinträchtigt wäre.

\subsubsection{Engel als „Scheinwerfer der Sensualität“}

In Rilkes temporal grundierter Poetik ist es die Sinnlichkeit der Engel, die sie als Zukunftsmedien in der ästhetisch verkümmerten Gegenwart so attraktiv macht. In seinem nach dem Krieg verfassten Aufsatz „Ur-Geräusch“ veranschlagt Rilke als Bedingung für das „,vollendete Gedicht [...], daß die mit fünf Hebeln gleichzeitig angegriffene Welt unter einem bestimmten Aspekt auf jener übernatürlichen Ebene erscheine, die eben die des Gedichtes ist“"141. Diese fünf Hebel sind die fünf Sinne, derer sich „der jetzige europäische Dichter“ nur „ungleich und einzeln bedient“142 - der Fragmentierung der Welt und dem Bruch des Wahrnehmungskontinuums korrespondiert ein ebenso fragmentierter dich-

140 Magnússon, Dichtung als Erfahrungsmetaphysik, S. 47.

141 Rilke, Ur-Geräusch, S. 702-703.

142 Rilke, Ur-Geräusch, S. 702. 
terischer Gebrauch der Sinne. In der Behauptung, dass Riechen, Schmecken, Tasten, Sehen und Hören in ihrem gleichwertigen Einsatz nicht nur kunstfähig, sondern für das „vollendete Gedicht“ notwendig sind, liegt ein weiterer Baustein von Rilkes spezifischer Modernität gegenüber der traditionellen abendländischen Privilegierung des Sehens und Hörens. ${ }^{143}$

Im Idealfall nimmt der Dichter Anlauf für „de[n] Sprung durch die fünf Gärten in einem Atem“144. Aufgabe der dichterischen Schöpfung ist es, über die holistische Bündelung aller Sinne neue Areale einer größtenteils im Dunkeln liegenden Wirklichkeit zu erschließen. Die „schwarzen Sektoren, die das Unerfahrbare bezeichnen“, sind ungleich größer als die „lichten Ausschnitt[e], die den Scheinwerfern der Sensualität entsprechen“"145, so Rilkes Befund. In dieser experimentellen Anordnung ist es die Aufgabe des Dichters, Teile des bis dato Unerfahrbaren $\mathrm{zu}$ ergründen und so Gebiete jenseits des verarmten menschlichen Wirklichkeitssinns künstlerisch erfahrbar zu machen. Das hyperästhetisch ausgerichtete Dichten soll eine Annäherung zwischen Sichtbarem und Unsichtbarem bewirken. Dies bedeutet in Anbetracht von Rilkes Gegenwartsdiagnose eine Anstrengung für den Künstler: Angesichts des Bruchs zwischen Mensch und Absolutem, aber auch zwischen Mensch und Welt ist der Künstler aufgerufen, wie im „Märchen“ Brücken zu bauen durch die menschliche Selbstaussage qua Kunst. Die konkrete Schwierigkeit, mit der sowohl die raumzeitliche Entgrenzung als auch die Verwandlung des Gegebenen im Modus der Kunst konfrontiert ist, besteht darin, dass dieses Neue als das in der Gegenwart Abwesende nur dargestellt werden kann, wenn es Aspekte von Bekanntheit aufweist, also selbst in jenem Grenzbereich von Bekanntem und Unbekanntem angesiedelt ist, der auch der des Engels ist.

Den Engel reklamiert Rilke in diesem poetischen Versuchszusammenhang an anderer Stelle für die auf den ersten Blick gegenläufige Bewegung, nämlich für die Verwandlung von Sichtbarem ins Unsichtbare: „Der Engel der Elegien ist dasjenige Geschöpf, in dem die Verwandlung des Sichtbaren in Unsichtbares, die wir leisten, schon vollzogen erscheint. “146 In den Elegien macht der Engel, wie gezeigt, Bereiche einer Überwindung des gegenwärtigen Exils sichtbar, die sich der menschlichen Wahrnehmung (noch) entziehen. Der Unterschied zu der

143 Vgl. Silke Pasewalck, „Die fünffingrige Hand“. Die Bedeutung der sinnlichen Wahrnehmung beim späten Rilke, Berlin; New York 2002, S. 6-8.

144 Rilke, Ur-Geräusch, S. 703.

145 Rilke, Ur-Geräusch, S. 703.

146 Rainer Maria Rilke, Brief an Witold Hulewicz, 13. November 1925. In: Rilke, Briefe aus Muzot 1921-1926, hg. von Ruth Sieber-Rilke u. Carl Sieber, Leipzig 1935, S. 330-338, hier S. 337 . 
von Rilke kritisierten modernen Verunsinnlichung, aber auch zu der Verarmung des Irdischen durch den christlichen Aufschub in ein Jenseits, besteht bei der Verwandlung ins Unsichtbare darin, dass die menschliche Wahrnehmung nicht verengt, sondern geweitet wird. Wie die Entstehung des vollendeten Gedichts, in dem die Welt auf einer supranaturalistischen Ebene erscheinen soll, wird auch die angelische Form sinnlicher Ausweitung über den Vorgang des Erscheinens und damit über eine spezifisch ästhetische Operation gefasst. Das Wort ,erscheinen' kann dabei unterschiedlich perspektiviert werden. Je nachdem bezeichnet es ein subjektives und möglicherweise nicht von der Realität gedecktes Wahrnehmen oder ein optisches Wahrnehmbar-Werden beziehungsweise Sich-Zeigen. Auch wenn die erste Variante dem allgemeinen Sprachgebrauch nähersteht, so spricht für die zweite Bedeutung die enge Verbindung von „Engel“ und „erscheinen“, wie Rilke sie auch in der Stelle aus dem „Ur-Geräusch“ verwendet. Damit ist aber nichts anderes bezeichnet als die Angelophanie, der hier die Kraft attestiert wird, als ästhetische Metalepse Zukünftiges bereits in der Gegenwart sichtbar zu machen (die „Verwandlung des Sichtbaren in Unsichtbares“, die im Engel „schon vollzogen erscheint“). Insofern der Engel die Präsenz des per definitionem Nichtpräsenten, also eines Scheins, erscheinen lässt, fallen in ihm die zwei Bedeutungen von ,erscheinen' zusammen.

In Anbetracht der von Rilke festgestellten Krise der Zukunft, die in verdichteter Form im Ersten Weltkrieg virulent wird, ist der Gebietsgewinn, den der Engel in Aussicht stellt, nicht nur ein räumlicher, sondern auch ein zeitlicher: In der Antizipation der Zukunft liegt die epistemische Bedeutung des Engels. Er soll die unbeweisbare Behauptung ästhetisch beglaubigen, dass es einen über den Bereich des gegenwärtig Einseh- und Wissbaren hinausreichenden Raum der noch unsichtbaren, aber potentiell erfahrbaren Phänomene und ein sich an diese knüpfendes Wissen gibt. Indem die Potentialität der Zukunft als angelische Realität in der Gegenwart erscheinen kann, trägt der Engel in Rilkes Sinnespoetik eine die ästhetisch verkümmerte Gegenwart überschreitende Temporalität ein. ${ }^{147}$ Diese hat ihr poetologisches Pendant in dem von Rilke vielfach bespielten Modell des Propheten.

Der Dichter als Seher überschreitet die sinnlichen Grenzen der Gegenwart und ist insofern „irrational“148, als er mit der Anmaßung eines Zukunftswissens aus unüberprüfbaren Quellen epistemische Grenzen sprengt. Das, was sich mit der Verwandlung von Sichtbarem in Unsichtbares im Erscheinen des Engels er-

147 Silke Pasewalck untersucht Rilkes Sinnespoetik mit Schwerpunkt auf dem Spätwerk, allerdings ohne den Engel dabei zu berücksichtigen (vgl. Pasewalck, „Die fünffingrige Hand“). 148 King, Pilger und Prophet, S. 286. 
eignen soll, bleibt entsprechend ein logisches Paradox: Wie kann die explizit vollzogene, also eben nicht nur angedeutete oder ansatzweise erfolgte Verwandlung des Sichtbaren in Unsichtbares optisch wahrnehmbar sein? Offensichtlich handelt es sich analog zu der im „Märchen“ wirksamen Unterscheidung zwischen kognitivem und ästhetischem Wissen um eine Erkenntnis, die nicht über logische Operationen gewonnen, sondern nur (kin-)ästhetisch evoziert werden kann. Zentral für diese Form ästhetischer Erkenntnis im Modus poetischer Imagination ist der Gedanke einer spezifischen Prozessualität, die sowohl der Verwandlung als auch dem Erscheinen und damit dem Gedicht eingetragen ist. So macht der Engel nicht die Unsichtbarkeit sichtbar, sondern den Vorgang der Transformation in sie und damit die Übergängigkeit zwischen beiden Zuständen.

In den Gedichten an die Nacht werden die angelischen „Scheinwerfe[r] der Sensualität“ ${ }^{\text {149 }}$ mehrfach für eine gesteigerte, den Bereich des Menschlichen von außen erhellende Sichtbarkeit eingesetzt. Damit wird die Paradoxie einer poetischen Rede ausgestellt, die von dem spricht, von dem sie als menschliche nichts wissen kann. In dem Gedicht „An den Engel“ (1913) wird dieser adressiert als „Starker stiller an den Rand gestellter / Leuchter“' ${ }^{150}$. Als solcher macht er die Konturen des Menschlichen und zugleich die Möglichkeit eines transhumanen Außen sichtbar: „Unser ist: den Ausgang nicht zu wissen / aus dem drinnen irrlichen Bezirk, / du erscheinst auf unsern Hindernissen / und beglühst sie wie ein Hochge-

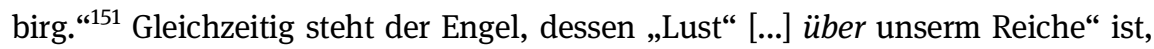
für das Versprechen eines irdische Nichtigkeiten Übersteigenden ein: „Du hast Herrlichkeit von allen Größen / und wir sind am Kleinlichsten geübt" ${ }^{\text {“152 }}$. Wie in der „Ersten Elegie“ wird auch hier die Möglichkeit von Verständigung bezweifelt: „[...] Engel, klag ich klag ich? / Doch wie wäre denn die Klage mein? / Ach ich schreie, mit zwei Hölzern schlag ich / und ich meine nicht, gehört zu sein.“" ${ }^{\text {"153 Über }}$ bloßen Lärm ist keine Verbindung zu stiften, nur über das Gefühl des Engels, das in den Gedichten an die Nacht immer wieder als Fluchtpunkt einer übermenschlichen Sensitivität bemüht wird: „Dass ich lärme, wird an dir nicht lauter, / wenn du mich nicht fühltest, weil ich bin.“154 Das Gedicht „An den Engel“ schließt mit dem Appell an den Engel, über sein Leuchten die Sichtbarkeit des lyrischen Ichs

149 Rilke, Ur-Geräusch, S. 703.

150 Rainer Maria Rilke, An den Engel. In: Rilke, Gedichte 1910-1926. Kommentierte Ausgabe in vier Bänden, Bd. 2, hg. von Manfred Engel u. Ulrich Fülleborn, Frankfurt am Main; Leipzig 1996, S. 46.

151 Rilke, An den Engel, S. 46.

152 Rilke, An den Engel, S. 46.

153 Rilke, An den Engel, S. 46.

154 Rilke, An den Engel, S. 46. 
zu vergrößern: „Leuchte, leuchte. Mach mich angeschauter / bei den Sternen. Denn ich schwinde hin. “155

Die ästhetische Potenz des Engels, die den anthropologisch ausgemessenen Innenraum auf einen angelischen Außenraum hin durchbricht, dient so nicht nur der Erweiterung der menschlichen Wahrnehmung, sondern wird wie in den Elegien auch für das Sichtbarmachen eines prekären anthropologischen Zustands und sodann für die Bewahrung des Menschen in dieser Sichtbarkeit eingesetzt. Entsprechend bricht sich die anvisierte Verwandlung ins Unsichtbare im Jubel und einem Kenntlicherwerden für die Engel in dem Gedicht „Klage“ (1914) Bahn: „Jetzt aber bricht mir mein Jubelbaum, / bricht mir im Sturme mein langsamer / Jubelbaum. / Schönster in meiner unsichtbaren / Landschaft, der du mich kenntlicher / machtest

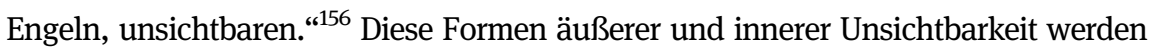
über die gesteigerte Rezeptionsfähigkeit und intensivierte Strahlkraft des Engels, der „fühlender fühlt“ (DE 228), wie es in der „Neunten Elegie“ heißt, in einem Feuerwerk von Bildern kurzgeschlossen: „Ach aus eines Engels Fühlung falle / Schein in dieses Meer auf einem Mond, / drin mein Herz, stillringende Koralle, / seine jüngsten Zweigungen bewohnt“157, wie ein anderes im Februar 1914 verfasstes Gedicht beginnt.

Auch die Kontrastrelation von menschlichem und angelischem Fühlen macht in ihrer ästhetischen Differenz nicht nur Krise und vielfach konjunktivisch-appellativ beschworene Rettung sichtbar, sondern auch, gemäß dem temporalen Index von Ästhetischem und Anästhetischem, die Differenz von menschlicher und angelischer Zeit:

Siehe, Engel fühlen durch den Raum ihre unaufhörlichen Gefühle.

Unsre Weißgluth wäre ihre Kühle.

Siehe, Engel glühen durch den Raum.

Während uns, die wirs nicht anders wissen, eins sich wehrt und eins umsonst geschieht, schreiten sie, von Zielen hingerissen, durch ihr ausgebildetes Gebiet. ${ }^{158}$

155 Rilke, An den Engel, S. 46.

156 Rainer Maria Rilke, Klage. In: Rilke, Gedichte 1910-1926. Kommentierte Ausgabe in vier Bänden, Bd. 2, hg. von Manfred Engel u. Ulrich Fülleborn, Frankfurt am Main; Leipzig 1996, S. 102.

157 Rainer Maria Rilke, Ach aus eines Engels Fühlung falle. In: Rilke, Gedichte 1910-1926. Kommentierte Ausgabe in vier Bänden, Bd. 2, hg. von Manfred Engel u. Ulrich Fülleborn, Frankfurt am Main; Leipzig 1996, S. 94.

158 Rainer Maria Rilke, Siehe, Engel fühlen durch den Raum. In: Rilke, Gedichte 1910-1926. Kommentierte Ausgabe in vier Bänden, Bd. 2, hg. von Manfred Engel u. Ulrich Fülleborn, Frankfurt am Main; Leipzig 1996, S. 79. 
Wie hier in Form des Appells, das Fühlen und Glühen der Engel zu sehen, ist im Zusammenhang mit dem Engel immer wieder die Aufforderung verbunden, den Bereich des Sicht- beziehungsweise allgemeiner des Erfahrbaren auszuweiten und zu einer neuen sensuellen Fülle zu gelangen. So wie in „Siehe, Engel fühlen durch den Raum“ (1913) Sinnhaftigkeit, Fülle und finale Bezogenheit über den Kontrast von angelischer Sensitivität und Zeitgestaltung einerseits und menschlicher Wahrnehmung andererseits evoziert werden, stellt der Engel auch in „L’Ange du Méridien“ (1906) aus den Neuen Gedichten die Figur bereit, über die zeitliche Fülle imaginiert wird:

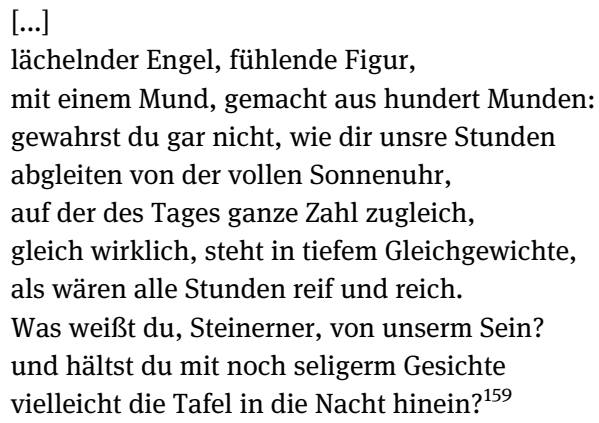

Im Gegensatz zu der fragmentierten menschlichen Wahrnehmung, die Rilke in „Ur-Geräusch“ als Ausgangspunkt poetischer Expeditionen beschreibt, stellt der Kathedralen-Engel eine anschauliche Denkmöglichkeit für den „vollen Kreis“ dar, als den Rilke „das gesamte Erfahrungsbereich der Welt“160 vorgestellt wissen will. Hier ist er als „voll[e] Sonnenuhr“ um die Dimension der Zeit ergänzt, die ihre Fülle durch ihre Funktionalität bei Nacht - und damit gerade unter Entziehung ihrer Möglichkeitsbedingung - erhält. Die Fülle kann der Mensch nicht selbst erfahren, aber über den Engel imaginieren.

Das Steinerne des Engels ist dabei zentraler Bestandteil des zweiten Pfeilers von Rilkes ästhetischem Verwandlungsprogramm. Denn die menschliche Wahrnehmung zu erweitern, bedeutet zugleich, eine künstlerische Ganzheitlichkeit zu entwerfen. Die ästhetischen Verwandlungen, die der Engel in einem Wechselspiel von Statik und Dynamik, von Sichtbarkeit und Unsichtbarkeit in Szene setzt, werden über verschiedene Kunst-Paradigmen organisiert. Die Engel sind einerseits Teil einer ätherisch-esoterischen Immaterialität, die in einer unan-

159 Rainer Maria Rilke, L’Ange du Méridien. In: Rilke, Gedichte 1895-1910. Kommentierte Ausgabe in vier Bänden, Bd. 1, hg. von Manfred Engel u. Ulrich Fülleborn, Frankfurt am Main; Leipzig 1996, S. 462-463.

160 Rilke, Ur-Geräusch, S. 703. 
schaulichen Sprache evoziert wird - etwa über die Umstülpung von Relationen wie in der Engelsbeschreibung als „Räume aus Wesen“ (DE 205) in der „Zweiten Elegie“ -, andererseits sind sie ebenso am anderen Ende der materiellen Verdichtung und Stillstellung als steinerne Engel zu finden. Damit verbunden sind wiederum unterschiedliche zeitliche Modalitäten einer kaum wahrnehmbaren Flüchtigkeit auf der einen Seite und der Assoziation ewiger Dauer des Steins auf der anderen. Zwischen diesen Extremen entwirft Rilke den Engel als eine Figur, die die Frage nach räumlichen und zeitlichen Grenzen zugleich prononciert stellt und abweist, die in ihrer Flüchtigkeit den Aspekt der Zeitlichkeit überbetont und sie in der Ewigkeit und in sich geschlossenen Materialität des Steins durchstreicht. Rilke macht über die Engelsfigur systematisch Mediendifferenzen fruchtbar, indem Engel nicht nur als anfangslose Skulpturen auftreten, ${ }^{161}$ sondern ebenso in der Dynamik des Erscheinens und Verschwindens, in der sie die Verlaufsformen des Sichtbar- und Unsichtbarwerdens, der Materialisierung und Immaterialisierung inszenieren.

(Im-)Materialität und (Un-)Zeitlichkeit, die durch den ätherisch entrückten, momenthaft erscheinenden Engel und seine potentiell unendliche Steinernheit aufgerufen werden, verweisen auf eine Palette unterschiedlichster ästhesiologischer Formen. Indem der Engel Grenzen absteckt und zugleich erweitert, eignet ihm eine Nähe zu dem aus der Bildhauerei beziehungsweise Malerei stammenden Begriff der Kontur, der Grenze und Übergang markiert und für Rilkes Wahrnehmungs- und Raumkonzept essentiell ist. ${ }^{162}$ Wie der Engel, der bei Rilke in Form einer charakteristischen Unbestimmtheit in Erscheinung tritt, ist auch die Kontur von einer unwirklichen Fluidität zwischen „hartnäckige[r] Vorhandenheit und [...] Nicht-Vorhandenheit“163. Die Grenze zwischen ästhetischer Fasslichkeit und Unfasslichkeit wird im Stunden-Buch wiederholt über die Metapher des Saums aufgerufen: In dem Gedicht „Gebet“ (1899) etwa wirkt das Bild eines Ebenholz-Engels als „saumsinnender Riese“6164 als Umschlagspunkt wechselseitiger, kunstbasierter Fühlung von Gott und Mensch.

161 Zur Anfangslosigkeit von Bildern und Skulpturen vgl. Andrea Polaschegg, (K)ein Anfang des Ganzen. Das skulpturale Werkkonzept der Klassik und seine Folgen für die Literaturwissenschaft. In: Konstellationen der Künste um 1800, hg. von Thorsten Valk u. Albert Meier, Berlin; Boston 2015, S. 99-124, hier S. 104.

162 Vgl. Pasewalck, „Die fünffingrige Hand“, S. 15-16 u. S. 68-80.

163 Pasewalck, „Die fünffingrige Hand“, S. 78.

164 Rainer Maria Rilke, Gebet. In: Rilke, Gedichte 1895-1910. Kommentierte Ausgabe in vier Bänden, Bd. 1, hg. von Manfred Engel u. Ulrich Fülleborn, Frankfurt am Main; Leipzig 1996, S. 76. In dem Gedicht „Was irren meine Hände in den Pinseln“ (1899) verläuft der Versuch künstlerischer Betätigung an einem instabilen Saum zwischen Sinnlichem und Übersinnlichem. Die Eingangsfrage des Gedichts lautet: „Was irren meine Hände in den Pinseln?“ Das 
Während über die Gestaltungsprinzipien von Bildhauerei und Malerei sinnliche Qualitäten evoziert werden, ermöglicht die Poesie mit ihrem transitorischen Charakter die Reflexion von Zeit, indem sie sprachlich das beschwört, was für Rilke von der Warte des Menschen aus betrachtet schon beziehungsweise noch unsichtbar ist und somit nicht über die bildende Kunst eingeholt werden kann: Vergangenheit und Zukunft. Zeitliche, räumliche und ästhetische Formen konvergieren in der Figur des Engels, die eine menschlicher Wahrnehmung konträre Identifikation von Existenz und Unsichtbarkeit umfasst. Sie enthält darin eine verlorene, also unsichtbare Vergangenheit wie wiederum eine entzogene, also ebenfalls unsichtbare Zukunft. Dies wird auch in Rilkes Brief zu den Duineser Elegien an seinen Übersetzer Witold Hulewicz vom 13. November 1925 deutlich: „Für den Engel der Elegien sind alle vergangenen Türme und Paläste existent, weil längst unsichtbar, und die noch bestehenden Türme und Brücken unseres Daseins schon unsichtbar, obwohl noch (für uns) körperhaft dauernd.“165 Diese Argumentation, die einmal aus angelischer Perspektive Existenz über Unsichtbarkeit begründet und einmal aus menschlicher Sicht Unsichtbarkeit trotz Existenz behauptet, ist gemäß der Spannung von Entgrenzung und Verdichtung nicht nur als Expansion in unbekannte Wirklichkeitsbereiche, sondern ebenso als Rückzug ins Innere zu denken. Beide sind dabei über ihre instabile Referentialität charakterisiert. So schreibt Rilke in einem Rückblick auf Toledo: „Erscheinung und Vision kamen gleichsam überall im Gegenstand zusammen, es war in jedem eine ganze Innenwelt herausgestellt, als ob ein Engel, der den Raum umfaßt, blind wäre und in sich schaute. Diese, nicht mehr vom Menschen aus, sondern im Engel geschaute Welt, ist vielleicht meine wirkliche Aufgabe ... “166

Eine zentrale Form räumlicher und zeitlicher Überschreitung der modernen Verarmung betrifft schließlich das Verhältnis von Leben und Tod, das insbesondere in einer Reihe von Gedichten im dritten Buch des Stunden-Buches „Von der Armut und vom Tod“ verhandelt wird, die am 15. und 16. April 1903 ent-

Malen Gottes, also der Versuch eines künstlerischen Erfassens, scheint hinsichtlich eines Kontakts wenig erfolgreich, denn: „Wenn ich dich male, Gott, du merkst es kaum.“ Umgekehrt jedoch konstatiert das lyrische Ich mit emphatischer Betonung: „Ich fühle dich.“ An den Rändern der Sinne fängt Gott an, aber nicht als bruchlose Entität, sondern als eine Art Archipel: „An meiner Sinne Saum / Beginnst du zögernd, wie mit vielen Inseln“ (Rainer Maria Rilke, Was irren meine Hände in den Pinseln. In: Rilke, Gedichte 1895-1910. Kommentierte Ausgabe in vier Bänden, Bd. 1, hg. von Manfred Engel u. Ulrich Fülleborn, Frankfurt am Main; Leipzig 1996, S. 165-166).

165 Rilke, Brief an Witold Hulewicz, 13. November 1925, S. 337.

166 Rainer Maria Rilke, Brief an Ellen Delp, 27. Oktober 1915. In: Rilke, Briefe aus den Jahren 1914 bis 1921, hg. von Ruth Sieber-Rilke u. Carl Sieber, Leipzig 1937, S. 80. 
standen sind. Die Überwindung zeitlich-räumlicher Beschränkungen wird hier vorbereitet durch mehrfache Verkehrungen, die gängige Assoziationen von Leben und Tod aushebeln. Das vielfach bemühte Bild für den Tod ist eine Frucht im Inneren des Menschen, deren Reifeprozess individuell und unabhängig von äußeren Alterungsprozessen erfolgt. In „Da leben Menschen, weißerblühte, blasse“ (1903) werden Menschen beschrieben, die vorzeitig altern und verblühen, „,entwürdigt durch die Müh, / sinnlosen Dingen ohne Mut zu dienen“167, während ihr Tod, der in den Hospitälern wartet, „grün und ohne Süße“

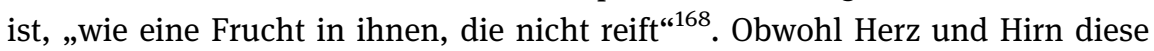
Todesfrucht nähren, finden prüfende Engel sie auch in „Denn wir sind nur die Schale und das Blatt“ (1903) zum Schluss des Gedichts unreif vor: „In sie ist eingegangen alle Wärme / der Herzen und der Hirne weißes Glühn -: / Doch deine Engel ziehn wie Vogelschwärme, / und sie erfanden alle Früchte grün.“169

„[D]es Todes tote Fehlgeburt“"170 ist die Folge eines falschen Umgangs der Menschen mit der Zeit: „Wir haben mit der Ewigkeit gehurt“171. In der künstlichen Unterscheidung zwischen Leben und Tod gerät für Rilke aus dem Blick, dass es sich um keine absoluten Gegensätze handelt, sondern dass gelungenes Leben und gelungener Tod organisch einander erwachsen; der ,gereifte Tod' wird so in den Bereich des Lebens als ein durch und im Leben gebildeter Tod integriert. Der verfehlte Tod hingegen ist dieser Logik nach ein ,toter Tod'. Indem Leben und Tod nicht kontradiktorisch, sondern als ein wechselseitiges Bedingungsverhältnis gedacht werden, wird auch das Konzept von Diesseits und Jenseits hinfällig: „[E]s gibt“, so schreibt Rilke an Witold Hulewicz, „weder ein Diesseits noch ein Jenseits, sondern die große Einheit, in der die uns übertreffenden Wesen, die ,Engel“, zu Hause sind“(172. Diese „große Einheit“, die als angelische Sphäre der menschlichen Einsicht entzogen ist, transzendiert in ihrer Verräumlichung die Sukzessivität des menschlichen Lebens und relativiert damit die Zeit als bestimmende Größe.

167 Rainer Maria Rilke, Da leben Menschen, weißerblühte, blasse. In: Rilke, Gedichte 18951910. Kommentierte Ausgabe in vier Bänden, Bd. 1, hg. von Manfred Engel u. Ulrich Fülleborn, Frankfurt am Main; Leipzig 1996, S. 235-236, hier S. 235.

168 Rilke, Da leben Menschen, weißerblühte, blasse, S. 236.

169 Rilke, Da leben Menschen, weißerblühte, blasse, S. 237.

170 Rilke, Da leben Menschen, weißerblühte, blasse, S. 237.

171 Rilke, Da leben Menschen, weißerblühte, blasse, S. 237.

172 Rilke, Brief an Witold Hulewicz, 13. November 1925, S. 233. 


\subsubsection{Geschichtsphilosophische Verbindungen von Petrologie und Angelologie}

Die Unsichtbarkeit umfasst bei Rilke nicht nur einen räumlich wie zeitlich jenseitigen Raum, sondern manifestiert sich auch in dem das menschliche Fassungsvermögen übersteigenden Schrecken des Ersten Weltkriegs. Dieser ist für Rilke charakterisiert durch eine Verarmung des sinnlich Erfahrbaren und eine Marginalisierung des individuellen Erlebens im Sog von Todestechnik, medialer Vermittlung und kapitalistischer Zirkulation. Während die über den Engel ästhetisch einholbare Unsichtbarkeit als Zugewinn an Wahrnehmung für Rilke eine erstrebenswerte Erweiterung bedeutet, ist die Unsichtbarkeit des Kriegs mit einer Form des Leids assoziiert, die sich durch ihre Unanschaulichkeit der menschlichen Erlebbarkeit strukturell entzieht. Vor diesem Hintergrund umfasst der Engel als den menschlichen Erfahrungsbereich übersteigende Figur in Rilkes Gedichten und Reflexionen nicht nur die Verstärkung der „Scheinwerfe[r] der Sensualität “"173, indem er das Sichtbare ins Unsichtbare erweitert. Durch seine ästhetische Form leistet er auch die umgekehrte Bewegung vom Unsichtbaren ins Sichtbare, über die das Leid bewältigt wird. So ist mit dem Eintritt in die Sichtbarkeit eine Verwandlung des Leids verbunden, die Rilke mehrfach als angelisch-mineralogische Transformation veranschaulicht.

An dieser Stelle sei an Rilkes Engel-Stein-Parabel der transhumanen Einsamkeit erinnert, in der er im Stein verschwindet und „bleiben oder höchstens von einem Engel gerettet sein“ will - „mit dem getraute ich mir schon den richtigen Umgang zu haben“174. „Auch giebt es“, so fährt Rilke fort, „sicher einen Grad von Noth, auf den die Engel hören, äußerste Nothstrahlen, die die Menschen gar nicht wahrnehmen, die durch ihre dichte Welt durchdringen und erst drüben in eines Engels Schein ein leises leidvolles Violett anschlagen, wie der Amethyst in den Drusen des Bergkrystalls“ ${ }^{175}$. In der die menschliche Wahrnehmung übersteigenden Perzeption der Engel wird Not sichtbar und zugleich transformierbar als Endpunkt eines mineralogischen Prozesses, indem die Engel als überirdische Figuren mit der anorganischen Welt der Kristallbildung in Gesteinshohlräumen kurzgeschlossen werden.

Analog zu dem aggressiven „Ultra-roth“ der Kriegszeit, „das über unsere Sinne geht ${ }^{\text {“176 }}$, fasst Rilke auch die Not in dem physikalischen Bild von unsichtbaren elektromagnetischen Strahlen, die erst im Bereich der Engel, die

173 Rilke, Ur-Geräusch, S. 703.

174 Rilke, Brief an Magda von Hattingberg, 4. Februar 1914, S. 36.

175 Rilke, Brief an Magda von Hattingberg, 4. Februar 1914, S. 36.

176 Rilke, Brief an Marie von Turn und Taxis, 2. August 1915, S. 129. 
über die entsprechenden Rezeptoren verfügen, farblich wahrnehmbar werden. So wie Drusen im Zuge von vulkanischen Verwerfungen entstehen, so schafft das Leid einen verborgenen Raum. In ihm kann sich der Amethyst als Bild für eine spezifische Form der Verwandlung von Leid in Schönheit bilden, die über den Engel wahrnehmbar wird. Auf diese Weise figuriert der Engel eine positive, trostspendende Form der Unsichtbarkeit, die der Denkmöglichkeit positiver Verwandlung in den unmenschlichen Regionen der Stein- und Engelsreiche Anschaulichkeit verleiht. In einer früheren Reflexion des Zusammenhangs von Schrecken, Engel und Kunst funktionalisiert Rilke das Angelische nicht als Rezeptor und Transformator; stattdessen beglaubigt der Engel die Potenz der Kunst, die als gestaltetes, abgeschlossenes Kunst-Ding die Negation des Schrecklichen übersteigt: „Es kann im Schrecklichen nichts so Absagendes und Verneinendes geben, daß nicht die multiple Aktion künstlerischer Bewältigung es mit einem großen, positiven Überschuß zurückließe, als ein Dasein-Aussagendes, Sein-Wollendes: als einen Engel.“" ${ }^{\text {“77 }}$ Den Zusammenhang von Engeln und transformierender Bewahrung einer unanschaulichen Not in der Kunst führt Rilke in dem Gedicht „Wie der Abendwind“ (Winter 1913/1914) wiederum über das Bild des Amethysten aus:

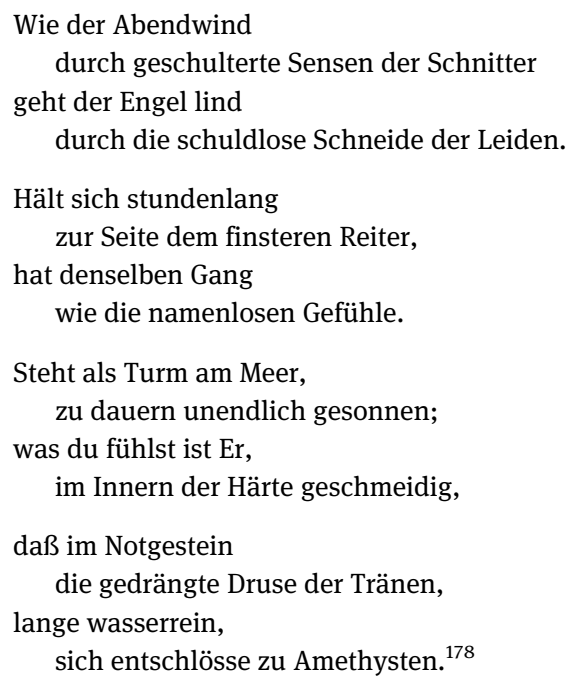

177 Rilke, Brief an Jakob von Uexküll, 19. August 1909, S. 74.

178 Rainer Maria Rilke, Wie der Abendwind. In: Rilke, Gedichte 1910-1926. Kommentierte Ausgabe in vier Bänden, Bd. 2, hg. von Manfred Engel u. Ulrich Fülleborn, Frankfurt am Main; Leipzig 1996, S. 89. 
„Lind“, ohne selbst von ihren scharfen Kanten beeinträchtigt zu werden, zieht der Engel durch die Leiden wie der Abendwind durch die Sensen. Durch die Beschreibung seines Inneren wird den unnennbaren Gefühlen und der Möglichkeit ihrer Verwandlung Anschaulichkeit verliehen - „was du fühlst ist Er, / im Innern der Härte geschmeidig“. Indem die Gefühle des angesprochenen Du mit dem Engel identifiziert werden, indem dessen innere Geschmeidigkeit ein Entwicklungspotential in der Härte und Starre in Aussicht stellt, wird über die Vermittlung des Gedichts eine Verwandlung konjunktivisch antizipiert: dass sich verborgen im „Notgestein“ aus den Tränen eine Druse, also ein mit Kristallen gefüllter Hohlraum im Gestein bilden und in dieser das Leid in kostbare Schönheit verwandelt werden möge.

Diese gewünschte Verwandlung wird in der Form des Gedichts selbst evoziert. Jeweils der erste und dritte Vers transportieren als gereimte in den ersten drei Strophen die Handlung - „Wie der Abendwind, geht der Engel lind“, „Hält sich stundenlang, hat denselben Gang“, „Steht als Turm am Meer, was du fühlst ist Er“ -, die durch die typographisch abgesetzten Einschübe des zweiten und vierten Verses interpunktiert werden. Gegen Ende gerät diese Anordnung allerdings aus dem Takt: Der erste Vers der letzten Strophe stellt eine erneute Beschreibung von Geschehen als Finalität in Aussicht (,daß im Notgestein“), dessen Fortgang allerdings durch den Einschub einer Durststrecke (,lange wasserrein“) von der dritten Zeile in die vierte sowie in den Optativ abgedrängt wird (,sich entschlösse zu Amethysten“). Während auch hier die tatsächliche Verwandlung als übermenschlicher, an den Engel geknüpfter Vorgang im Modus des Konjunktivs (oder der Frage) verbleibt, wirkt das Gedicht selbst als Darstellung dieser im verborgenen Engelsinneren sich abspielenden Sichtbarwerdung und Transformation, die das Leid heilt - denn das, was die Sprache nicht als Realität behaupten kann, wird durch die unmittelbare Evidenz überlagert, die das Bild des Amethysten als Schlussstein der Verwandlung und des Gedichts selbst setzt.

Der Amethyst verweist auf das grundsätzliche Faszinosum, das der Stein für Rilke in der Vorstellung birgt, entgegen seiner unbelebten Anmutung schlummere in ihm eine besondere Zeitlichkeit. Insofern ist auch die Opposition von mortifiziertem Ding und zeitgebundener, transitorischer Poesie keine stabile. In seiner Studie „Auguste Rodin“ (1902) spricht Rilke von Steinen, „die schliefen, und man fühlte, daß sie erwachen würden bei irgend einem Jüngsten Gericht“, und von wieder ,andere[n], die eine Bewegung trugen, eine Gebärde, die so frisch geblieben war,als sollte sie hier nur aufbewahrt und eines Tages irgend einem Kinde gegeben werden, das vorüberkam ““179. Im Stein vibriert

179 Rilke, Auguste Rodin, S. 406. 
eine Spannung von Tod und Leben, die auch das zunächst eher einfältig anmutende frühe Gedicht „Der Engel“ aus dem Gedichtband Larenopfer (1895) durchzieht und die das mit dem Engel verbundene Potential der Verwandlung freisetzt:

Der Engel
Hin geh ich durch die Malvasinka
die Kinderreih, wo sanft und gut
die kleine Anka oder Ninka
in ihrem letzten Bettchen ruht.
Auf einem schmalen Schollenhügel
kniet, ganz versteckt in hohem Mohn,
mit staubigem, gebrochnem Flügel
ein Engelchen aus rohem Thon.
Das flügellahme Kindchen flößte
mir Mitleid ein, - das arme Ding ...
Da, sieh! Von seinen Lippen löste
sich leicht ein kleiner Schmetterling.

Auch dieser werkgeschichtlich frühe Engel ist mit der für Rilke typischen Verkettung von Anfang und Ende in Form des frühen Todes verknüpft. Als „Engelchen“ ist er Teil einer Miniatur des Todes, in der dieser mit „Bettchen“, „Kindchen“ und den Diminutivformen Anka und Ninka zu einem niedlichen Kindertod verkleinert ist. Der Mohn, der den Engel versteckt und der in der christlichen Ikonographie mit dem im Blüteninneren erkennbaren Kreuz auch für die Passion Christi steht, umrahmt dieses Bild eines friedlichen Todes. ${ }^{181}$ In dem „flügellahmen Kindchen“ und angestoßen durch das Mitleid, das sich entgegen der Rezeptionserwartung nicht auf die gestorbenen Kinder, sondern auf den toten, steinernen und vermeintlich fühllosen Engel richtet, verschmelzen in der letzten Strophe Engel und tote Kinder in der Evokation des unausgesprochenen Kompositums „Engelskinder“ als Bezeichnung für Kinder, die vor oder kurz nach der Geburt gestorben sind.

Auf den ersten Blick scheint der Engel hier festgeschrieben auf das Gegenteil seiner ätherisch-transitorischen Erscheinung. Seine Flügel, Voraussetzung seiner Bewegung zwischen den Sphären, sind staubig und gebrochen, also nicht einsatzfähig. Gleichzeitig relativieren eben jene gebrochenen Flügel die

180 Rainer Maria Rilke, Der Engel. In: Rilke, Gedichte 1895-1910. Kommentierte Ausgabe in vier Bänden, Bd. 1, hg. von Manfred Engel u. Ulrich Fülleborn, Frankfurt am Main; Leipzig 1996, S. 23.

181 Vgl. Peter Schmersahl, Mohn in der bildenden Kunst - Eine Pflanze zwischen Traum und Tod. In: Deutsche Apotheker Zeitung, 5, 2003, S. 45. 
Dauer und zeitliche Begrenztheit der gestalteten Materie und verweisen damit auf die Auflösung des Engels ins Unstoffliche. Dass diese Auflösung nicht als bloßer Verfallsprozess zu begreifen ist, illustriert der Schmetterling, der sich in einer plötzlichen Wendung, typographisch vorbereitet durch eine Häufung von Satzzeichen - ... !, von der zerfallenen Steinfigur mit Leichtigkeit „löste“, und der stellvertretend jene fliegende Flüchtigkeit des Engels ausdrückt. Der Schmetterling, Symbol für die körperlose Seele, die die todverfallene Materie (der zerfallende Stein) überwindet, verkörpert den Prozess der Transformation der (toten) Kinder in Engel. Über die Spannung von transitorischer Poesie und ästhetischer Evidenz, ausgedrückt in einer Inversion der Zeitformen, wird diese Transformation poetisch realisiert: In der letzten Strophe wechselt das Tempus vom Präsens ins Präteritum und in dieses fährt wiederum der präsentische Imperativ mit „Da, sieh!“ als paradoxe Aufforderung, im gegenwärtigen Augenblick etwas Vergangenes zu sehen.

Auf diese Weise wird das Geschehen in eine erzählte Vergangenheit transponiert und zugleich in der Ansprache präsentisch durchbrochen, was an das deiktische Präteritum in slawischen Sprachen erinnert. ${ }^{182}$ Während das Präsens der ersten beiden Strophen zeitlos erscheint, schärft in der letzten Strophe die Vergangenheitsform, in die die Aufforderung, zu sehen, einbricht, den Blick für die Einzigartigkeit des Vorgangs. In einer paradoxen Form wird dieser retrospektiv vergegenwärtigt und dadurch besonders betont. Die Spannung von narrativem Präteritum und präsentisch-ästhetischem Imperativ in der letzten Strophe stellt eine grammatikalische Übersetzung der Aussage des ganzen Gedichtes dar, dass aus dem frühen Tod die (dichterische) Verwandlung ins Unstoffliche entspringt. Figuriert wird sie durch den Engel in der Spannung von zeitverfallenem, irdischem Stein und körperlos-leichter Erscheinung, die in den Schmetterling übergegangen ist. Metapoetisch sagt der Engel diese Gedankenfigur selbst aus, indem sich der Schmetterling, der das Endstadium der Entwicklung von raupenhafter Erdgebundenheit hin zu schwereloser Leichtigkeit verkörpert, von den Engellippen löst. Gleichzeitig wird sie aber auch ästhetisch in Szene gesetzt durch die Aufforderung, diesen Vorgang zu schauen („Da, sieh!“), die den Erzählfluss unterbricht und darin das Unerzählbare der Verwandlung markiert. Das Gedicht evoziert auf diese Weise sowohl den dichterisch-transitorischen Vollzug als auch die ästhetische Wahrnehmung, ${ }^{183}$ die die

182 Vgl. Volker Lehmann, Der narrative Redetyp und seine Analyse. In: Textkohärenz und Narration. Untersuchungen russischer Texte des Realismus und der Moderne, hg. von Robert Hodel u. Volker Lehmann, Berlin 2008, S. 179-226, hier S. 199-200.

183 Zum Aspekt des lyrischen Stimmungsbilds, speziell im Zusammenhang mit den Grenzen der Sprache in Larenopfer, vgl. Sascha Löwenstein, Poetik und dichterisches Selbstverständnis. Eine Einführung in Rainer Maria Rilkes frühe Dichtungen (1884-1906), Würzburg 2004, S. 73. 
Narration durchbricht und auf die bildliche Veranschaulichung eines an sich unanschaulichen Vorgangs verweist. Im Modus der Sprache soll deren Beschränkung transzendiert werden.

Um das umgekehrte Verhältnis von Leben und Tod im Zusammenhang mit Engel und Stein geht es in einem anderen frühen Gedicht, „Asrael“ (1896), das vermutlich Mitte September 1896 als Reaktion auf ein Gemälde von Hermione von Preuschen entstanden ist. Statt der Lösung der Seele von toter Materie steht hier am Schluss ihre Auslöschung. Der Engel erscheint, gänzlich losgelöst von der christlichen Dialektik von Leben und Tod, als dämonischer Seelenvernichter:

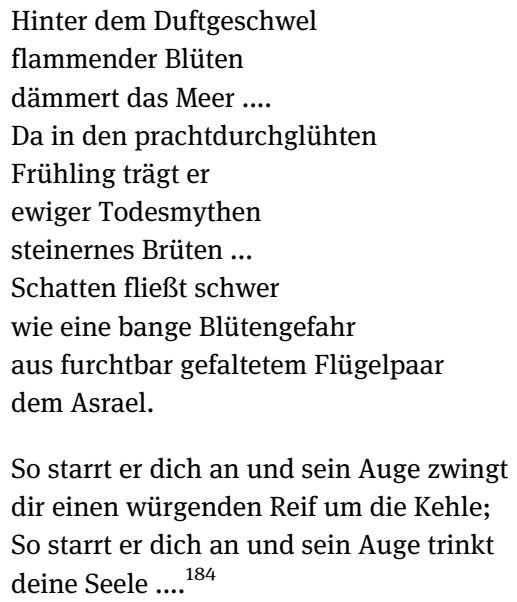

„Duftgeschwel“, „flammende Blüte“, „dämmerndes Meer“ und vier bedeutungsschwangere Punkte lassen zunächst ein opulentes Stimmungsgedicht erwarten, das allerdings sogleich deiktisch durchbrochen wird. Auf das oxymoronisch anmutende „Duftgeschwel“ des ersten Verses reimt sich erst am Ende der elfversigen Strophe wieder ein Wort, „Asrael“, der dadurch als ambivalenter Todesengel von Anfang an in dem Gedicht schwelt und in kataphorischem Spannungsaufbau erst ganz zum Schluss der Strophe genannt wird. Im Vergleich zu dem stimmungsvollen Beginn entwickelt die zweite Strophe mit vier Versen im Kreuzreim und annähernd doppelter Silbenzahl einen deutlichen narrativen Zug, die extensiv entfaltete Szenerie der ersten Strophe ist als Modalität in dem ,So` komprimiert. Der starrende Blick des Engels, dem in den Elegien eine bewahrende Funktion zukommt, ist hier der eines Würgeengels und Seelenvampirs. Die bis auf das

184 Rilke, Asrael, S. 264-265. 
letzte Wort identischen Verse eins und drei entfalten in ihrer Iteration eine suggestiv-beschwörende Wirkung. Ihre Wiederholung lässt außerdem die Differenz der Verse zwei und vier hervortreten - letzterer schließt mit reduzierter Silbenzahl (,deine Seele“) und wiederum vier bedeutungsschwanger-ikonischen Punkten, die die Folgen dieser Handlung im Ungefähren belassen. Die evozierte Schönheit des Frühlings, deren Unterwanderung sich in dem „Da“ in Vers vier ankündigt - der Frühling selbst ist von der Bedrohung durchdrungen, wie die „Blütengefahr“ indiziert -, dient als Kontrastfolie für den Schrecken des Todesengels.

Der Engelsschatten, der in „Asrael“ aus dem „furchtbar gefalteten Flügelpaar“ fließt, ist auch in dem zwei Jahre später verfassten „Gebet“ (1898) Attribut eines schrecklichen Engels, der nicht direkt aus Stein, sondern aus Holz besteht, dann jedoch „versteint““185. Dieser Engel wird mit einer Vielzahl verschiedener Apostrophen versehen, in der ersten Strophe durchweg in Form von Alliterationen: „Ernster Engel aus Ebenholz“, „Du riesige Ruh“, „Flammenumflehter!“186. In der zweiten und dritten Strophe kommen „König“, „saumsinnender Riese“, „Du, aller Matten / Furchteinflößer“"187 hinzu. Dessen Schweigen „schmolz / noch nie in den Bränden / von Büßerhänden“188. Als Gegenstand der Anbetung („Deine Beter“), als „Riese“ und „König“, der aufgefordert wird, sich „ein Geschlecht, / dem du gerecht / erscheinst“189, zu wählen, tritt der Engel hier gottgleich auf. ${ }^{190}$ Einerseits erscheint er aus Holz und mit Stein assoziiert in materieller Dichte, gleichzeitig ist auch in dieser seine Ungreifbarkeit wirksam, die ihn der menschlichen Wahrnehmung entzieht: „Der du versteinst, / du über den Blicken beginnender / König““191. Das Versteinen ist ambivalent, da es als mittelhochdeutsche Form von ,versteinern' transitiv und intransitiv

185 Rilke, Gebet, S. 76.

186 Rilke, Gebet, S. 76.

187 Rilke, Gebet, S. 76.

188 Rilke, Gebet, S. 76.

189 Rilke, Gebet, S. 76.

190 Das Ebenholz ist nicht nur ein Hinweis auf die Materialität des Engels, sondern auch, durch die Verbindung des dunklen Holzes mit dem dunkel gedachten Gott, ein weiteres Indiz für die latente Göttlichkeit des Engels (vgl. Rainer Maria Rilke, So viele Engel suchen dich im Lichte. In: Rilke, Gedichte 1895-1910. Kommentierte Ausgabe in vier Bänden, Bd. 1, hg. von Manfred Engel u. Ulrich Fülleborn, Frankfurt am Main; Leipzig 1996, S. 171-172, hier 172). In der zweiten Strophe finden sich weitere Überschneidungen: „Nur einer Zeit zuliebe, die dich flehte / in ihre klaren marmornen Gebete, / erschienst du wie der König der Komete, / auf deiner Stirne Strahlenströme stolz“ (Rilke, So viele Engel suchen dich im Lichte, S 171). Mit Flehen („Flammenumflehter“), Gebeten („Deine Beter“), König und Stolz („Deine Beter / sind stolz / wie du“) sowie dem Erscheinen überschneiden sich in beiden Gedichten angelisch-göttliche Attribute.

191 Rilke, Gebet, S. 76. 
gelesen werden kann: als längerer Prozess der Versteinerung oder im übertragenen Sinne als plötzliche Form des Zu-Stein-Werdens. Als weitere Bedeutung der intransitiven Form führt das Mittelhochdeutsche Taschenwörterbuch außerdem ,verstocken' an, also sich einer Sache in uneinsichtiger Weise verschließen. ${ }^{192}$ In der implizierten Prozessualität der intransitiven Form lässt sich das Versteinen als Ausdruck des Kunstschaffens, als mediale Transformation verstehen, die Rilke, wie gezeigt, vielfach über den Engel in Szene setzt.

Eine weitere Bedeutung der transitiven Form bezieht sich auf die Verwendung von Steinen zur Markierung einer Grenze. Auch dieser Aspekt des Begriffs ist für das Gedicht wichtig, da sowohl mit dem Beginn über den Blicken als auch mit dem Engel als „saumsinnende[m] Riese[n]“193 die Frage nach der Grenze zwischen Menschlichem und Unmenschlichem gestellt wird. Denn der Saum als umgeschlagener und fixierter Stoff markiert eine an dem und zugleich durch das Material abgesteckte Grenze zwischen Materiellem und Nichtmateriellem. Auch die Bezeichnung „Riese“ verweist in ihrer biblischen Semantik auf den Saum zwischen Angelischem und Menschlichem: „Gottessöhne“, später als „Engel“ bezeichnet, begehren in 1 Mos 6,1-4 Menschenfrauen und zeugen mit ihnen soge-

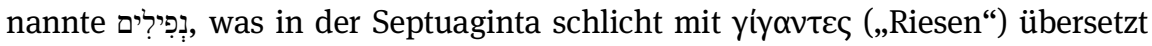
wird. ${ }^{194}$ Der Engel mit der in seiner Beschreibung evozierten Nähe zum Göttlichen wie als „saumsinnender Riese“ ist also eine Figur, die über die Grenze zwischen kategorial verschiedenen Bereichen, zwischen Materiellem und Immateriellem nachdenkt und damit gewissermaßen (metapoetisch) über seine eigene Stellung in Rilkes Werk als skulpturale Figur und transitorische Erscheinung.

\subsubsection{Ringen mit dem Engel}

Das Schreckliche des Engels tritt bei Rilke nicht nur als abstrakte Todes- und Überwältigungsdrohung auf, sondern auch in Form des handfesten Kampfs den Einsamen sucht der Engel auch als Angreifer auf. Als Vexierbild von Sieg und Niederlage nutzt Rilke Jakobs biblisches Ringen mit einem unbestimmten Widersacher für die Reflexion paradoxer Machtbalancen. Der Engel gestaltet hier eine weitere Spielart des Überwindens: Er reißt keine ästhetischen oder epistemischen Grenzen ein, sondern spannt als Widerpart die Pole von Ich-Verlust und

192 Vgl. Matthias Lexer, Mittelhochdeutsches Taschenwörterbuch, Leipzig 1992, S. 332.

193 Rilke, Gebet, S. 76.

194 Vgl. Kapitel 2.2 dieser Studie. 
Selbstbehauptung auf, die in eine agonale Poetik münden. Diese liegt zum einen dem Kunstschaffen als erzwungenem Bezwungenwerden im einsamen Ringen mit einer überlegenen und zugleich abhängigen Macht zugrunde. Zum anderen werden die ringenden Körper selbst in ihrer poetischen Form als Gesamtkunstwerk inszeniert. Die Uneindeutigkeit dieser Relationalität ist Teil des biblischen Prätextes. In der Bibelepisode in 1 Mos 32,24-31 ringt Jakob an der Furt des Jabbok mit „einem Mann“, der wahlweise als Gott, Mensch oder, wie von Rilke, als Engel identifiziert wird. Der Kampf dauert bis zur Morgenröte, dann verpasst der Mann Jakob einen Schlag auf die Hüfte und fordert ihn auf, ihn gehen zu lassen. Jakob will aber zuerst gesegnet werden. Der Mann fragt daraufhin nach Jakobs Namen und nennt ihn Israel, will umgekehrt seinen Namen nicht verraten und segnet schließlich seinen Widersacher. Während im Bibeltext Jakob vor und im Kampf gegen den Engel explizit „allein“ (1 Mos 32,26) ist, geht Rilke in einem Brief an Sidonie Nádherný einen Schritt weiter und identifiziert Einsamkeit und Engel als übermächtige Herausforderungen miteinander: „Jetzt bin ich ganz allein hier in den starken alten Mauern; der Aufenthalt, zumal an den Windtagen, ist nicht ohne Strenge, aber ich kann ja zum Glück mich mit der Einsamkeit einrichten [...]. So leist ichs nur wie Jakob mit dem Engel: sie ist ja natürlich die stärkere, und doch wird's mein Schaden nicht sein.."195

Die geheimnisvolle Paradoxie, die hier aufscheint - der Kampf mit einer stärkeren Macht, der trotz Unterlegenheit nicht zum Nachteil gereicht -, macht Roland Barthes bereits in der Struktur der ursprünglichen Bibelepisode aus: Der Sieg Jakobs sei ein „unlogische[r] ${ }^{\text {‘196 }}$, da der Schlag auf die Hüfte als besondere Technik eigentlich der entscheidende sein müsste, sich tatsächlich aber als völlig irrelevant für den Ausgang des Kampfs erweist. Dieses strukturelle Paradox der Episode wird in Rilkes Bearbeitungen in das semantische des „,überwundenen Überwinders ‘“'197 überführt. Es steht im Kern einer medialen Poetik, in der Anmaßung und Demut, Schaffensstolz und Heteronomie des prophetischen Sprachrohrs keine Gegensätze sind, sondern sich wechselseitig bedingen:

Der Schauende

Ich sehe den Bäumen die Stürme an, die aus laugewordenen Tagen

195 Rainer Maria Rilke, Brief an Sidonie Nádherný von Borutin, 4. Februar 1912. In: Rilke, Briefe an Sidonie Nádherný von Borutin, hg. von Bernhard Blume, Frankfurt am Main 1973, S. 141-144, hier S. 144.

196 Roland Barthes, Der Kampf mit dem Engel. Textanalyse der Genesis 32,23-33. In: Barthes, Das semiologische Abenteuer, Frankfurt am Main 1988, S. 251-265, hier S. 256.

197 Wacker, Poetik des Prophetischen, S. 239. 


\begin{abstract}
an meine ängstlichen Fenster schlagen, und höre die Fernen Dinge sagen, die ich nicht ohne Freund ertragen, nicht ohne Schwester lieben kann.

Da geht der Sturm, ein Umgestalter, geht durch den Wald und durch die Zeit, und alles ist wie ohne Alter:

die Landschaft, wie ein Vers im Psalter, ist Ernst und Wucht und Ewigkeit.
\end{abstract}

Wie ist das klein, womit wir ringen, was mit uns ringt, wie ist das groß; ließen wir, ähnlicher den Dingen, uns so vom großen Sturm bezwingen, wir würden weit und namenlos.

Was wir besiegen, ist das Kleine, und der Erfolg selbst macht uns klein.

Das Ewige und Ungemeine will nicht von uns gebogen sein. Das ist der Engel, der den Ringern des Alten Testaments erschien: wenn seiner Widersacher Sehnen im Kampfe sich metallen dehnen, fühlt er sie unter seinen Fingern wie Saiten tiefer Melodien.

Wen dieser Engel überwand, welcher so oft auf Kampf verzichtet, der geht gerecht und aufgerichtet und groß aus jener harten Hand, die sich, wie formend, an ihn schmiegte. Die Siege laden ihn nicht ein.

Sein Wachstum ist: der Tiefbesiegte von immer Größerem zu sein. ${ }^{198}$

Die Crux der Menschen, so ließe sich zusammenfassen, sind ihre leichten Erfolge. Anders die Dinge, die sich dem Sturm aussetzen, sich bezwingen lassen und so in Kontakt mit dem „Ewige[n] und Ungemeine[n]“ kommen. Diesem Gedicht von 1901, das ein Jahr später im Buch der Bilder erschien, geht eine frühere, Clara Westhoff gewidmete und posthum veröffentlichte Version mit dem Titel „Sturm“ voraus, das eine andere letzte Strophe enthält, die die Relationali-

198 Rainer Maria Rilke, Der Schauende. In: Rilke, Gedichte 1895-1910. Kommentierte Ausgabe in vier Bänden, Bd. 1, hg. von Manfred Engel u. Ulrich Fülleborn, Frankfurt am Main; Leipzig 1996, S. 332-333. 
tät von Sieger und Besiegtem aus ihrer semantischen Verankerung löst: „Und der Besiegte von den Beiden / [der Sieg macht leicht verwöhnt und klein] / der wie der Sieger ist - und rein, - / verlangt, aus Demut unbescheiden, / von immer

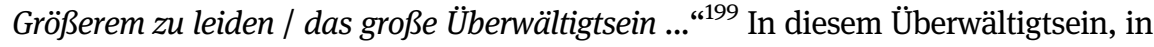
dem die Gewichtung von Sieger und Besiegtem bis zur Unkenntlichkeit resignifiziert wird, tritt die Frage von Sieg und Niederlage hinter der Besonderheit des Kampfs mit einem Engel zurück, „welcher so oft auf Kampf verzichtet“. Dieser Kampf läuft bei Rilke nicht auf einen einfachen Sieg hinaus und der ,Segen' wird auch nicht durch Beharrungskraft erzwungen wie im biblischen Prätext, sondern erwächst vielmehr einer Affirmation des Scheiterns. Dieser liegt die angelische Struktur komparativischer Größe zugrunde, die eine potentiell unendliche Wachstumsdynamik verheißt, wenn man sich ihr unterwirft. Indem aus dem Zustand des Tiefbesiegtseins Wachstum entspringt, wird die starre Opposition von Sieg und Niederlage in die Dynamik von Wachsen und (Geformt-)Werden überführt.

Die Erhabenheit dieses „große[n] Überwältigtseins“ wird domestiziert und durch die ästhetische Einhegung im Gedicht durch die beiden Versionen in Szene gesetzt: Nur in der ersten Fassung „Sturm“ werden das schlechthin Große als das, was sämtliches Fassungsvermögen übersteigt - „was mit uns ringt - wie ist das groß ${ }^{\prime 200}$-, und das entsprechende Überwältigtsein erwähnt und zwar in einer Stelle, deren fortlaufende Kursivierung im Gegensatz zu der zweiten Version, in der nur einzelne Wörter markiert sind, auch auf graphischer Ebene das Hyperbolische dieses Kampfs zum Ausdruck bringt (,von immer Größerem zu leiden / das große Überwältigtsein"). Indem diese Beschwörung der Überwältigung in der zweiten, geglätteten Version getilgt ist, wird das künstlerische Bezwingen durch die Form vorgeführt - der Engel erscheint hier als Herold einer vermittelten, formästhetisch unterlaufenen Erhabenheit.

Diese Entwicklung wiederum ist selbst bereits in nuce in der Darstellung des Ringens als Verwandlung des polemos in den musischen agon durch den Engel enthalten: Die Sehnen seines Widersachers werden unter seinem Fingergefühl im Modus des poetischen Vergleichs zu „Saiten tiefer Melodien“201, womit einmal mehr das Transformationspotential aufgerufen ist, das sich an die Vorstellung einer besonderen sensorischen Rezeptivität der Engel knüpft. Über diese vollzieht sich hier der Übergang vom Waffenkampf in einen kulturellen Wettkampf. So erscheinen die ringenden Körper selbst als ein Gesamtkunstwerk, das den Vorgang medialen Übersetzens und Verwandelns ausstellt.

199 Rainer Maria Rilke, Sturm. In: Rilke, Jugendgedichte. Sämtliche Werke, Bd. 3, hg. von Ernst Zinn u. Ruth Sieber-Rilke, Wiesbaden 1959, S. 725-727, hier S. 726.

200 Rilke, Sturm, S. 726.

201 Rilke, Der Schauende, S. 333. 
Als Interferenzfigur der ausdifferenzierten Künste verwandelt sich der Körper unter der Hand des Engels in ein Instrument, dessen Musikalität zunächst in Form der „tiefe[n] Melodien“ im Vordergrund steht, während die folgende Strophe mit dem Bild der harten, formenden Engelshand, das den Körper modelliert, die bildhauerische Tätigkeit aufruft. ${ }^{202}$

Dieses komplexe Wechselspiel zwischen Autonomie und Heteronomie stilisiert Rilke in einem Brief vom 24. April 1903 zur Prämisse seines Schaffensprozesses: „[...] [U]nd dann will ich daran bauen mit aller Andacht, die ich in meinen Händen habe, und will von keiner Stelle lassen, solange sie geringer ist als ich selbst, und will jede zu einem Engel machen und mich von ihm überwinden lassen und ihn zwingen, daß er mich beuge, obwohl ich ihn gemacht habe ...“203 Diese Verschlungenheit wird im „Sturm“ extrapoetisch in einer zusätzlichen, typographisch abgesetzten allerletzten Strophe reflektiert, die kein Äquivalent in der zweiten Fassung hat und retrospektiv die Nähe zur apokalyptischen Schau der Johannes-Offenbarung und der Verschriftlichung einer höheren Botschaft ausstellt: „Das war im Sturm. Die Ferne sprach. / Ich sann es nach und schrieb es nach, - / Und wäre ich heute gewandert im Moor, / so spräche ich Ihnen es leise vor / in einer dämmernden Stunde. / So aber schrieb ich es auf ein Blatt / wie mancher es auf alten Bildern hat / vor seinem gemalten Munde.“204 Als Seismograph notiert das lyrische Ich im Diktat eine Botschaft aus Ferne und Sturm anstelle eines Vorsprechens im Moor. In einem erneuten Medienwechsel wird diese Botschaft in eine Genealogie der bildenden Kunst eingetragen, in der mit dem „gemalten Munde“ abermals die Unmittelbarkeit des gesprochenen Wortes in ihrer Vermittlung evoziert wird. In dieser Kette, in der das geschriebene Wort ins Bild transferiert und dort wiederum an das gesprochene Wort rückgebunden wird, kommt die ästhetisch-intermediale Transgression zum Ausdruck, die Rilke zum lyrischen Programm erhoben hat.

Die Zwiespältigkeit der Übermacht ist prägendes Thema auch der „Engellieder“ aus dem Gedichtband Mir zur Feier (1899), einem Zyklus von ursprünglich acht Gedichten, von denen eines - „So sah der Engel aus, den ich zu Gast ge-

202 Auch in dem Gedicht „Der Engel“ ist das Ringen verbunden mit der Gewaltsamkeit des Geformt-Werdens durch Engelhände und so mit Kampf und Kunst: „Gieb seinen leichten Händen nichts zu halten / Aus deinem Lastenden. Sie kämen denn / bei Nacht zu dir, dich ringender zu prüfen, / und gingen wie Erzürnte durch das Haus / und griffen dich als ob sie dich erschüfen / und brächen dich aus deiner Form heraus“ (Rilke, Der Engel, S. 23).

203 Rainer Maria Rilke, Brief an Clara Rilke, 24. April 1903. In: Rilke, Gesammelte Briefe in sechs Bänden, Bd. I, hg. von Ruth Sieber-Rilke u. Carl Sieber, Leipzig 1939, S. 352-355, hier S. 355.

204 Rilke, Sturm, S. 727. 
glaubt“ - in der überarbeiteten Neuausgabe 1909 gestrichen wurde. Diese Gedichte verhandeln biographische Übergänge auf der Schwelle zwischen kindlicher Verbundenheit mit dem Engel und dem Ausbruch aus dieser Dyade, der in dem Gedicht „Ich ließ meinen Engel lange nicht los“ das Leben erst ermöglicht - eine weitere Variation des Verhältnisses von Bruch und Anfang. Im Gegensatz zum Ringen mit dem Engel liegt das Übergewicht in diesem Zyklus auf Seiten des lyrischen Ichs, allerdings markiert auch hier der Engel eine Bedrohung: nicht die des Ausgeliefertseins, sondern die, die mit dem Besitz einhergeht.

Ich ließ meinen Engel lange nicht los, und er verarmte mir in den Armen und wurde klein, und ich wurde groß: und auf einmal war ich das Erbarmen, und er eine zitternde Bitte bloß.

Da hab ich ihm seine Himmel gegeben, und er ließ mir das Nahe, daraus er entschwand; er lernte das Schweben, ich lernte das Leben, und wir haben langsam einander erkannt ...205

Der Eingangsvers erinnert an das „Ich lasse dich nicht“ (1 Mos 32,27), das Jakob zu dem Engel spricht, mit dem er ringt. Auch in diesem Gedicht hält sein Antagonist den Engel fest, anstatt ihn aber zu segnen, wie Jakob verlangt, „verarmt“ der Engel. Auf den ersten Blick scheint die Relation zwischen lyrischem Ich und Engel eindeutig: Das lyrische Ich hat offenkundig die Macht, „seinen“ Engel festzuhalten, wodurch es „groß“ wird und in der Position ist, „Erbarmen“ zu spenden, während jener „verarmt“, „klein“ und zur „zitternde[n] Bitte“ wird. Dem zweiten Blick erschließt sich jedoch die dieser Relation innewohnende, bereits bekannte Dialektik (,und der Erfolg selbst macht uns klein““206), deren Dynamik nicht aus dem umschlagenden Verhältnis von Sieg und Niederlage, sondern aus der Verkehrung von Armut und Besitz herrührt: Das Kleine ist bei Rilke oft - wie in „Der Engel“ oder der Erzählung „König Bohusch“ - nicht das Unfertige oder Mangelhafte, sondern Bedingung für inneren Reichtum und poetische Verwandlung.

In diesem Fall hält die Asymmetrie von lyrischem Ich und Engel allerdings beide gefangen. Die Homonymie von „arm“ und „Arme“ ist bedeutungstragend, die Arme stehen für das Armut erwirkende Festhalten. In dieser besitzenden Beziehung ist nicht nur der Engel, sondern auch das lyrische Ich blockiert.

205 Rainer Maria Rilke, Ich ließ meinen Engel lange nicht los. In: Rilke, Gedichte 1895-1910. Kommentierte Ausgabe in vier Bänden, Bd. 1, hg. von Manfred Engel u. Ulrich Fülleborn, Frankfurt am Main; Leipzig 1996, S. 73.

206 Rilke, Der Schauende, S. 332. 
Erst nach dem Loslassen „lernt“ es das „Leben“, das offensichtlich durch Besitz maßgeblich behindert wird, so wie umgekehrt der Engel seinen Himmeln entzogen war. Der Machtkampf ist einer, der in Wahrheit zwei Verlierer hat. ${ }^{207}$ Auch in den „Engelliedern“ steht der Engel so auf der Schwelle zwischen Ende und Anfang, wobei der Anfang einmal mehr mit einer Entzweiung einhergeht: Der Besitz des Engels („mein Engel“) ist nicht Endpunkt einer Entwicklung, sondern Ausgangspunkt eines defizitären Zustands, das Lösen aus diesem ist die Grundlage für den Beginn des Lebens und wirkt nicht nur als epistemischer, sondern latent auch als erotischer Katalysator (,und wir haben langsam einander erkannt“). ${ }^{208}$

Als fugenloses Ineinander, das auf einer anerkannten Überlegenheit des Engels basiert, gestaltet Rilke das Zusammenspiel von Ich und Engel in dem Gedicht „Der Schutzengel“ (1899). In ihm werden sowohl die Frage nach Macht-

207 Vgl. Rösch, Die Hermeneutik des Boten, S. 166.

208 Vgl. Rösch, Die Hermeneutik des Boten, S. 168. Auch die Gedichte „Seit mich mein Engel nicht mehr bewacht“ und „Hat auch mein Engel keine Pflicht mehr“ sind auf dieser Schwelle angesiedelt, wobei der Ausgangspunkt das Nicht-Mehr ist: „Seit mich mein Engel nicht mehr bewacht, / kann er frei seine Flügel entfalten / und die Stille der Sterne durchspalten, - / denn er muß meiner einsamen Nacht / nicht mehr die ängstlichen Hände halten - / seit mich mein Engel nicht mehr bewacht“ (Rainer Maria Rilke, Seit mein Engel mich nicht mehr bewacht. In: Rilke, Gedichte 1895-1910. Kommentierte Ausgabe in vier Bänden, Bd. 1, hg. von Manfred Engel u. Ulrich Fülleborn, Frankfurt am Main; Leipzig 1996, S. 73). Auch dieses Gedicht ist durch eine seltsame Verschlungenheit gekennzeichnet, da durch das Wachen offenkundig nicht in erster Linie der Bewachte, sondern der Wachende oder Wächter unfrei war, für den das Wachen einen irgendwie gearteten Zwang bedeutet hat („muß“). Paradox wird das Gedicht, wenn man es liest wie Perdita Rösch, die darauf hinweist, dass sich die letzten drei Verse auch so verstehen lassen, dass die Notwenigkeit des Beschützens mit dem Ende des Bewachtwerdens durch den Engel entfällt, der Engel hier also eine seltsam ambivalente Rolle zwischen Schutz und Bedrohung einnimmt (vgl. Rösch, Die Hermeneutik des Boten, S. 164). Die Loslösung, die in diesem Gedicht mit dem Freiwerden des Engels gleichgesetzt wird, ist in dem Gedicht „Hat auch mein Engel keine Pflicht mehr“ der Ausgangspunkt einer rückwärtsgewandten Sehnsucht des Engels: Auch wenn der Engel in Bezug auf das lyrische Ich keine Pflichten mehr hat, nachdem ihn dessen „strenger Tag vertrieb“, senkt der Engel „oft [...] sehnend sein Gesicht her / und hat die Himmel nicht mehr lieb“ (Rainer Maria Rilke, Hat auch mein Engel keine Pflicht mehr. In: Rilke, Gedichte 1895-1910. Kommentierte Ausgabe in vier Bänden, Bd. 1, hg. von Manfred Engel u. Ulrich Fülleborn, Frankfurt am Main; Leipzig 1996, S. 73-74, hier S. 73). Tatsächlich sind es die „kleinen Leiden“, die in der „Heimat der Cherubim“, wohin der Engel sie mit dem „frühe[n] Weinen / und Bedanken“ des lyrischen Ichs getragen hat, zu „Hainen“ gewachsen sind, „,welche flüstern über ihm ...“ (Rilke, Hat auch mein Engel keine Pflicht mehr, S. 74). Auf diese Weise wird in der letzten Strophe die scheinbare Trennung zwischen Ich-Welt und Engel-Welt, die als konstitutiv für das Wachstum gezeigt wird, unterlaufen, da die kleinen Kindheitsleiden des lyrischen Ichs sich in der Welt des Engels ausgewachsen haben zu Hainen, die sogar den Engel in der Heimat der Cherubim überragen - sie flüstern „über“ ihm. 
balancen als auch die künstlerische Formungskraft des Engels thematisiert. Es setzt ein mit der Anrede eines Schutzengels: „Du bist der Vogel, dessen Flügel kamen, / wenn ich erwachte in der Nacht und rief.“209 Dieses Rufen erfolgt nicht sprachlich, sondern über eine Gebärde: „Nur mit den Armen rief ich, denn dein Name / ist wie ein Abgrund, tausend Nächte tief.“210 Hier ist die Asymmetrie keine der Friktion, aus der eine Dynamik des Ringens entsteht, sondern ein vollkommenes Ergänzungsverhältnis, das anstelle des ausgelassenen Namens in mehreren Bildern anbetungsartig zelebriert wird: „Du bist der Schatten / drin ich still entschlief, / und jeden Traum ersinnt in mir dein Samen, - / du bist das Bild, ich aber bin der Rahmen, / der dich ergänzt in glänzendem Relief.“211

In der zweiten Strophe wird ein erneuter Anlauf der sprachlichen Erfassung des Engels unternommen, der wieder scheitert und sich erneut in der Evidenz des Bilds auflöst: „Wie nenn ich dich? Sieh, meine Lippen lahmen. / Du bist der Anfang, der sich groß ergießt, / ich bin das langsame und bange Amen, / das deine Schönheit scheu beschließt.“212 Das Kunstwerk von Ich und Engel, das im Ringen einer agonalen Konstellation erwächst, entsteht in „Der Schutzengel“ über eine Art pas de deux. Engel und Ich sind keine Kontrahenten, dennoch birgt ihr Verhältnis einen Konflikt, der in der Gottesanmaßung dieses Zusammenspiels liegt; denn über die Inanspruchnahme seiner Attribute wird der abwesende Gott ostentativ überschrieben: Die Unaussprechlichkeit des abgründigen Engelnamens, die Behauptung, der Engel sei der „Anfang, der sich groß ergießt“, und das abschließende „Amen“ sind allesamt traditionelle Zuschreibungen beziehungsweise Reverenzbekundungen gegenüber Gott. Anders als das Absolutum Gott aber, der laut Offenbarung „das A und das O, der Erste und der Letzte, der Anfang und das Ende“ (Offb 22,13) ist, also aus einer in sich geschlossenen Vollkommenheit besteht, entsteht Vollkommenheit hier über die Komplementarität von Engel und lyrischem Ich.

Nachdem in der dritten Strophe die Rettungstaten des Engels dargestellt wurden (,Du hast mich oft aus dunklem Ruhn gerissen, / wenn mir das Schlafen wie ein Grab erschien / und wie Verlorengehen und Entfliehn, -“213), kulminiert die Kette der Gottesanmaßungen in der letzten Strophe, die wie die erste und die dritte mit einer Apostrophe des Engels einsetzt. Im Kontrast zu

209 Rainer Maria Rilke, Der Schutzengel. In: Rilke, Gedichte 1895-1910. Kommentierte Ausgabe in vier Bänden, Bd. 1, hg. von Manfred Engel u. Ulrich Fülleborn. Frankfurt am Main; Leipzig 1996, S. 265-266, hier S. 265.

210 Rilke, Der Schutzengel, S. 265.

211 Rilke, Der Schutzengel, S. 265.

212 Rilke, Der Schutzengel, S. 265.

213 Rilke, Der Schutzengel, S. 265. 
dem misslingenden Benennungsversuch des lyrischen Ichs wird darin über den Engel Transformation und performative Kraft des poetischen Sprechens und Schauens vorgeführt: „Du: der von Wundern redest wie vom Wissen / und von den Menschen wie von Melodien / und von den Rosen: von Ereignissen, / die flammend sich in deinem Blick vollziehn, -“214. Während die bildliche Evidenz des Verhältnisses von lyrischem Ich und Engel, die an die Stelle der Benennung tritt, in Form von Seinsaussagen beschworen wird („Du bist“ - „Ich bin“), bleibt im Sprechen über das Sprechen und Schauen des Engels die Differenz der Ebenen und damit auch die Alterität des Engels über den Wie-Vergleich gewahrt. Durch das lyrische Ich ehrfurchtsvoll artikuliert und durch Alliterationen lautlich unterstrichen wird der Engel als Figur einer anderen Ordnung ausgewiesen, in der Wunder gesichertes Wissen darstellen und Menschen wie in „Sturm“ beziehungsweise „Der Schauende“ in Musik transformiert erscheinen.

Mit dem Wunder fällt überdies das Stichwort, das in „Ur-Geräusch“ zum entscheidenden Moment der ästhetischen Gebietserweiterung durch das Dichten erhoben wird, ${ }^{215}$ die der Engel hier in der Verwandlung von Lebewesen in eine musikalische Figur demonstriert. Die Fülle ästhetischer Potenz, die das lyrische Ich als Charakteristikum des Engels anführt, wird zum Schluss ein letztes Mal mit der ausgesparten Benennung kontrastiert. So wie das lyrische Ich vor der Benennung des Engel versagt, so verschweigt der Engel Gott: „[D]u Seliger, wann nennst du einmal Ihn, / aus dessen siebentem und letztem Tage / noch immer Glanz auf deinem Flügelschlage / verloren liegt ... / Befiehlst du, daß ich frage?" ${ }^{216}$ Gott wird hier zweifach marginalisiert, durch das lyrische Ich, das bei der Schönheit des Engels, seinen gottgleichen Attributen und seiner schöpferisch-transformatorischen Kraft verweilt, und durch den Engel selbst, der von Gott offensichtlich nicht spricht.

Insofern weist auch in dieser Konstellation die Vordergründigkeit des Engels, der eigentlich hinter Gott zurücktreten sollte, auf eine aus den Fugen geratene Tradition hin. Diese Verschiebung ist künstlerisch überaus produktiv und wird über das Ringen des Künstlers mit dem Engel reflektiert. Nicht nur gegen-

214 Rilke, Der Schutzengel, S. 265.

215 Vgl. folgenden Passus in „Ur-Geräusch“: „Es möchte nicht voreilig sein, zu vermuten, daß der Künstler, der diese (wenn man es so nennen darf) fünffingrige Hand seiner Sinne zu immer regerem und geistigerem Griffe entwickelt, am entscheidendsten an einer Erweiterung der einzelnen Sinn-Gebiete arbeitet, nur daß seine beweisende Leistung, da sie ohne das Wunder zuletzt nicht möglich ist, ihm nicht erlaubt, den persönlichen Gebietsgewinn in die aufgeschlagene allgemeine Karte einzutragen“ (Rilke, Ur-Geräusch, S. 704).

216 Rilke, Der Schutzengel, S. 265-266. 
über dem Menschen, auch gegenüber Gott stehen Engel in einem agonalen Verhältnis. Gleichzeitig treten sie, wie in diesem Kapitel deutlich geworden, neben ihrer kämpferischen und störenden Rolle auch als Medien der Überwindung von Beschränkungen auf. Das betrifft sowohl die Verarmung der Menschen als Folge modernespezifischer Entwicklungen als auch die individuelle Not, vor der der Engel als Schutzengel bewahrt. In dieser Eigenschaft ist er eine zutiefst ambivalente Figur, die einerseits Vermittlung und Verständigung in Aussicht stellt, andererseits den Menschen angreift und Gott verdrängt. In beiden Fällen aber ist damit eine gesteigerte künstlerische Produktivität verbunden: Dank dem Engel gibt es etwas zu erzählen („Märchen“), dank ihm entsteht Vergangenheits- und Zukunftsbezug sowie die Möglichkeit für den Menschen, ein Außen seiner selbst zu imaginieren. 